\title{
WestVirginiaUniversity
}

THE RESEARCH REPOSITORY @ WVU

Graduate Theses, Dissertations, and Problem Reports

2020

\section{The Museum of Queer Curiosities}

\author{
Reba "Feliks" Kay Pyron \\ West Virginia University, rkp0004@mix.wvu.edu
}

Follow this and additional works at: https://researchrepository.wvu.edu/etd

Part of the Fine Arts Commons

\section{Recommended Citation}

Pyron, Reba "Feliks" Kay, "The Museum of Queer Curiosities" (2020). Graduate Theses, Dissertations, and Problem Reports. 7512.

https://researchrepository.wvu.edu/etd/7512

This Thesis is protected by copyright and/or related rights. It has been brought to you by the The Research Repository @ WVU with permission from the rights-holder(s). You are free to use this Thesis in any way that is permitted by the copyright and related rights legislation that applies to your use. For other uses you must obtain permission from the rights-holder(s) directly, unless additional rights are indicated by a Creative Commons license in the record and/ or on the work itself. This Thesis has been accepted for inclusion in WVU Graduate Theses, Dissertations, and Problem Reports collection by an authorized administrator of The Research Repository @ WVU. For more information, please contact researchrepository@mail.wvu.edu. 
The Museum of Queer Curiosities

Feliks RK Pyron

\author{
Thesis submitted to the \\ College of Creative Arts \\ at \\ West Virginia University
}

\begin{abstract}
In partial fulfillment of the requirements for the degree of
Master of Fine Arts in Printmaking
\end{abstract}

\author{
Joseph Lupo, Chair \\ Jason Lee \\ Gerald Habarth \\ Joseph Galbreath
}

School of Art and Design

Morgantown, West Virginia 2020

Keywords: Art, Fine Art, Art History, Queer Art, Identity politics, Museum, Printmaking Copyright 2020 Feliks RK Pyron 


\section{ABSTRACT \\ The Museum of Queer Curiosities}

Feliks RK Pyron

This paper documents the research, personal motivations, and processes that make The Museum of Queer Curiosities (TMOQC). The installation, exhibited in the Paul Mesaros Gallery, uses the manipulation of traditional techniques in printmaking, sculpture, and craft, to create a space in which authority, labels, confusion, and compassion are discussed. Through the synthesis of familiar visual art installation techniques and museum display, the work attempts to provide a foothold for the viewer to navigate queerness and ephemeral identity. The body of work that occupies $T M O Q C$ creates the surreal simulation of a scientific museum, transforming the art gallery into a stage where the phenomenon of the viewer experiencing the work can translate as a metaphor for how we can engage with the unknown and misunderstood, and to encourage trust in people's identities, even when the language used is completely alien to normative ways of thinking. Through the navigation of labels and artifacts 'curated' by TMOQC, this thesis exhibition intends to pose the questions: who has authority when describing one's identity, and how is being queer understood in a society that reinforces a fixed sense of self? This paper examines the conceptual and artistic threads that both inspire and justify this work as a simulation of a strange museum, and examines the cultural norms that necessitate such an exhibit as TMOQC in the first place. 


\section{ACKNOWLEDGEMENTS}

I would like to sincerely thank the entirety of West Virginia University's College of Creative Arts faculty for their acceptance, support, and opportunity to pursue the research for my master's degree. I am extremely grateful for all the opportunities attending WVU has given me, both in academic study, invaluable teaching experience, and the opportunity to work alongside so many incredible faculty, peers, and students. I cannot say enough how exceptionally thankful I am to Joseph Lupo, as chair of my committee, advisor, and colleague. His genuine counsel and support made navigating the uncertain waters of graduate school a realistic possibility. The sincere, accepting scholastic environment he fostered as a teacher allowed me to have confident discussions about queerness, not only in my work, but with my peers, and I hope to emulate this in my own methods of teaching. I would also like to greatly thank Jason Lee, Joseph Galbreath, and Gerald Habarth for their challenging and unique insights as my committee, and their support. The multidisciplinary aspect of this program was one element that attracted me to WVU in the first place, and it is incredibly special to be able to receive feedback across so many disciplines. Special thanks are also necessary for Jason Lee, Dylan Collins, and Shalya Marsh, as they provided helpful instruction, experience, and humor whenever I tried to make, combine, or mount things that were truly out of left field, opening the doors for new ways of creating all the bits of this thesis. All the faculty at the CCA made this graduate experience exceptional.

I have had the chance to work with some amazing peers during my time at WVU. The list of things I must thank Erin McCarty and Olivia Oddo, my fellow same-year graduate students, for is near infinite. I am also grateful for my fellow printmaking grads, Stephanie Alaniz and Hanna Kesty, and many other colleagues: Tyler Carter, Michael Parsons, Byrd Battista, and the whole WVU Print Club, to name a few. Their friendship, support, unique perspectives, and excellent company over good food made the experience of being a graduate student here that much more bountiful. There are so many more people I am grateful for; printmaking has an incredible community of peers, and I am always touched by the chance to work with them.

Thanks go to my parents, Dennis and Brenda Pyron, and my brother and his wife, Jonathan and Kelly Pyron, as well as the rest of my family. I am so incredibly privileged to have such an amazing support network in my life, and I could always count on them for love, good 
drinks, and fishing when everything else in being a student was chaotic and stressful. During my thesis year I came out to my family, and the threads of their response and acceptance helped inform the thoughts and goals of this thesis in the first place. Their support meant everything to me, and to this work.

At the time of this thesis we are experiencing unprecedented world events. The quickness with which the faculty, namely Joseph Lupo and Shalya Marsh, responded to the hurdles presented by dealing with the COVID-19 virus that jeopardized this year's thesis work deserves special acknowledgement. If there was a medal for fighting for the graduates to still have great documentation of their work, I would nominate them. Their flexibility, support, and communication skills made the rapidly decreasing window of chance for the grads attainable, and it is thanks in no small part to their coordination that we were able to put four thesis shows up and down in five days.

Lastly, I would like to thank my wonderful partner, Ludo Graves, who I met at the same time I came to WVU. Throughout the trials of grad school, they kept me grounded (and reminded me to sleep). At the same time, the great fire of their compassion and consideration helped me realize that there are kindnesses that we as a society do not remember to uphold, and I wholly credit them for influencing this work's message of understanding and trust in spite of nihilism, confusion, and anger. I literally mean that without them and their incredible stamina and ability this show would not exist. When no one else could help, The Museum of Queer Curiosities was born because they stood by me in all forms, and for that service I will never be able to thank them enough. I hope that together we can continue to work towards a broader compassion for our queer community. 


\section{TABLE OF CONTENTS}

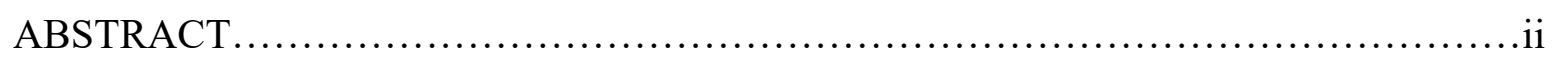

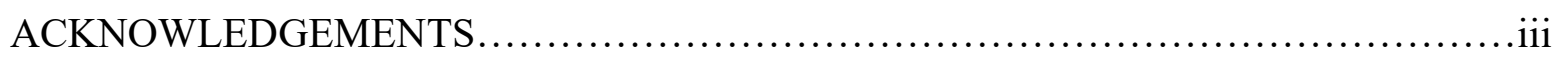

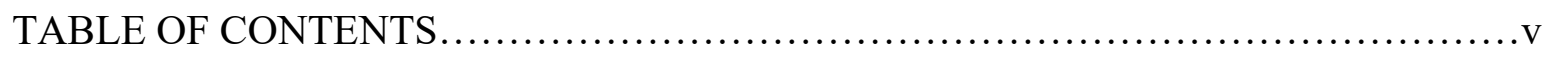

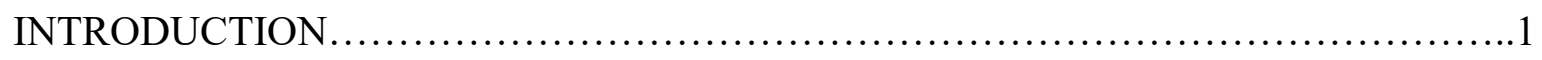

THE MUSEUM OF QUEER CURIOSITIES $\ldots \ldots \ldots \ldots \ldots \ldots \ldots \ldots \ldots \ldots \ldots \ldots \ldots \ldots \ldots . \ldots . \ldots \ldots$

TOO QUEER TO FUNCTION: THE DILEMA OF BEING NON-BINARY .............12

CREATING COMPASSION IN THE UNKNOWN............................... 18

MYSTERY FISH: A HISTORY OF MISLABELING AND OBSCURANTISM..........24

SURREALISM, SYMBOLISM, AND FANTASY:

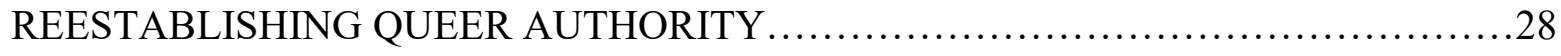

MAKING A MUSEUM.................................................... 32

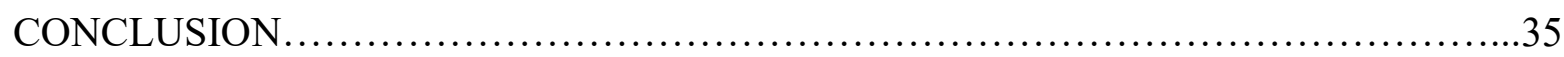

FIGURES .............................................................. 37

BIBLIOGRAPHY ....................................................... 


\section{INTRODUCTION}

Stasis is something we are taught to value by the norms of our Western capitalist society. There is an expectation that our lives, our families, our work, and at the core of it, ourselves, will remain consistent. This behavior is practiced by purchasing only a specific brand or color of clothing, or using the same personal products to present ourselves publicly in a way that is easily understandable. ${ }^{1}$ We are encouraged to pursue predictable milestones of growth, evidenced by the disdain for any failings of achieving those points, ${ }^{2,3}$ and the attempts to mitigate and correct back to milestones rather than settle with the failure of them. ${ }^{4}$ These social expectations create an inflexibility that we apply to ourselves. We understand a continuous self, but gaps in continuity allow for the unknown, and we have been trained to react to this with stress, fear, and in some cases, violence. Arne Roets, Professor in the Department of Developmental, Personal, and Social Psychology at the University of Ghent, describes that in persons predisposed to extreme prejudice, opinions of others are formed quickly using the first information available to reduce their own ambiguity and fear. That fear is increased by the perception of harm and hatred propagated when that information comes from institutionalized racism, homophobia, and heteronormativity. ${ }^{5}$ The sense of self is informed by so many things in and out of our control and

\footnotetext{
${ }^{1}$ Diana Crane, Fashion and Its Social Agendas: Class, Gender, and Identity in Clothing (Chicago, III: University of Chicago Press, 2000, p.11)

2 "Another Way Millennials Are Ruining Their Parents' Retirement," Money (Ad Practitioners, LLC, February 10, 2017, https://money.com/millennials-ruining-parents-retirement/)

${ }^{3}$ Sandy Hingston, "How Millennials Are Ruining the Workforce - and Everything Else," Philadelphia Magazine (Philadelphia Magazine, January 9, 2016, https://www.phillymag.com/news/2016/01/08/boomers-millennials-workforce/)

${ }^{4}$ Christinne Elliot and William Reynolds, "Making It Millennial," Deloitte (Deloitte Insights, April 2, 2014), https://www2.deloitte.com/us/en/insights/industry/public-sector/making-it-millennial.html)

${ }^{5}$ Arne Roets, and Alain Van Hiel. "Allport's Prejudiced Personality Today: Need for Closure as the Motivated Cognitive Basis of Prejudice." Current Directions in Psychological Science 20, no. 6 (December 2011): 349-54. doi:10.1177/0963721411424894.)
} 
can change rapidly. Identity and individuation are "the recognition of the self as a discrete entity," ${ }^{6}$ but at a certain stage of life. Throughout our life, our sense of identity changes. As author Parker J. Palmer puts it, identity is an "evolving nexus where all the forces that constitute my life converge in the mystery of self," perceived threat to one's sense of self, there must be a push to help each other understand that we are not constant. Through understanding this, there is room to accept even those radically different from our own understanding.

The Museum of Queer Curiosities (TMOQC) is the culmination of many attempts to communicate trust as it relates to the concept of a shiftable and unknown identity. Trust is important to understanding queer identity. This work acknowledges that those who live an experience are the best source for describing that experience and should be trusted even if there is disagreement. These ideas are communicated through the simulation of a museum space and its contents using traditional printmaking, sculpture, and accessible craft. This strategy of creation and display provides a setting in which the viewer understands their role as learner, while creating an artistic installation designed to challenge and subvert the expectations about who can define one's identity. This thesis provides the research to prove why the museum, a seemingly straightforward syntax, is necessary to facilitate understanding about queerness, and how laying out the broader expectations, stereotypes, and misunderstandings of queerness make an open and plain discussion about identity difficult.

The simulated museum can help to establish both trust and compassion between the viewer and the curated 'subjects'. Emulating display and educational methods of the museum

\footnotetext{
${ }^{6}$ American Heritage ${ }^{\circledR}$ Dictionary of the English Language. (Fifth Edition. S.v. "individuation." https://www.thefreedictionary.com/individuation)

7 Parker J. Palmer, "The Heart of a Teacher Identity and Integrity in Teaching," (Change: The Magazine of Higher Learning 29, no. 6 (1997): pp. 14-21, https://doi.org/10.1080/00091389709602343, p.18)
} 
allows me to delve into questions about the history of unreliable, assumed, or established information. At the same time this strategy also allows the viewer to question what $T M O Q C$ is and why. TMOQC can present examples of how cultural unknowns and assumptions are handled, through parallels with fantasy, surrealism, and symbolism. These conceptual threads work together to form a physical simulation that is recognizable as both a niche museum and a body of queer art, in order to create a complex net of both confusion and understanding.

While TMOQC attempts to place the confusion of the unknown as something to be trusted, explicit communication and education is difficult when the essential core of this education is almost alien to the learner. An experience that is common to the non-binary existence, as laid out here by J.C. Hale in "Consuming the Living, (Dis)Remembering the Dead":

"...[O]ur embodiments and our subjectivities are abjected from social ontology: we cannot fit ourselves into extant categories without denying, eliding, erasing, or otherwise abjecting personally significant aspects of ourselves ... When we choose to live with and in our dislocatedness, fractured from social ontology, we choose to forgo intelligibility: lost in language and in social life, we become virtually unintelligible, even to ourselves..."

For example, as a queer, non-binary person, the relationship I have with everything from clothing to language is rendered "outsider" by harmful standards set by Western capitalist society. Queer authors like Judith Butler and Michael Warner explain how dominant social structures are subverted by queer existence, ${ }^{9}$ and how identity is not something innate but made through repetition and social influence ${ }^{10}$. For many queer people who regularly engage with the language and experiences of being queer, these ideas are easy to understand. Yet the reach of understanding queer studies, at least in an academic sense, are not accessible, especially for those

\footnotetext{
${ }^{8}$ C. Jacob Hale, "Consuming the Living, Dis(Re)Membering the Dead in the Butch/Ftm Borderlands," GLQ: A Journal of Lesbian and Gay Studies 4, no. 2 (1998): pp. 311-348, https://doi.org/10.1215/10642684-4-2-311, p.311, 336) ${ }_{9}^{9}$ Meg-John Barker and Jules Scheele, Queer: A Graphic History (London: Icon Books, (2016), p.63) 10 Judith Butler, "Performative Acts and Gender Constitution: An Essay in Phenomenology and Feminist Theory," (Theatre Journal 40, no. 4 (1988): p. 519, https://doi.org/10.2307/3207893)
} 
who are comfortable in the idea that their gender and social situation are immutable.

Additionally, a complex philosophical theory is not easily explained in a casual encounter. The work within the exhibit makes constant reference to the confusion I have experienced attempting this kind of communication. A look at the minutiae and background of this confusion will help make a case for why experiencing visual art can help bridge the gap when words fall short.

Ideas about the inconstant self, queerness, and the difficulty of asking others to engage with it compassionately are constants in my work. Compassion is defined as the "sympathetic consciousness of others' distress together with a desire to alleviate it."11 If the distress of being queer comes from a lack of understanding, trust, and respect, then alleviating this distress can come in the form of affirmation and recognition. Through this exhibition, I hope to create a space that asks for affirmation and recognition without putting the viewer on the prejudicial defensive described earlier by Roets. TMOQC is also intended to be an environment where the viewer suspends their disbelief and enters a realm where they understand that they are safe and expected to learn.

This research will also look at how contemporary learning and museum theory, combined with theories of installation art are used to engage the viewer and ask for compassion with their subjects. The variety of media used to create the work physically overwhelms the space, but also provides symbolism to the facets of desire to be understood as a queer person. Although the viewer is enveloped in this visual and conceptual chaos, I hope to encourage compassion and a willingness to learn through the replication and manipulation of trusted visual structures like museums, while also encouraging the viewer to embrace their ephemeral communities and identities. Additionally, though much of the content comes from my own personal experience as

\footnotetext{
${ }^{11}$ Merriam-Webster.com Dictionary, s.v. "compassion." (https://www.merriamwebster.com/dictionary/compassion.)
} 
a queer person, this is never explicitly stated, and the vagueness of these artifacts invite the viewer to involve their own experiences. This, in turn, fixates the museum as a tool in which perhaps the viewer's internal dialogue creates the content. It is a museum, not about artifacts and simulated histories, but about understanding and compassion.

Ironically, at first glance most of the work in $T M O Q C$ is illegible, despite the goal of being about understanding the unfamiliar. This, however, is entirely crucial to inviting the viewer to question who is capable of defining one's existence. To do this, TMOQC uses its intentionally oblique and vague labels, combined with oversaturation of symbols and simulations of mishandling, to redistribute and discredit authority from the institution, back to the idea of the self represented by the artifacts. Several pieces in $T M O Q C$ also reference history. Information is incorrectly assumed or left to arbitrary calculation. These references act as metaphors for the discrimination faced by misgendering that takes place against trans and nonbinary individuals. ${ }^{12}$ Obscurantism, or the intentional muddling of information, used alongside blatant disregard, adds another layer to the representation of the types of misunderstanding queer people face every day.

There is another facet to the abstraction of the representational nature of TMOQC beyond strictly obscuring the space. The abstraction of the installation relies upon strategies and concepts coming from the surrealism, symbolism, stylization, as well as the illusion of a fantasy setting or narrative, in order to encourage the viewer to engage with the exhibit in a state of suspended disbelief and extended investigation. $T M O Q C$ requires the juxtaposition of known and confusing symbols in two-dimensional and three-dimensional space in order to fully envelop the viewer. These different forms of visual communication also help TMOQC become an incubator for

\footnotetext{
12 Kevin A. Mclemore, "Experiences with Misgendering: Identity Misclassification of Transgender Spectrum Individuals," Self and Identity 14, no. 1 (2014), https://doi.org/10.1080/15298868.2014.950691
} 
inquiry, and the use of museum theory and obscurantism help to provide checkpoints for the viewer's understanding of the content.

Previously laid out is the approach to the various theories that $T M O Q C$ are founded on, and the order in which they will be analyzed. This thesis will conclude by looking at the physicality of TMOQC which enables the phenomenon of experiencing it. The variety of crafted art objects and made artifacts are installed in a way that mimics trends in museums such as the Carnegie Museum of Art and trends in the contemporary language of queer art. The artifacts' existence relative to each other, to the labels, and to decoration shows $T M O Q C$ not as an installation of art, but as an experience. Showing the connective threads between contemporary structures of queer art and broader ideas in museum theory, can also open up the physical continuation of the museum in the future, in which artifacts are added to the installation, allowing the possibility of more identities and persons reclaiming and subverting institutional power for their own otherness.

The viewer is invited to witness The Museum of Queer Curiosities as a simulation of a museum and understand their role as an audience to be educated. In our current Western culture museums have a specific job, outlined by George Hein in the aptly named "The Role of Museums in Society: Education and Social Action":

"...the raison d'etre of the museum is education broadly defined... It's possible to have collections of objects, even collections carefully classified, organized, and preserved, that are not primarily educational... but as soon as these are open to the public, the museum becomes an educational institution." 13

As a queer person, I have the authority to reclaim the power and purpose of the syntax of a museum, as museums have historically been used to define the other. Museums such as the

\footnotetext{
${ }^{13}$ George E. Hein, "The Role of Museums in Society: Education and Social Action," Curator: The Museum Journal 48, no. 4 (2005): pp. 357-363, https://doi.org/10.1111/j.2151-6952.2005.tb00180.x, p.357)
} 
Victorian-era cabinet of curiosities repeatedly used to ostracize individuals who did not meet Western physical and cultural (white, able-bodied, straight) ideals as much as they were physical collections of natural fauna. As French Historian Pascal Blanchard notes in the era of early museums and cabinets of curiosity, "one can observe the spread of an iconographic grammar, a corpus of imagery of the Other which manufactured and permanently defined the Other." ${ }^{14}$ Even today, those existing as other, including queer and its racial and class intersections, still struggle against institutionalized separation.

In this thesis I hope to establish this work in the context of surrealism, queer art, and museum theory, and how it relates to the broader ideas of what it means to experience and to consider compassion in the face of misunderstanding. I hope to make confusion and the idea of a flexible self relatable by grounding an unusual visual experience in my own experience as a queer person. Finally, I want to create work that acknowledges how confusing issues of the self are, and how the authority to define oneself must come from the person having that experience. Trust is critical when trying to understand another's identity or situation, unknowing should be celebrated and not feared. Through the strategies of $T M O Q C$, the viewer can comfortably raise the questions: Where does the authority of how we call or see each other come from? How can we know the identity of someone else, and should we know? Like a real museum, the simulation that is $T M O Q C$ acts in its genesis as evidence, celebration, and education of queerness and exists outside of what others tell us is stable.

\footnotetext{
${ }^{14}$ Morgan Quaintance, "Human Zoos: From Colonial Practice to Participatory Art," Contemporary \& (Institut für Auslandsbeziehungen, April 19, 2014), https://www.contemporaryand.com/magazines/fromcolonial-practice-to-participatory-art/)
} 


\section{THE MUSEUM OF QUEER CURIOSITIES}

A vinyl banner officially welcomes visitors as they enter. A large hodge-podge of fabric climbs high on the wall opposite the entrance to the large white room. A pattern of misshapen polygons guides visitors around the tile floor, interrupting the space of the objects in the room. A careful display of odd coins on a pedestal spills from a pile onto the floor. Around the room, black and white drawings float against white walls, sometimes acting as the objects they share space with. A catalog of information provides the viewer with the tools needed to experience the mysterious Museum of Queer Curiosities. (Figure 1.)

This is a small illustration of the installation that makes up The Museum of Queer Curiosities. Before delving further into the theoretical justifications for the museum's existence, it is important to note the various symbols, materials, and objects evident in the museum, and its visual syntax.

There are four major layers to $T M O Q C$ 's physical structure. First are the accoutrement or accessories of the museum. These are the props that help establish that the viewer has entered a legitimate, institutionalized space, designed to mimic formal structures of anthropological and niche museums, such as the Science and Natural History sections of the Carnegie Museum. The Catalog (Fig. 2), the Title Banner (Fig. 3), the Announcement Card (Fig. 4), and the Guide Path (Fig. 5) are all visual signifiers essential to this transformation of the Paul Mesaros Gallery. Another important accessory of TMOQC is Additional Information, a series of black and white illustrations attached to the walls (Fig. 6 \& 7), whose cohesiveness helps fill much more space than the objects themselves. These illustrations are repeated in the Catalog (Fig. 2), cementing them as an important element of 
the museum's voice and providing a link between the objects they illustrate, and the symbols present in the rest of the work.

Another accessory of TMOQC is its voice, most evident in the Catalog, but also in its handling of the pieces. This voice, also referred to as the Curator, is vague, generally unhelpful, and damaging to the overall understanding of the work. The Catalog voice repeatedly hints at a cohesiveness in the artifacts' origins being an "Other from All Over". This term is intended to be both unintentionally vague when used by the museum, but also an intentional reference to the multiplicity and widespread occurrence of the queer experience. Additionally, parts of the Catalog are intentionally illegible due to the repeating black and white illustrations mentioned earlier. When seen in the Catalog, these images offer additional clues to the intent behind each artifact, but also create an obscure, collapsed aesthetic (Fig. 8), supporting the idea of the Curator as an unreliable narrator. This idea is also perpetuated through the handling of the museum artifacts. The handling of the Formulaic Statue (fig. 9), the MQC Coin Collection (Fig. 10), and the opened 'geode' in Successful Reveal (Fig. 11) insinuates, or perhaps is evident of, a carelessness and intentional obscurantism the museum is culpable in. Adding to this, many objects are not placed at the proper gallery height, 60 inches at center for easy viewing, nor is the installation preoccupied with the traditional rules of spacing between objects. Rather than giving each specimen space for careful visual analysis, the Curator has installed pieces too low, leaning on other objects, or far too high. These installation decisions are intended to further transform the space from that of a traditional gallery space (Fig. 12) and into the realm of the spectacle of contemporary niche museum display (Fig. 13) 
The artifacts make up the second layer to $T M O Q C$ 's physical structure and are the main attraction of the installation. These artifacts are intended to be seen as individual pieces, yet their full interpretation cannot exist without the interaction from $T M O Q C$ 's sometimes vague and illegible information. The bright colors of the objects combined with a welcoming environment, was key to creating a museum that did not feel cold, miserable, or as is often the case in stories involving the other, tragic. Additionally, the color magenta is used throughout the exhibit, as in Strange Shield (Fig. 14), Historic Shroud (Fig. 15) the MQC Coin Collection (Fig. 16). Magenta is the only color not within the visible spectrum as a single wavelength and must be synthesized by the human brain by other colors. ${ }^{15}$ Its use creates a thematic symbol with the idea of being non-binary in a binary world, and is evidence that the brain is capable of synthesizing things that are beyond easy definition.

The physical items in the museum are influenced by actual historical objects. For example, the Historic Shroud is inspired from tapestries hung in museums the world over (Fig. 17) and Instructional Book of Progress (Fig. 18) is based on the Ancient Egyptian "Book of the Dead," a scroll used to navigate the afterlife. The Formulaic Statue (Fig. 19) is based on the Colossus of Constantine (Fig. 20), an immense statue found in pieces, whose full shape is left to old records and estimations. These artifacts allude to history, imbibing them with a sense of their own authority, while also adding to the simulation of a real museum. That they are actuality-adjacent may make it easier for the viewer to embrace that the things in the museum are truly queer.

The third layer to $T M O Q C$, is the symbolic thread of the museum. Additional Information (Fig. 6,7), arguably the largest piece in the museum, occupies space on the walls

\footnotetext{
15 The Royal Institute, "Color Mixing: The Mystery of Magenta," Youtube video, 5:13, February 13, 2013. https://www.youtube.com/watch?v=iPPYGJjKVco.
} 
and in the Catalog. The prevalence of these images, as they bleed into the artifacts' surfaces, encourage the viewer to look for conceptual connections between the pieces and the museum. These illustrations set up the symbolism present in the work, and the threads of gendered imagery such as in Bow Trap, Large Lights, and Car Fob help inform the viewer what each smaller installation is attempting to discuss. The thematic repetition helps bridge the gap between a piece and its label. These symbols: eyes, hands, elephant skulls both real and stylized, and textures, are directly referencing my personal ideas around queerness and form a personal complex visual lexicon. Their application over the whole museum adheres it together, informing the viewer to see this as a representation of a whole experience, rather than an installation of individual things.

Finally, the fourth layer of the TMOQC are the various formal and aesthetics decisions. I am attracted to the visual layering of symbols as a way of encouraging their group interpretations. I am inspired by the collapsed and symbolic space in the work of German Expressionist Max Beckmann (Fig. 21), the symbol-laden and superimposed prints by Aaron Coleman (Fig. 22), and the complex representations of Johanna Mueller's monoprints and drawings (Fig. 23). I am also intrigued by the semi-chaotic assemblages and the creation of artifacts that often exist in queer art. Such as Alex Martin's 2017 installation It's Safe in Here (Fig. 24), and their Queercraft series (Fig. 25), or Pepe Mar's installation Varla TV (Fig. 26). I also find stylized drawings such as David Shrigley's untitled ink drawings (Fig. 27) both whimsical and relatable, which influenced my decision to lean more stylized for my own lexicon in TMOQC.

I want my work to be aesthetically pleasing to help invoke intrigue, awe, and a strange sense of celebration. This approach is realized through the use of bright colors, 
interesting and varied textures, a broad use of materials and application, and a more-is-more approach that borders on horror vacui. Anything is fair game, even in creating representational artifacts. I use any process or material that might create a striking interest in the viewer, such as the difference in sheen or the combination of a found material with traditional process. Most of my work utilizes techniques from craft or cosplay creation, such as paper mache. I consider this not only reminiscent of found objects used in the queer art previously mentioned, but potentially visually mirroring the desire to be approachable and accessible in both concept and material. I have always considered a best tool for the job approach to medium selection. Due to printmaking's variety of processes, and its history as a medium utilizing the sharing of information ${ }^{16}$, the artifacts of the museum all incorporate some sort of printmaking process, from relief to screenprint to monoprint. Printmaking's flexibility was a necessary component in making the sheer variety of artifacts that live in $T M O Q C$.

\section{TOO QUEER TO FUNCTION: THE DILEMMA OF BEING NON-BINARY}

Establishing trust and understanding between people is remarkably easier when speaking the same language, but this is not a guarantee. Many strategies exist that make communication successful: we encourage the avoidance of speaking in jargon in common conversation $^{17}$, we use relatable examples from our own experience to describe solutions ${ }^{18}$,

\footnotetext{
${ }^{16}$ Gabor F Peterdi, "History of Printmaking," in Encyclopedia Britannica (Encyclopedia Britannica, Inc., January 21, 2019, https://www.britannica.com/art/printmaking/History-of-printmaking)

${ }^{17}$ Lena Schnitzler et al., "Communication during Radiation Therapy Education Sessions: The Role of Medical Jargon and Emotional Support in Clarifying Patient Confusion," (Patient Education and Counseling 100, no. 1 (January 2017): pp. 112-120, https://doi.org/10.1016/j.pec.2016.08.006) ${ }^{18}$ Eshin Jolly et al., "Wanting without Enjoying: The Social Value of Sharing Experiences," (PLOS One, April 18, 2019, https://doi.org/10.1371/journal.pone.0215318)
} 
and we use visual understanding of each other's appearance to establish an expectation of how we speak to one another. ${ }^{19}$ Yet even when speaking the same language, there can exist a disconnect between understandings that cannot be solved by a simple discussion and can even result in harm.

Meriam-Webster's first definition of queer is simple:

"1 a: differing in some way from what is usual or normal : ODD, STRANGE, WEIRD." 20

At its heart, that is what every other iteration of queer means. In speaking of Queer theory, Queer: A Graphic History by Meg-John Barker and Julia Scheele offer a succinct explanation: “...a theoretical approach that goes beyond queer studies to question the categories and assumptions on which current popular and academic understandings are based. ${ }^{21}$ " This speaks to alternatives of intangible matter, such as philosophies of identity. More direct is the identity of queer. This is an umbrella term for anyone who does not identify as their assigned gender, and/or is not attracted to solely the opposite sex. ${ }^{22}$ Many theorists such as Judith Butler and Michel Foucault have discussed that gender and sexuality are made to feel real through repeated performance and discourse, established mostly by heteronormative assumptions. ${ }^{23}$ While it seems easy to explain in the context of this document, there exists a myriad of problems in communicating this idea in a social context. Opportunities for misunderstanding and negative reactions exist in people who do not question the dominant cisgendered, heteronormative perspective.

\footnotetext{
${ }^{19}$ Erving Goffman, "Gender Display," (Studies in the Anthropology of Visual Communications 3, no. 2 (1976): pp. 69-77, https://repository.upenn.edu/svc/vol3/iss2/3, p.69)

20 Merriam-Webster.com Dictionary, s.v. "queer," accessed April 21, 2020, https://www.merriamwebster.com/dictionary/queer.

${ }^{21}$ Barker, Queer: A Graphic History, 15.

22 Barker, 12.

${ }^{23}$ Barker, 82.
} 
Western capitalist society constantly sends messaging through advertising and social pressure for people to exist and present as an understandable gender binary. This binary is supposed to be expressed through our relationships, our clothing, the way we talk, and act. ${ }^{24}$ This information is mostly visual and is exclusive to only two genders. The repeated participation creates a compulsory link between a person's visual presentation and the assumption of identity. These expectations make up the dominant heteronormative and cisnormative social expectations. These expectations assume that people will be the gender assigned at birth and will be attracted to the opposite sex. Author Michael Warner, in Fear of a Queer Planet, states that these social expectations and norms are "so deeply embedded by now in an indescribably wide range of social institutions, and is embedded in the most standard accounts of the world," 25 that trying to communicate anything that goes against the cishetero-complex is met with confusion, fear, and a lack of processing. This is evidenced by the notion of gender non-conforming people to 'pass,' or follow rigid gender expectations in clothing and body, and the transphobia directed at those that do not or cannot pass. ${ }^{26}$

Because understanding one's identity is largely determined by assumptions based on physical traits, the body is used against queer persons to invalidate their claims to a nonessentialist understanding of their own gender. In the paper Gender Display, by Erving Goffman, a $20^{\text {th }}$ Century sociologist and social psychologist, Goffman speaks on how much our physical presentation plays into our interaction with each other:

\footnotetext{
24 Joy L. Johnson and Robin Repta, "Sex and Gender: Beyond the Binaries," (Designing and Conducting Gender, Sex, \& Health Research, 2012, pp. 17-38, https://doi.org/10.4135/9781452230610.n2)

${ }^{25}$ Michael Warner, Fear of a Queer Planet: Queer Politics and Social Theory (Minneapolis, MN: Univ. of Minnesota Press, 1995), p. 6)

${ }^{26}$ Emilia Lombardi, "Varieties of Transgender/Transsexual Lives and Their Relationship with Transphobia," (Journal of Homosexuality 56, no. 8 (2009): pp. 977-992, https://doi.org/10.1080/00918360903275393)
} 
"A version of display for humans would go something like this: Assume all of an individual's behavior and appearance informs those who witness him, minimally telling them something about his social identity, about his mood, intent, and expectations, and about the state of his relation to them... One can call these indicative events displays. As suggested, they tentatively establish the terms of the contact, the mode or style or formula for the dealings that are to ensue between the persons providing the display and the persons perceiving it. Finally, our special concern: If gender be defined as the culturally established correlates of sex (whether in consequence of biology or learning), then gender display refers to conventionalized portrayals of these correlates." 27

Media representations of queer persons also create confusion. Currently, homosexuality has become more and more 'accepted' in mainstream society and understood through media representations in contemporary television shows like Modern Family and Queer Eye. Ironically though, homosexuality and certain queer expression is still limited by social expectations acceptable to heteronormativity, thus defining LGBTQ+-ness in language still in the hetero-repertoire. Because of this tension, transgender and gender non-conforming persons must consider their relationship to certain kinds of assimilation politics. Those in favor of more liberation-based strategies push against the idea that queerness must still abide by norms such as binary genders and anti-trans rhetoric, to avoid being deviant. Rather than encourage understanding for differences, much of queerness is still being asked to exist within heteronormative expectations. This strict understanding of identity and existence creates a myriad of problems for anyone who is gender non-conforming on any level.

This is the dilemma faced by many transgender and gender non-conforming persons. As a non-binary person, I can speak from experience about the difficulty non-affirmation creates in day-to-day life. Non-affirmation is the denial of one's identity that comes from constant misgendering and microaggressions related to it. For many gender non-conforming people, this experience is a potential threat with every new social introduction. The Williams

${ }^{27}$ Goffman, Gender Display, p. 1. 
Institute, a leading research center on sexual orientation and gender identity law and public policy, conducted a National Transgender Discrimination survey in 2014. This survey found that compared to a $4.6 \%$ rate of lifetime suicide attempts on the national average, the rate for transgender and gender non-conforming individuals was $41 \%$, nearly ten times as high. ${ }^{28}$ It should be no surprise that constant ostracization and assault lead to isolating conditions that nurture suicidal tendencies. The survey goes on to indicate “...respondents who experienced rejection by family and friends, discrimination, victimization, or violence had elevated prevalence of suicide attempts." These problems are not going away. With the current national shift to a more conservative political climate, a recent report by the National Sexual Violence Resource Center indicated that the new suicide rate in 2019 is $47 \%$, and $37 \%$ of respondents in grades K-12 experienced physical assault. ${ }^{29}$ With the difficulty in communicating and the shame forced on non-conforming genders, especially non-binary and xenogender individuals, and even more so in queer people of color, these numbers may actually be higher. These are very real problems, which is why it is important for me to use my work to call into question our assumptions about visual presentation, understanding, and trust which is at the core of so much suffering in the queer community.

While it has been difficult to create trust that translates to the use of "they/them" pronouns, it is important to note that in queerness there are a myriad of expressions of identity, with and without dysphoria (extreme physical and mental duress due to a mismatch of the sense of self and the body) that is difficult for even binary trans people to understand.

\footnotetext{
28 Jaime M. Grant, Lisa A. Mottet, Justin Tanis, Jack Harrison, Jody L. Herman, and Mara Keisling. Injustice at Every Turn: A Report of the National Transgender Discrimination Survey. (Washington: National Center for Transgender Equality and National Gay and Lesbian Task Force, 2011.) ${ }^{29}$ Sexual Violence \& Transgender/Non-Binary Communities, (National Sexual Violence Resource Center, https://www.nsvrc.org/sites/default/files/publications/2019-02/Transgender_infographic_508_0.pdf, 2019.)
} 
Sandra Bem, an American psychologist known for her works in androgyny and gender studies, proposed the following as a solution for dissolving heteronormative practice:

“...let a thousand categories of sex/gender/desire begin to bloom in any and all fluid and permeable configurations and, through that very proliferation, that we thereby undo (or, if you prefer, that we de-privilege or de-center or de-stabilize) the privileged status of the two-and-only-two that are currently treated as normal and natural." 30

This solution is already happening. Online communities like Tumblr.com, for example, are regarded as a safe place of identity expression. Tumblr has an entire platform dedicated to alternative genders, such as uncommongenders.tumblr.com, which showcases genders such as heavengender, genderfalle, and persongender. ${ }^{31}$ Though outside an online community such as Tumblr, made safe both by its ability to be anonymous and regular involvement and discussion of gender, it is extremely difficult to open a progressive conversation about marginalized and unique genders. In my experience, the language barely exists to casually discuss common use of gender-neutral pronouns. Additionally, the growing use of so-called "neopronouns," requires a shift in the conversation from simply being about fill-in-the-box expressions of gender, to allowing someone's identity to exist despite not having the means to completely understand it. A shift in mindset is needed to ensure that when presented with expressions of identity, one does not react with hatred, or ostracization, but with implicit trust. The discussion around the challenges of one's expressions of identity is imperative to understand the motivation that informs every decision in the creation of The Museum of Queer Curiosities. The installation illustrates the difficulties of communicating

\footnotetext{
${ }^{30}$ Sandra Lipsitz Bem. "Dismantling Gender Polarization and Compulsory Heterosexuality: Should We Turn the Volume down or Up?" (The Journal of Sex Research 32, no. 4 (1995): 329-34. Accessed April 20, 2020. www.jstor.org/stable/3813357.)

31 "The Clouds of MOGAI Heaven," tumblr, accessed April 2, 2020, http://uncommongenders.tumblr.com/)
} 
queerness and attempts to set a stage to invite the viewer to question those same authorities that keep a rigid gender binary in place.

\section{CREATING COMPASSION IN THE UNKNOWN}

Trepidation and misunderstanding about the unknown create fear and intense fight-orflight responses. For most, understanding gender happens in an expected and binary way. Gender is assumed because one has certain body parts, clothes, and mannerisms understood and reinforced through specific social, political, and commercial institutions.

Misunderstanding and fear happens when someone who shares the same binary "visual evidence" but claims it as something entirely different. For many non-binary people, this moment is often met with negativity, judgement, and an attempt to correct into binary terms as these shared signifiers of identity are no longer predictable. ${ }^{32}$

There is evidence that compassion is tantamount to reducing prejudice in many forms, ${ }^{33}$ but prejudice can also be reduced by education which can lead to compassion. ${ }^{34}$ Examples in contemporary media, from The Addams Family (2019) to The Shape of Water (2017) attempt to illustrate the value of compassion. The examples used in these stories reference a concrete, unshared difference between the main characters and the prejudicial party. This story structure makes the differences obvious; The Addams Family is rendered monotone and spindly versus the rotund and colorful townsfolk; the fishman in The Shape of

\footnotetext{
32 Kevin L. Nadal et al., "Microaggressions Toward Lesbian, Gay, Bisexual, Transgender, Queer, and Genderqueer People: A Review of the Literature," (The Journal of Sex Research 53, no. 4-5 (2016): p. 488-508. https://doi.org/10.1080/00224499.2016.1142495)

${ }^{33}$ Lisa Sinclair, Beverley Fehr, Wan Wang, and Elise Regehr. "The Relation Between Compassionate Love and Prejudice: The Mediating Role of Inclusion of Out-Group Members in the Self." (Social Psychological and Personality Science 7, no. 2 (March 2016): 176-83. doi:10.1177/1948550615609736.) $34 \mathrm{Jim}$ Sidanius, Stacey Sinclair, and Felicia Pratto, "Social Dominance Orientation, Gender, and Increasing Educational Exposure1," (Journal of Applied Social Psychology 36, no. 7 (2006): pp. 16401653, https://doi.org/10.1111/j.0021-9029.2006.00074.x)
} 
Water is definitively non-human. Communicating that compassion is valuable is easier when differences are clearly discerned and there is no jeopardy to understanding one's individuation.

Encouraging compassion becomes more difficult when differences involve a shared physicality and threaten how one understands concepts of gender and identity. Tactics used by institutions to create understanding informed the decision to simulate a museum for the thesis exhibition. A 2016 study by researchers at the University of Southern California found that when socio-political ideas are challenged, the brain has a stress response similar to physical danger, which in turn leads to defensiveness and a reluctance to change. The brain is specifically geared to protecting itself, and that means its sense of self as well. ${ }^{35}$ When the gender norms presented by a capitalist Western society are considered essential, it creates a rigidity that refuses to acknowledge the idea that gender and identity are mutable, and therefore disallows the existence of others who exist outside those norms. Therefore, it is important to use approachable, trusted, and safe tools to invite a dismantling of the assumptions about the experience of those considered other. If gender binarism is institutionalized, it stands to reason that using an institution and subverting its purpose in a genuine way enables a safe and more trusted approach to the viewer. In the case of The Museum of Queer Curiosities, the simulation of a museum appropriates its role as an educator. To understand the effectiveness of an institution's ability to evoke a sympathetic reaction, one must understand the specifics of what sympathy and compassion are, as they are easily confused with empathy but have different results. The Merriam-Webster Dictionary defines sympathy as such:

"3. a: the act or capacity of entering or sharing the feelings or interests

35 Jonas T. Kaplan, Sarah I. Gimbel, and Sam Harris, "Neural Correlates of Maintaining One's Political Beliefs in the Face of Counterevidence," Scientific Reports 6, no. 1 (2016), https://doi.org/10.1038/srep39589 
of another

b: the feeling or mental state brought about by such sensitivity"36

Sympathy is, quite simply, the understanding of another's feelings. Sympathy can come from a logical conclusion; one understands how someone is able to reach their current emotional state from preceding events. Sympathy can also be triggered through an emotional understanding of someone's emotions, and either of these routes enable decision-making which can lead to compassion. ${ }^{37}$ Compassion is defined by Merriam-Webster as:

"sympathetic consciousness of others' distress together with a desire to alleviate it." 38

That last distinction is important, compassion involves a call to action to consciously decide to alleviate distress. In relation to the queer community, compassion can have a range of applications, from the willingness to trust one's identity, to the defense against nonaffirmation. By combining the implicit trust of an institution with the emotions evoked by fictitious circumstances to explicitly create the syntax for guiding the viewer, $T M O Q C$ attempts to lead the viewer to a compassionate response for the other.

In The Art of Sympathy in Fiction, author and Professor of English Howard Sklar explains how fiction authors craft narratives to evoke a compassionate response, and discusses the pedagogical implications of doing so. Sklar analyzes the tactics of creating what he refers to as "moral imagination," when looking at the tactics of emotional persuasion in fiction. For example, Sklar encourages students to specifically discuss the emotions

\footnotetext{
${ }^{36}$ Merriam-Webster.com Dictionary, s.v. "sympathy," accessed April 19, 2020, https://www.merriamwebster.com/dictionary/sympathy.

${ }^{37}$ Arthur Clark, "Empathy and Sympathy: Therapeutic Distinctions in Counseling," (Journal of Mental Health Counseling 32, no. 2 (2010): P. 95-101, https://doi.org/10.17744/mehc.32.2.228n116thw397504) ${ }^{38}$ Merriam-Webster.com Dictionary, s.v. "compassion," accessed April 19, 2020, https://www.merriamwebster.com/dictionary/compassion.
} 
fictitious stories create. He notes that while not the best format for understanding, these emotions do "provide a means for accessing that situation, for raising questions that are worthy of consideration, and even for leading individuals towards reflection." 39 Sklar's observation of the emotions evoked by engaging in fiction directly lead to the same process of logic that leads to sympathy. Taken a step further, if the simulation of the museum is a form of fiction, then one can assume the museum has this same capability to invoke sympathy. However, it is important to analyze how Sklar provides an environment for his students that encourages this kind of engagement. For one, this environment exists in a school, the readers are students; they are in a space designated for learning. Secondly, reading fiction creates a suspension of disbelief in the reader. Writing about a fictitious world will rarely offer a complete description. The reader relies on their background and experiences to fill in missing details, making a fictitious world more believable. This interaction creates a connection to and investment in the fictitious world. ${ }^{40}$ TMOQC utilizes this same setup. It exists with an assumed purpose as an educational tool and authoritative voice in which the viewer understands their purpose to learn. When this authoritarian voice is combined with an engagement in a fictitious world, TMOQC hopefully creates an environment that allows the viewer to challenge assumptions of gender and identity that are inherently hostile or dangerous.

$T M O Q C$ considers the museum as both an institution and a fictitious construct. This consideration is a strategy used to evoke understanding from the viewer. The reader becomes the viewer, and a written fictitious world becomes a space populated by otherworldly objects,

\footnotetext{
39 Howard Sklar, The Art of Sympathy in Fiction: Forms of Ethical and Emotional Persuasion (Amsterdam: John Benjamins Publishing Company, 2013. p. 160.)

40 Sklar, The Art of Sympathy, 161.
} 
familiar, yet disconnected and strange. Details left out become the mystery of art that invites the viewer to populate the space with their own experience. By mirroring an institution such as a niche or scientific museum, the gallery is transformed into a similar environment where the viewer, no matter how unknowing of academic queer theory and identity politics, can at least engage and be provided a safe space in which to question ideas of gender and assumption.

A few notes on these strategies. In no way should any queer person be satisfied in letting fiction or fiction-adjacent representations have more authority than their own experiences, especially when trying to convince a population to stop being hostile. This exhibition is an attempt to create a space that is safe, where questions can be invited nonaggressively, where confusion can be celebrated instead of shamed. It is also important to note that, for very specific reasons, I am not invoking empathy in the viewer. At the core of this research is an understanding that some situations exist where there is no chance for someone to feel the exact emotions of another. Every individual has a specific life, background, way of learning, privilege, identity, etc. It is impossible to expect total relatability. The work I have created does not need complete understanding from the viewer but seeks a reaffirmation in the trust that others know themselves and can define their experience. Even when one does not understand someone, an attempt and trust, even amidst confusion, is much more valuable than waiting for feelings to arise from a situation never experienced before.

My work also recognizes that the viewer has a sense of self and a cultural identity, and that this in turn gives them agency to explore the museum. In her book Installation Art, Professor of Art History and critic Claire Bishop points out that one of the early criticisms of 
phenomenology was the assumption that the viewer would be void of gender; in the way that insinuates the white, cis male as neutral or the default. ${ }^{41}$ The $T M O Q C$ relies on the opposite of this assumption. The viewer is encouraged to recognize themselves as an individual entity and use their identity to understand the objects within the gallery. Bishop also notes that, in the history of installation art, the viewer's experience of being contained within a space serves to provide a more vivid engagement with abstract ideas. ${ }^{42} T M O Q C$ uses these ideas behind the viewer's relationship to installation to evoke an emotional and compassionate response. By sharing their physicality and their emotions with the space and the strange objects that inhabit it, the viewer could in turn be more invested in the outcome of their overall experience.

\section{MYSTERY FISH: A HISTORY OF MISLABELING AND OBSCURANTISM}

As previously explained, people provide and interpret physical visual information to communicate identity. This process relies on our ability to quickly assume information and ideas, not only about people, but objects too. My work calls into question the "authority" of such visual information, and their interpretation. Assumptions about people and objects often lead to mislabeling and confusion. Mislabeling has been repeatedly seen in accounts of new "breakthroughs" in Western discovery, namely archaeology. In keeping with the theme of using the museum as a lens for critique, it seems fitting that there are references to mislabeling in $T M O Q C$. Pieces in the museum reference this type of disrespect often, either

\footnotetext{
${ }^{41}$ Claire Bishop. Installation Art: A Critical History. New York: Routledge, 2005. p. 69.
}

42 Bishop, p. 10-11. 
through indirect symbols, tongue in cheek and sarcastic labels, or vague and incorrect object information, to discredit the institutions that encourage presumption over consideration.

An early example of this kind of mislabeling is estimated to have come from Ancient Greece and makes several appearances in the symbolism in the work. According to folklorist and researcher of ancient science Adrienne Mayor, in 1914 a paleontologist from Austria named Othenio Abel pointed out that the skull of extinct Pleistocene dwarf elephants (Fig. 28) resembled grotesque human skulls. The large shallow eye sockets on the side of elephant skulls were missed, and more attention was paid to the large trunk nasal cavity. This cavity was seen as evidence of a large, central eye, and its massive bones could be laid out in the shape of a man. Due to their existence in Sicily dated well before Greek records of elephants, Grecian sailors were said to have seen the ancient skeletons and assumed they were the skeletons of giant humanoids. ${ }^{43}$ Cyclops and elephants regularly appear throughout TMOQC. For example, Historic Shroud (Fig. 15) is a large piece that references the Cyclops and Casting (Fig. 29) is a representation of elephant footprints. These references are representations of other, of misunderstanding, and of the confusion that comes from repeatedly engaging in a world that mislabels and often intentionally misunderstands. This is not a direct one to one metaphor. The blend between the "science" of Cyclopean myth and the presentation of the Cyclops/elephant divide in the work may be considered fluid, and its definitiveness non-existent.

Another example of misattribution based on physical evidence is the discovery of a fossil by Albertus Magnus, a 13th German scholar later canonized as a saint for the amount of research into the natural world he did in the middle ages. According to Aaron Mahnke,

\footnotetext{
${ }^{43}$ Mayor, Adrienne. The First Fossil Hunters: Paleontology in Greek and Roman Times (Princeton, NJ: Princeton Univ. Press, 2001, www.jstor.org/stable/j.ctt7s6mm.9. p. 35-37.)
} 
creator, producer, and host of the LORE podcast and author of The World of Lore book series, Magnus preferred first hand evidence, and often went to local mines to observe gems and minerals directly. One trip, a strange, "egg-shaped" rock was discovered, which contained a small skeleton that looked like a bird in all ways, save for its monstrous head. Magnus assumed the rock had created life. The creature, unable to escape the rock, died and returned to the earth beneath the cave. As Mahnke states, "looking back with our modern understanding of the natural world, it's clear that Albertus had discovered a fossil, but simply lacked the understanding to put the pieces together." 44 This is similair to the type of misunderstanding that happens when trying to discuss being non-binary with someone who has never had the trains of thought to make that discussion completely clear. Rather, they are stuck using and assuming based off the limited information provided by a society that benefits from conformist gender binary.

In a similar vein, human remains can be mislabeled as well, usually because of assumptions about the objects they are buried with. In southwest Sweden, the crypt of a Viking was discovered, surrounded by sacrificial horses and weapons. Because of contemporary gender stereotyping, the Viking was assumed to be a male by archaeologists when first discovered, but in actuality was a female. ${ }^{45}$ In the piece Successful Reveal, the postmortem misattribution of something that has lived a life is combined with the problematic contemporary fad of the preemptive "gender reveal party". Confetti has been

\footnotetext{
44 Aaron Mahnke. "Hard Rain". (LORE. Podcast audio, Sept. 3, 2018. http://www.radiolab.org/story/91518-goat-on-a-cow/. 28:35-30:40.)

${ }_{45}$ Michael Greshko, "Famous Viking Warrior Was a Woman, DNA Reveals," National Geographic Magazine (National Geographic Society, September 12, 2017). https://www.nationalgeographic.com/news/2017/09/viking-warrior-woman-archaeology-spd/\#close)
} 
thrown over the empty half of a broken fossil, criticizing and calling out the assumptions made when prescribing identity based on the very limited information available (Fig. 30).

Still, there is a lot about queerness that can be hard to communicate, even with the benefit of our contemporary understanding. Beyond the physical proof of mislabeling that exists in historical references, The Museum of Queer Curiosities also acknowledges the difficulty of speaking individually for a group. For example, The Mil Touchstone, covered in symbols of eyes and hundreds of small figures, invites the viewer to try to understand this simplistically styled symbolism. The intent behind the all-over visual design is to draw the viewer in, provide them with enough information to try to fill the scene and make sense of the symbols. While at the same time the layering of the glyphs on the "stone" makes this challenging and potentially impossible. (Fig. 31) This piece is also a direct reference to how obscurantism, the intentional hiding and obscuring of information, is used by those in authority.

The Museum of Queer Curiosities uses obscurantism in an ironic way to create obvious references to ideas about the difficulty of understanding the unknown, translating visual information, and the strangeness of authority. Throughout $T M O Q C$, elements like the confusing design of information labels and the mishandling of objects are intended to illustrate this ironic use of obscurantism. The labels, like the observations of St. Albertus Magnus, seem at first glance to be authoritative. In general, museum labels are usually didactic and deserving of the viewer's trust. However, upon scrutiny the text and information contained in $T M O Q C$ 's labels are inherently wrong. Specific information, like measurements, are miscalculated, such as the size estimations of the rest of the Formulaic Statue (Fig. 32), and information is vague, such as the label for the Strange Shield (Fig. 33). 
As the viewer experiences the rest of the museum, obscurantism is used through the physical mishandling of the work as well. Pieces are left on the floor haphazardly, some are seemingly broken, and others are split and invaded by the walking path designated by the museum. This intentional chaotic display creates an ironic relationship between an authoritative museum and the callous and careless handling of its charges. At the same time, most of the objects, such as the Shroud and Instructional Scroll (Figures 15, 18) and the previously discussed Touchstone reference some form of communication. The repeated motifs of eyes, hands, or people, combined with their titles that reference existence as objects of recording, hint at some communication or puzzle to unlock between them. These pieces also hint at the potential for their own authority, free of the museum. While this metaphor may be relatively obtuse, the way the objects interact with each other is not. This tension between an assumption about an object's meaning being reliant on institutional authority and the reality of its autonomy mirrors the priorities of the museum, to acknowledge the difficulty of communicating complex ideas, to remove the authority from institutions and return autonomy, trust, and authority to the individual and the objects themselves.

There is an important distinction to be made about $T M O Q C$ from the historical examples previously referenced. Unlike the skulls and fossils of the past, there are living people on earth sharing their experiences and trying to get their perspectives heard. By alluding to the misinterpretations of the past, I hope to reestablish the authority of anyone, past or present, regarding their own truth. 


\section{SURREALISM, SYMBOLISM, AND FANTASY: REESTABLISHING QUEER AUTHORITY}

Suspension of disbelief from the audience is sought after in any setting that is fantastical, and for someone who is not accustomed to questioning gender, what could be more beyond belief than the changing, warping, or obliteration of gender? Aristotle first wrote of ideas similar to what would become known as the suspension of disbelief as a means of obtaining catharsis when watching a play. As the audience removed themselves from the logic that they were in attendance of a performance, and became invested in the actions of the characters on stage, they could experience catharsis, or the purification of emotions, most notably fear. ${ }^{46}$ In my work, the desire to create a quasi-real environment in which the viewer can move around and exist in order to illicit a similar cathartic experience is imperative. Surrealism, fantasy, and symbolist art create an opportunity for the viewer to exist as 'other'. If the viewer's belief is suspended in this way, authority and responsibility falls further to $T M O Q C$ and its content, to guide this catharsis.

As previously stated, one of the intentions behind $T M O Q C$ is to create a safe space for compassion through the simulation of a trusted institution. Additionally, the viewer's suspension of logic and disbelief is encouraged through the stylization of both the environment of and the artifacts contained in $T M O Q C$. For example, the simplified drawings and forms that accompany the museum installation suggest an interpretation that is incongruent with contemporary states of gender. According to The Great Soviet Encyclopedia, this incongruence was one of the many purposes of stylization, as "stylization... often served as a means of retreating into an imaginary, idealized world... as a sign of dissatisfaction with the ordinary and

46 "Catharsis - Cristicism" in Encyclopedia Britannica (Encyclopedia Britannica, Inc., September 26, 2018), https://www.britannica.com/art/catharsis-criticism 
commonplace and with traditional ideological and artistic norms." The Encyclopedia further notes the importance of stylization in "recreating the folklore of various people." 47

The work of TMQOC uses my experiences as a queer person as the folklore it captures. The stylization of the work from Formulaic Statue (Fig. 19) to illustrations on the wall (Fig. 7) in the TMQOC is intended to establish a feeling of otherness in the viewer and promote a misalignment with identity norms. While the simulation and appropriation of the museum and its authority is important, also important is the viewer's understanding of how the abstraction of $T M Q O C$ 's space and contents promotes its adjacency, not symmetry, with a museum's goals.

$T M Q O C$ 's contents are intended to escape a concrete reality, as they are physically juxtaposed between three-dimensional space and two-dimensional "drawings". This presentation is intended to emphasize stylization and hint at the surreal world the artifacts come from. The best example of this 'evidence of a fictional world' lies in the Historical Shroud (Fig. 15). The title, grand chaotic figures, and scale hint at an underlying and lived history, but its contemporary fabrics, paints, and even the stylized nature of the monoprints involved disjoints it from this implied reality (Fig. 34). When presented with such an unstable setting, I hope the viewer finds safety in $T M Q O C$ 's obvious disguise as an institution, emphasis in stylization, and trusts that there are specific intentions behind the puzzles TMQOC presents.

In art history, late figurative surrealism represents an exploration of meaning beyond the concrete. Influenced by psychology, culture, and Dadaist appropriation of found objects, figurative surrealist artists presented the known in unknown ways to explore meaning taken

\footnotetext{
47 The Great Soviet Encyclopedia, 3rd Edition. S.v. "Stylization." (Retrieved April 1, 2020 from https://encyclopedia2.thefreedictionary.com/Stylization.)
} 
from odd juxtapositions of dreamlike symbolism and materials. ${ }^{48}$ Sculptures like Meret Oppenheim's Fur Teacup (Fig. 35), Salvador Dali's Lobster Telephone (Fig. 36), and Man Ray's Object of Destruction (Fig. 37) take existing artifacts and objects out of context, combine them in surprising ways, and offer new meaning. My own work takes a similar approach, such as the sculpture MQC Coin Collection (Fig. 38), constructed of disassembled keys. For me and people in my position, keys represent access, or future success. Keys symbolize access or ownership to commodities like cars or homes. For many queer people, the act of being oneself puts them in jeopardy of that access being cut off by a prejudiced economic system. That connotation can become clear to others when the keys are amputated, brightly colored, and presented as coins. In the book Fantastic Art, Dada, and Surrealism, art historian and the first director of the Museum of Modern Art Alfred H. Barr, Jr., describes Surrealist art as objects of "concrete irrationality." ${ }^{49}$ In light of trying to invoke specific questions about content and focus less on formalist interpretations, Barr Jr. quotes Salvador Dali about the purpose of surrealist objects, a summary that is applicable to the work in TMOQC: "Objects with symbolic function leave no loophole for formal preoccupations. Only amorous imagination..." ${ }^{50}$ The objects in the museum use two and three-dimensional combinations of recognizable and stylized imagery and objects so the viewer is able to focus on their relationships to one another, rather than be lost in abstract unrecognizability.

There are some objects within The Museum of Queer Curiosities that are not found objects (despite the "Curator's" assertions that all objects in the Museum are found), nor are all parts of their form made of complete integration of recognizable parts. The Strange Shield

\footnotetext{
48 "Surrealism," Heilbrunn Timeline of Art History (The Metropolitan Museum of Art, n.d., http://www.metmuseum.org/toah/hd/surr/hd_surr.htm)

${ }^{49}$ Alfred H. Barr, Fantastic Art, Dada and Surrealism, 3rd ed. New York: Arno Press, 1936. p. 12.

${ }^{50}$ Salvador Dali (as cited by Alfred H. Barr), Fantastic Art, p. 49.
} 
(Fig. 14), uses the base form of a shield but is covered in abstract and printed on paper shapes of hands (Fig. 39), and the Informative Book on Progress, which has minimal physical representations making up its form, come to mind. But similar concepts of symbolism still apply (Fig. 40). Meaning in the TMOQC is generated in the same way as an individual's identity, it is gathered collectively from every piece of media, every interaction, the surfaces of objects interact with the meaning of other objects that inform and intrigue the viewer and add to its overall truth.

Throughout $T M O Q C$, symbols are a grounding factor. They serve as a unifying visual element intended to amplify the viewer's experience, as a guidepost for interpretation, and opportunity to create obscuration. To condense my queer experience throughout TMOQC, I created around 30 symbolic ink drawings, that individually are capable of standing alone, yet work together to offer more opportunities to create meaning. While all the drawings are representational and hold a significant and personal meaning, some are more abstract than others (Fig. 6). The application of these symbols to the walls and objects of $T M O Q C$, is intended to collapse the space between objects and offer new ways to construct meaning, the same way Dali creates meaning by combining a plastic lobster to a phone base. Silkscreen was used to apply images to the surfaces of TMOQC objects, such as the ends of the Instructional Book, the interior of the Formulaic Statue, and the surface of The Mil Touchstone (Figs. 40, 41, and $31 \mathrm{rsp}$.$) . Screen printing utilizes a transparency and flexibility of layering imagery on$ paper and objects. As stated previously, the inclusion of transparent layers of symbols aids in the obscuration of their information, but more so in these examples serves to underlie their outward meaning. In the catalog, these images serve the same purpose, their metaphor becomes 
more complex the more information placed on top or alongside them, but so too does the bewilderment.

Throughout $T M O Q C$, the meticulously cut out illustrations blend with the wall (Fig. 14). These representational illustrations work well as the "decoration" of the museum. Some of the drawings become artifacts and inform other objects in their proximity. All objects in $T M O Q C$ are related to each other, laterally, vertically, and inter-spatially. The illustrations serve to visually tie these seemingly unrelated objects together. For example, the illustration Car Fob lining up with the MQC Coin Collection (Fig. 42), the illustration Long Hair lining up with the Successful Reveal (Fig. 43), and the illustration Emergency Contact hovering behind the Instructional Book of Progress (Fig. 44) provide more context and meaning to both drawing and object. Even when spaced apart, certain objects such as the $M Q C$ Coin Collection are arranged in such a way that when viewed from a distance, they still line up with illustrations on the wall.

\section{MAKING A MUSEUM}

Many decisions went into the installation of The Museum of Queer Curiosities. The foremost of these decisions being that at a first glance, the exhibition is intended to have the semblance of a niche or otherwise non-artistic museum. Museum labels were the first consideration in transforming the viewer's understanding of the space. Traditional label information printed on white paper mounted on foam core and displayed next to a work of art were jettisoned for labels that reflected the treatment of information at museums like the Carnegie Museum of Science and the Corpus Christi Museum of Natural Science and History. Providing information that is available under the control of the reader was also important. To 
achieve this same sense of educational autonomy, information about the contents of $T M O Q C$ is available in a catalog. Strategies for installation and display offers another opportunity to create the distinct feeling of a niche museum. Traditionally, two-dimensional works of art are expected to be displayed at 60 inches on center from the floor, to maintain hanging the work at eye level. Walls, if colored, are to be completely solid. Enough wall and floor space are to be given between artworks to prevent pieces from visually interacting with each other. In traditional science and history museums, artifacts are overloaded, and display is cluttered. In less-dense galleries, walls are still decorated, and the space seems as much about entertainment as education. Utilizing similar formal qualities was important to break up the Mesaros gallery space for $T M O Q C$. For instance, illustrations posted on the wall and a path laid on the floor help visually activate blank spaces between work. Individual pieces are installed dramatically high, more interested in presenting the work as a spectacle, pieces also exist on the floor and invade the viewer's designated space. The entire display is intended to make $T M O Q C$ feel less like a sterilized contemporary gallery installation and more like a niche museum, approachable, educational, and entertaining for the viewer.

In the book Art Theory: A Very Short Introduction, author Cynthia Freeland creates a differentiation between the museum as a beacon of taste in art versus the "a la Disneyland" approach of more immersive museums. Freeland argues that museums have to decide between content or experience, as if the two were divided from each other. ${ }^{51}$ However Rachel Morris' essay "Imaginary Museums" in the book Museum Making: Narrative, Architecture, and Exhibition, has a different approach. Morris notes that museums are culturally capable of illuminating "social, spiritual, and emotional" satisfaction and activating a sense of

\footnotetext{
${ }^{51}$ Freeland, Cynthia A. Art Theory: A Very Short Introduction. Oxford: Oxford University Press, 2003. P. 83-94.
} 
engagement through exciting exhibit strategies. For Morris, museums may not go far enough in facilitating viewer engagement that is so critical to an exhibition's success:

"...their desire to use their imaginations... is very often ignored by museums. In other words, visitors come to museums with their imaginations ready to be deployed, only to find that their imaginations are not required.... visitors move through museums ready to use their empathy, creativity and understanding in order to reach a state of emotional and imaginative openness. It's a journey that requires museums also to play their parts, by offering back to the visitors atmosphere and opportunities to feel." 52

There are a few important factors to the presentation of The Museum of Queer Curiosities. First, TMOQC does not exist as parody or institutional critique. Its thesis is in a genuine, albeit sometimes confusing, experience. For me, the use of parody, aggression, and sarcasm, which rely on concrete terms to rail against, would not have the same effect of evoking a compassionate response from the viewer.

Additionally, while much of the discussion about $T M O Q C$ has focused on the Museum solely as a non-artistic entity, the obvious materiality of the pieces ground them to references of historic and contemporary art. As stated earlier, screen printing was an ideal printmaking process used for the surface treatment of many of the objects throughout TMOQC. But the objects in $T M O Q C$ utilized a variety of different print and sculpture media for their creation. Monoprinting was used to produce the ephemeral tonal images of Historic Shroud (Fig 15 ). The surface imagery on the main egg of Successful Reveal was created with relief printed on toned paper, hinting at age associated with historic relief prints. Pieces that have no printed images still utilize the repetition of symbols to convey their information, relating to the history of print used for the dissemination of information.

52 Suzanne Macleod, Racheal Morris et al., "Imaginary Museums," Museum Making: Narratives, Architectures, Exhibitions (Abingdon: Routledge, 2012), https://ebookcentral.proquest.com/lib/wvu/reader.action?doclD=956902\&ppg=27\#. p. 10. 
The materiality of the work in $T M O Q C$ is also a visual reference queer art. Manufactured objects and piles on the gallery floor invading the viewer's space reference the phenomenon and interactivity of Candy Piles by Felix Gonzales-Torres (Fig. 47). Found artifacts and familiar, stylized imagery in juxtaposition to historic forms alludes to the relatability of Grayson Perry's tapestries and ceramic work (Fig. 48). Illustrative stylization is influenced by both modern cartooning and the emotional symbolism of Keith Haring (Fig. 49), the symbolist illustrations of Marco DaSilva (Fig. 50), and the autobiographical comics of Barbara Tharas. (Fig. 51) Found objects are also a common and constant thread in queer work, from the assemblage of Alex Martin, to the 2017 group exhibition "Found: Queer Archaeology, Queer Abstraction" at The Leslie-Lohman Museum of Gay and Lesbian Art (Fig. 52). There are as many artistic mediums used in queer art as there are identities. Utilizing a varied artistic toolkit acts as a metaphor for the many facets of being queer. Creating work that has an incongruous materiality with their representation is important to my own feelings of dysphoria. This art making strategy also celebrates art's capability of transforming material and the identity of found objects, which again, creates a link to ideas about the flexibility of the self.

\section{CONCLUSION}

Queerness encompasses a breadth of experiences and ideas. I cannot expect to entirely convey the experience of being queer to someone outside its reach any more than I can expect to completely share the experience of every single queer person on Earth. Communication seems difficult, if not impossible, about a topic that challenges the essentialism of 
cisnormativity. The Museum of Queer Curiosities acts a tool to share, interrogate, celebrate strangeness.

I am inherently the subject of the museum; but also, am not. The work inhabiting $T M O Q C$ utilizes personal symbolism informed by my lived experience. Specific information and ideas are intentionally vague. The work hints at the fact the entire $T M O Q C$ is a selfportrait, and the broad spectrum of work informs the viewer of the scale and impossibility of communicating the entire existence of one person succinctly. I am the Curator, the voice of the Catalog, the collector and mis-handler of objects. I am The Museum of Queer Curiosities. Acting as a tool that simulates something trustworthy, TMOQC attempts to capture something ephemeral, only to be left inept and untrustworthy by the objects it houses. TMOQC encourages the viewer to embrace the weird, confusing nature that is someone else's experience with identity. And in turn, come to the realization that the real strangeness comes from trying to trust and listen to outside information over their own, or someone else's, voice. 


\section{FIGURES}

Figure 1. The Museum of Queer Curiosities, installation shot
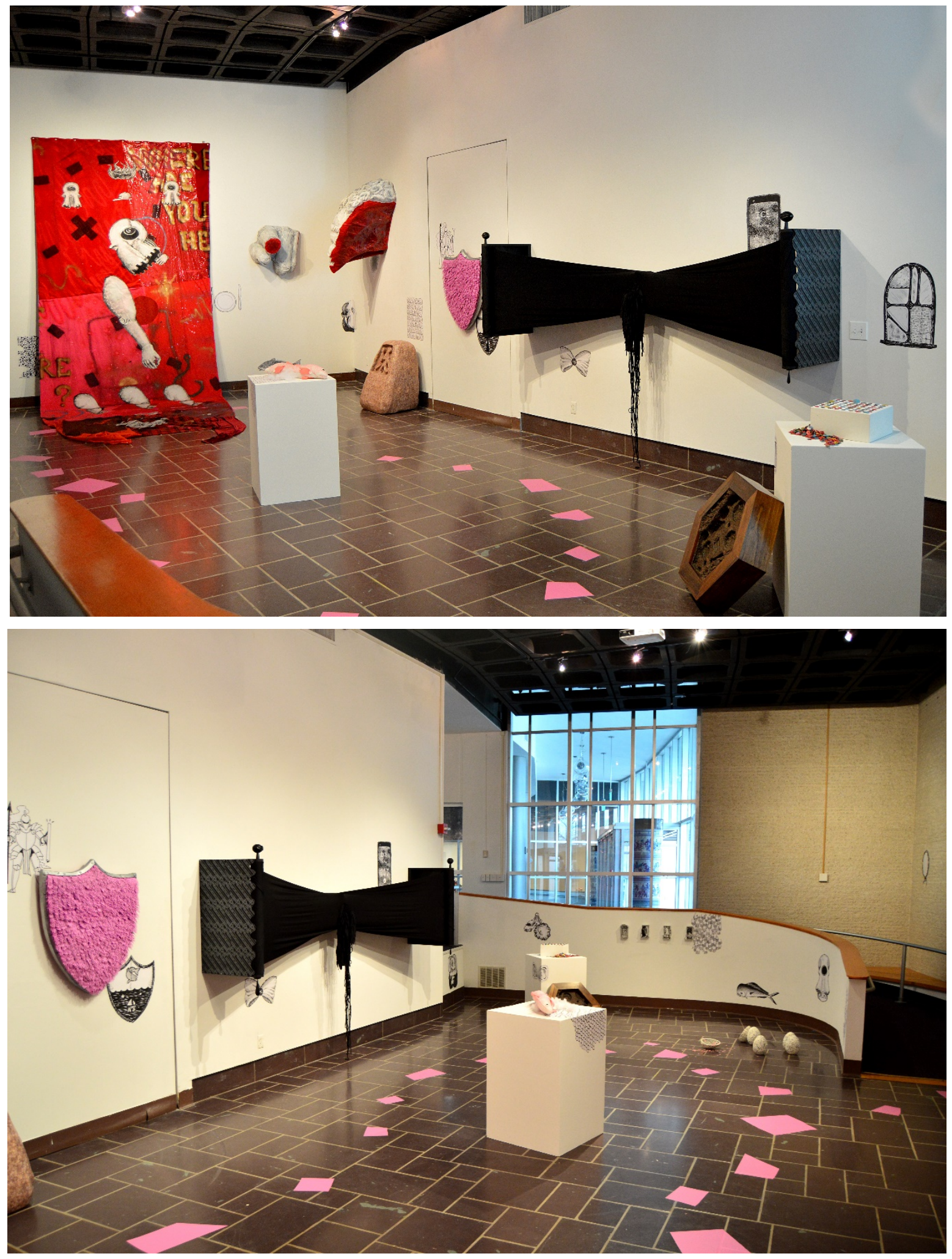
Fig 2. Catalog, digital media part of the installation of The Museum of Queer Curiosities (following)
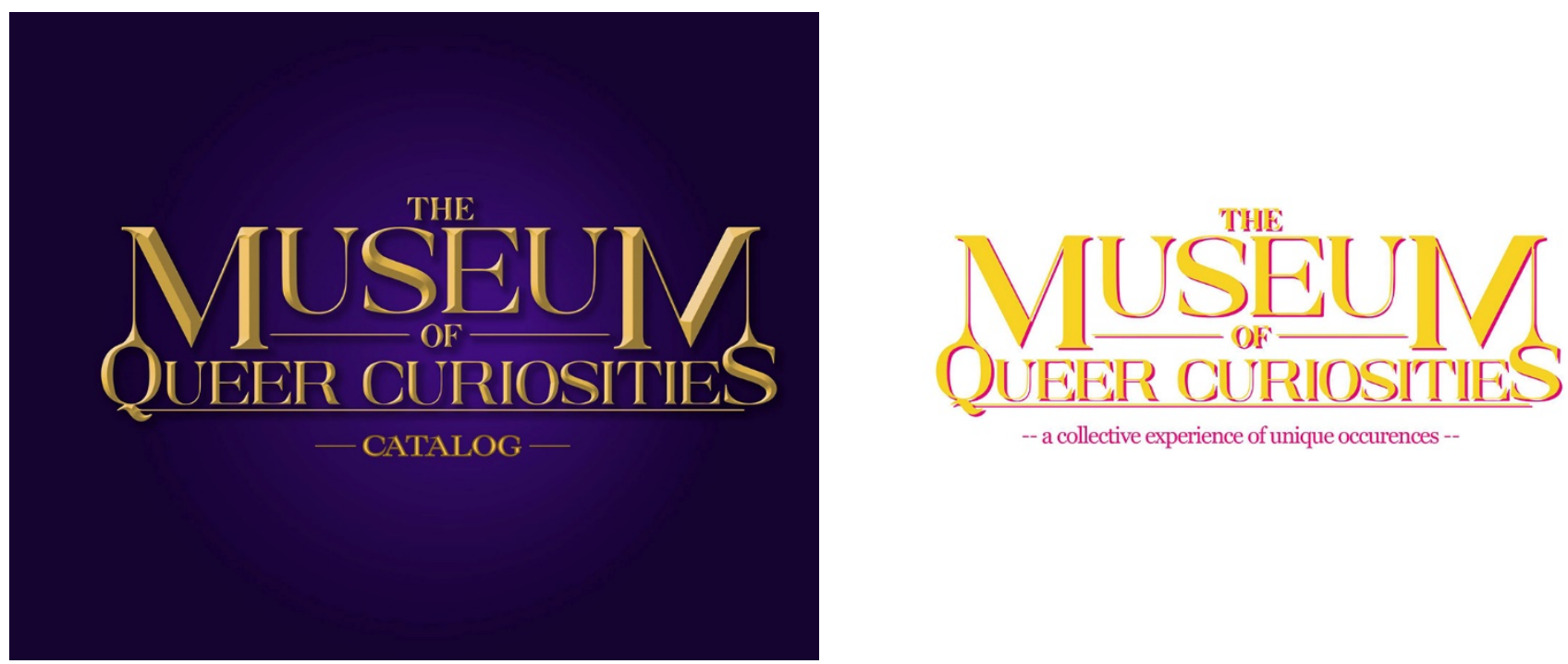

-- a collective experience of unique occurences -

Do you keep record on your life? Are you still the same person? Are you certain?

THE MUSEUM OF QUEER CURIOSITIES is a chronicle of a very specific time in which the self was taken into consideration for records amount of time. Every day, food is eaten, clothes

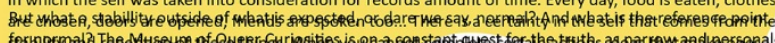

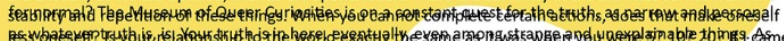

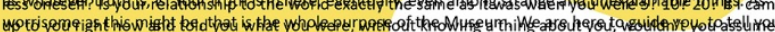

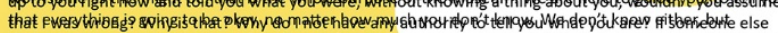

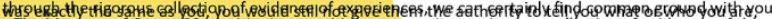

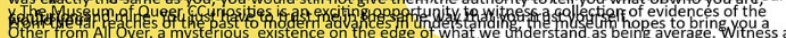

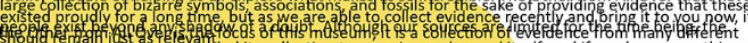

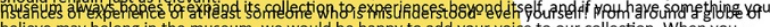

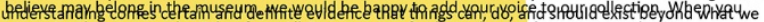

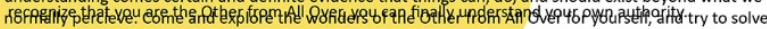
what the most complicated questions of all is. 


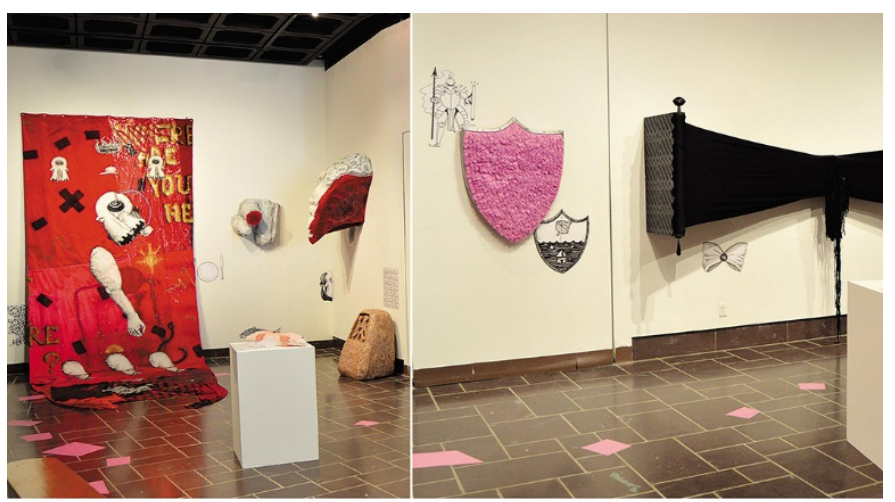

The Museum of Queer Curiosities currently is exhibiting selectively from a variated collection focusing on historically relevant artifacts, collected from All Over. Skulls, shields, scrolls, and other discoveries line the gallery with intrique. 2020.
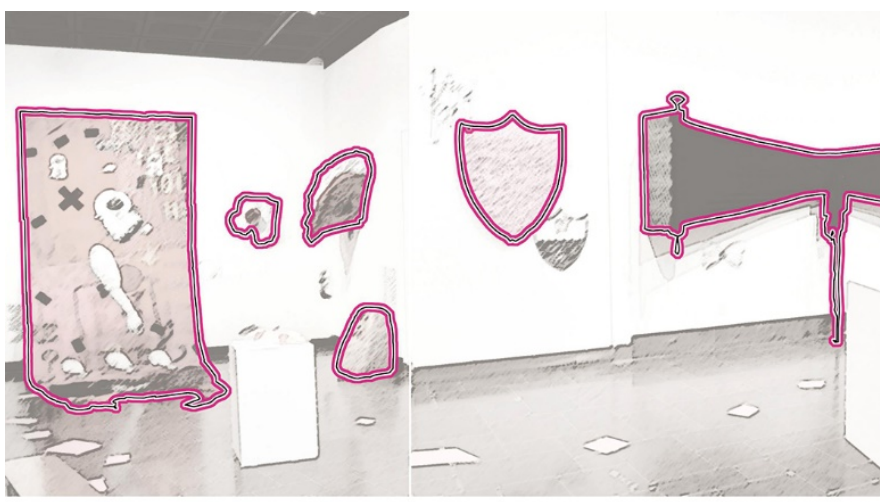

HISTORICAL SHROUD OF TRAVELLING

FORMULAIC STATUE

StRANGE SHIELD

MIL TOUCHSTONE

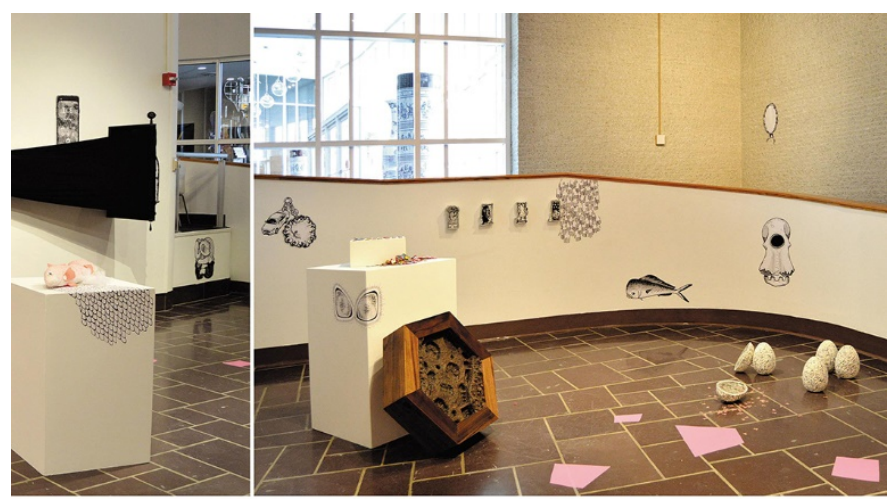

The museum prides itself on its fufilling and respectable handling of ancient artifacts, carefully curated and protected. We encourage exploration of our own exploration.

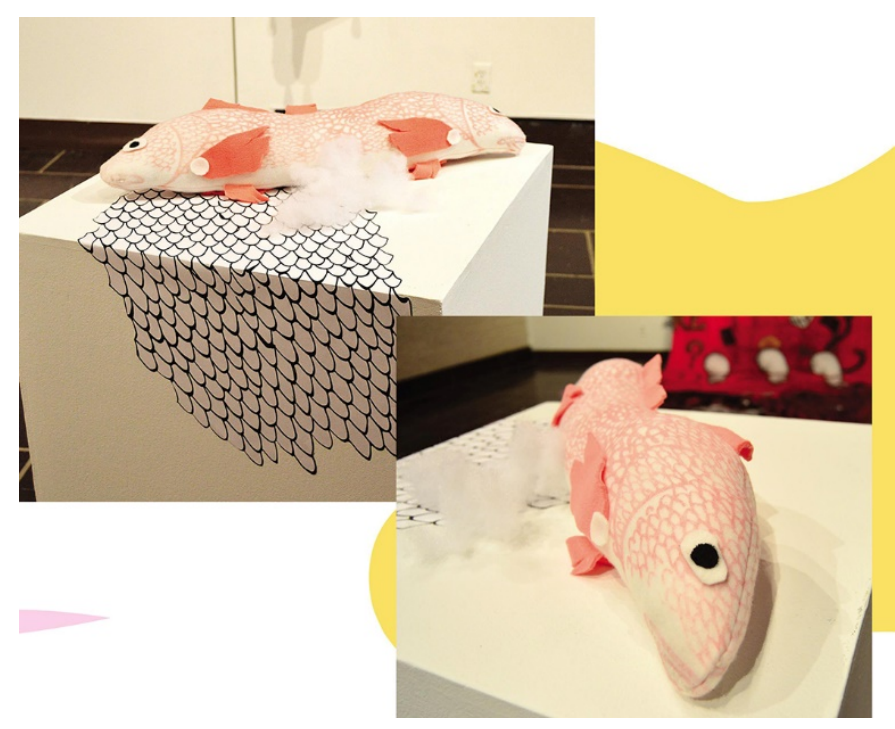

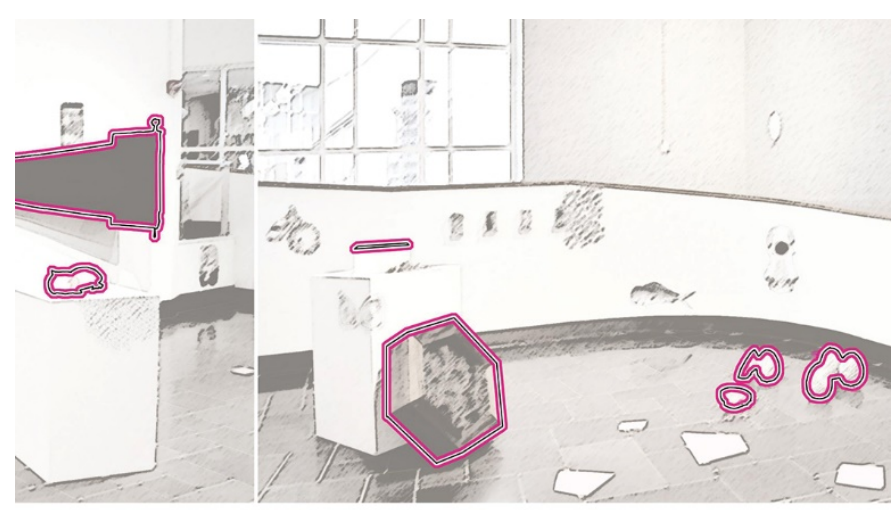

UNCONDITIONAL FISH

SUCCESSFUL REVEAL
MQC COIN COLLECTION

CASTING

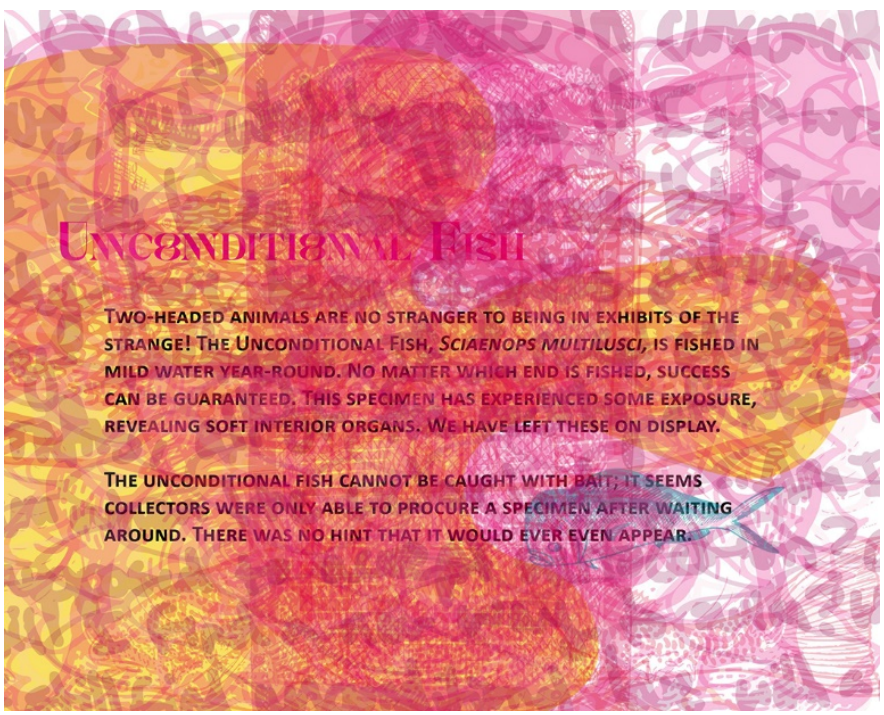



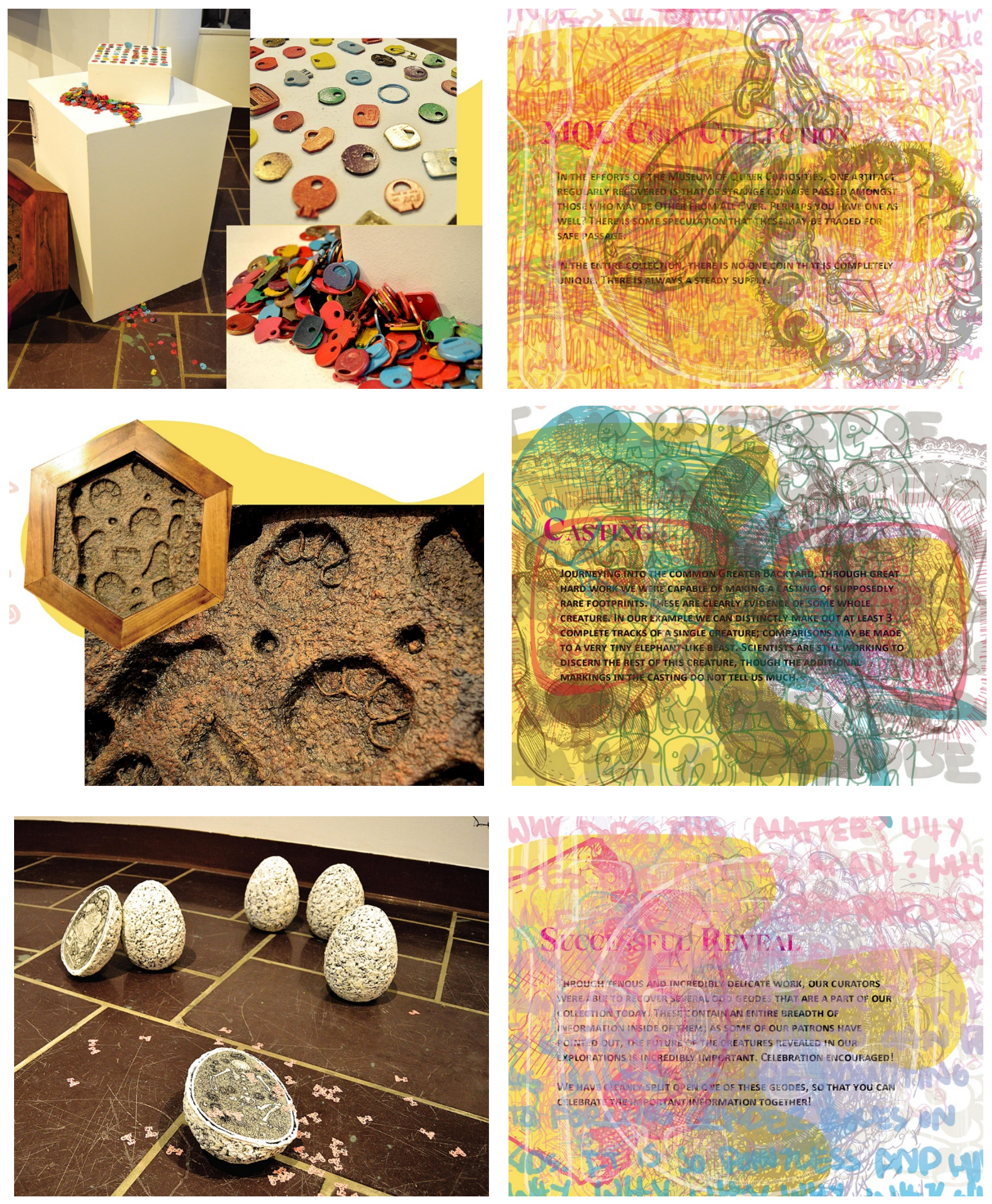


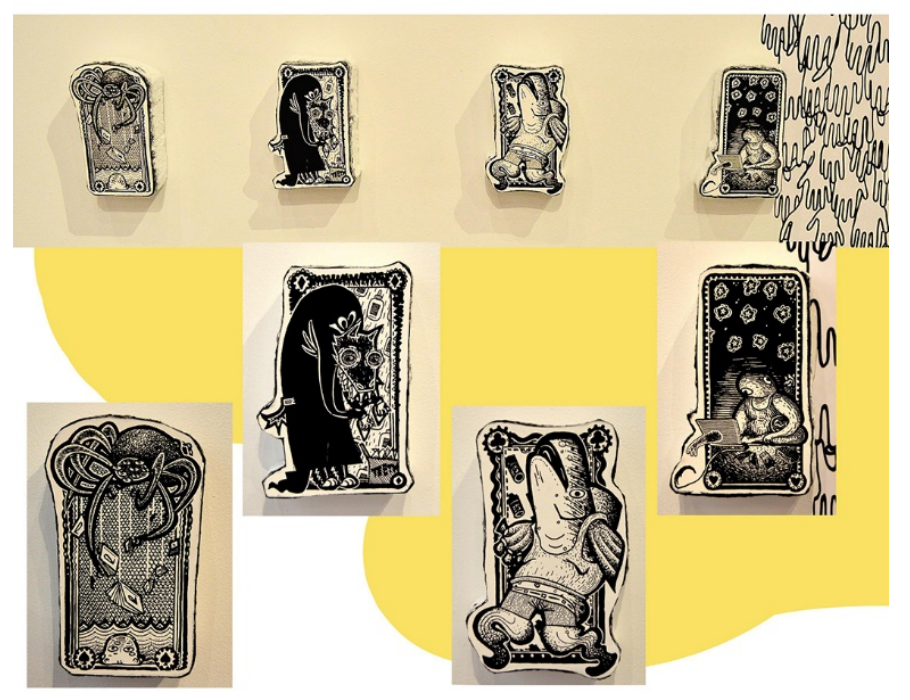

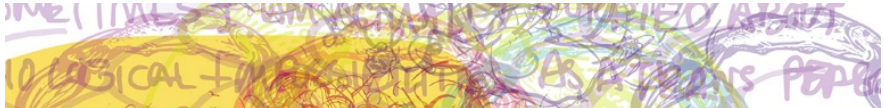

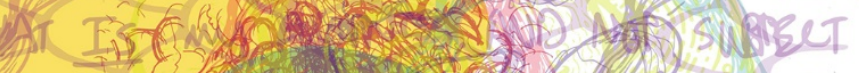

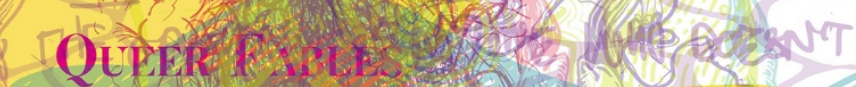

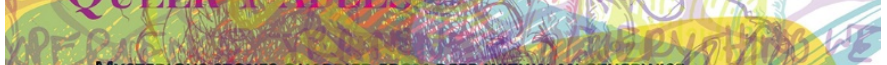
Q. MYSTER OUS STONES QUARRISD FROM DEEP WITHIN AN OTHERWISE Y YAC NONDESCRI PTIVE MUNE. THEY WERE DISCOVERED WUHEN CURATORS WERE

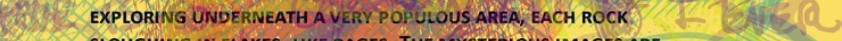
SLOUGHING IN FLAKES, LIKE PAGES. THE MYSTERIOUS IMAGES ARE PERMANENTLY FORMED IN THE SURFACE, AND OUR INDICATORS HINT 9) THAT THERE MAY BE MANY MORE, RELATEABLE STORIES. Di THE SUBJECT MATIER ALL SEEMS TO DEAL WITH DIFFERENT ITERATIONS

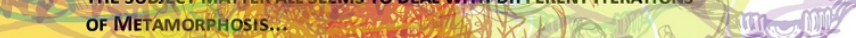

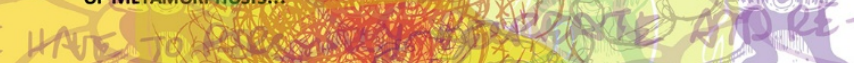

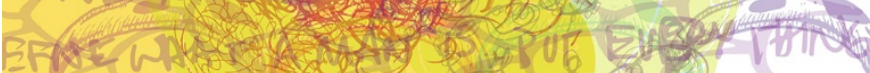

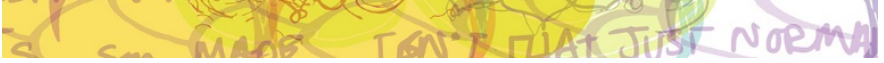
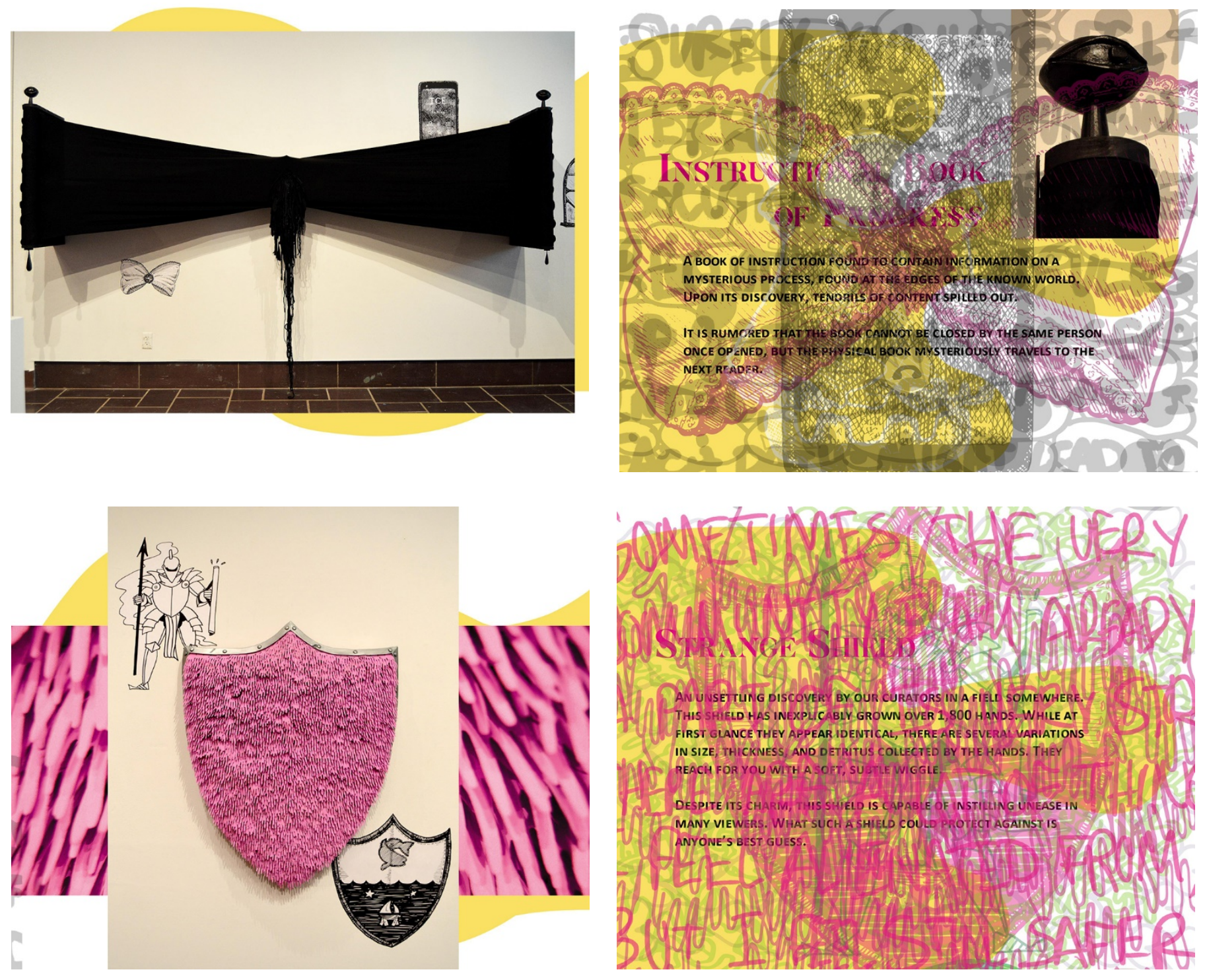

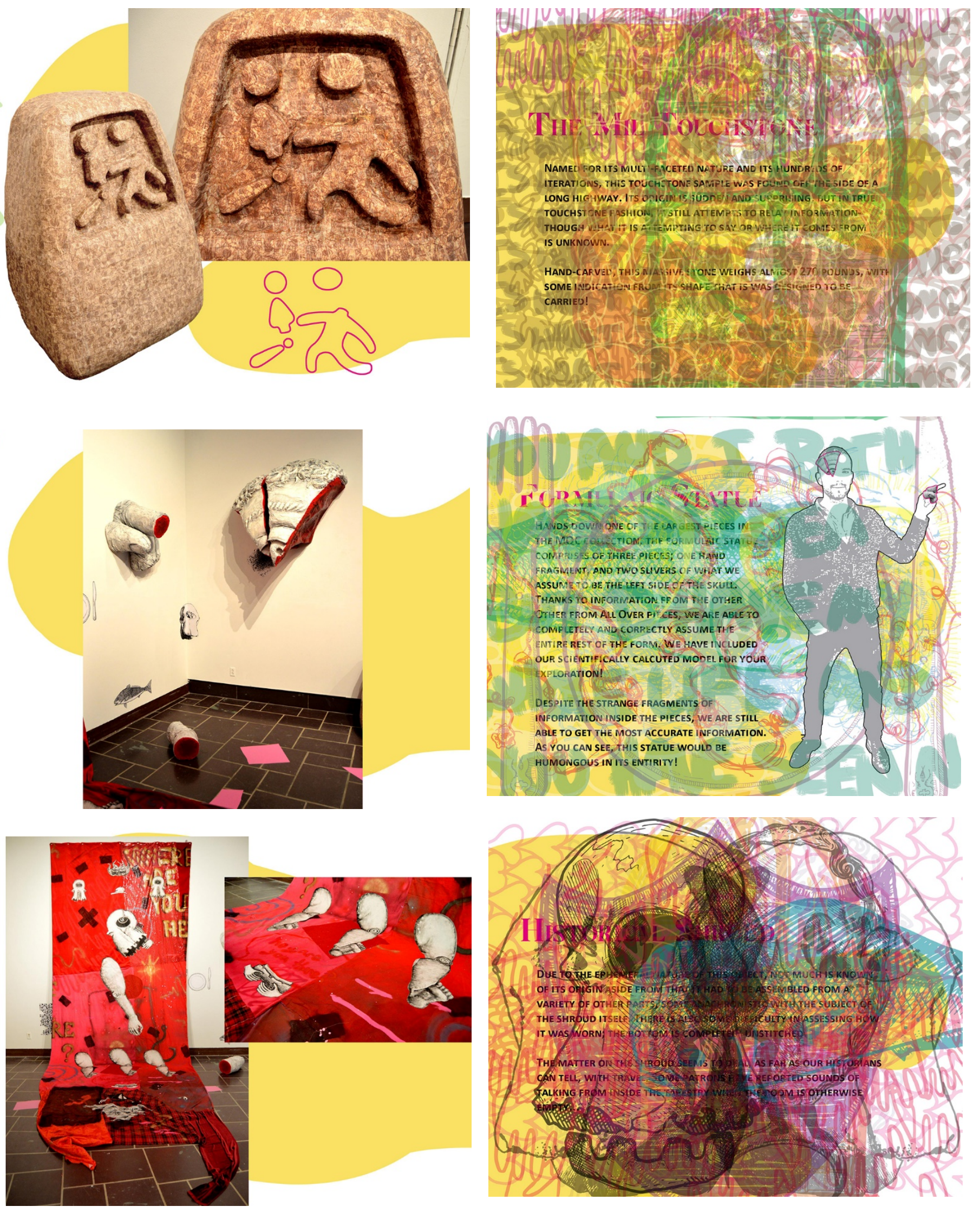


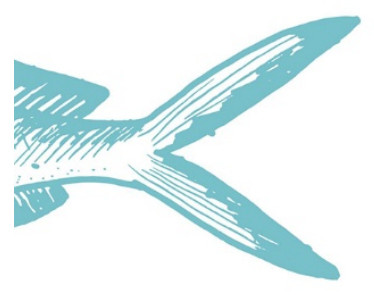

Thank you for your support of the Museum of Queer Curiosities! If you think you have a valuable artifact that may fit our collection, please email:

Feliks RK Pyron

Curator of Exhibits

the_mqc@gmail.com
Fig. 2, Catalog, end.

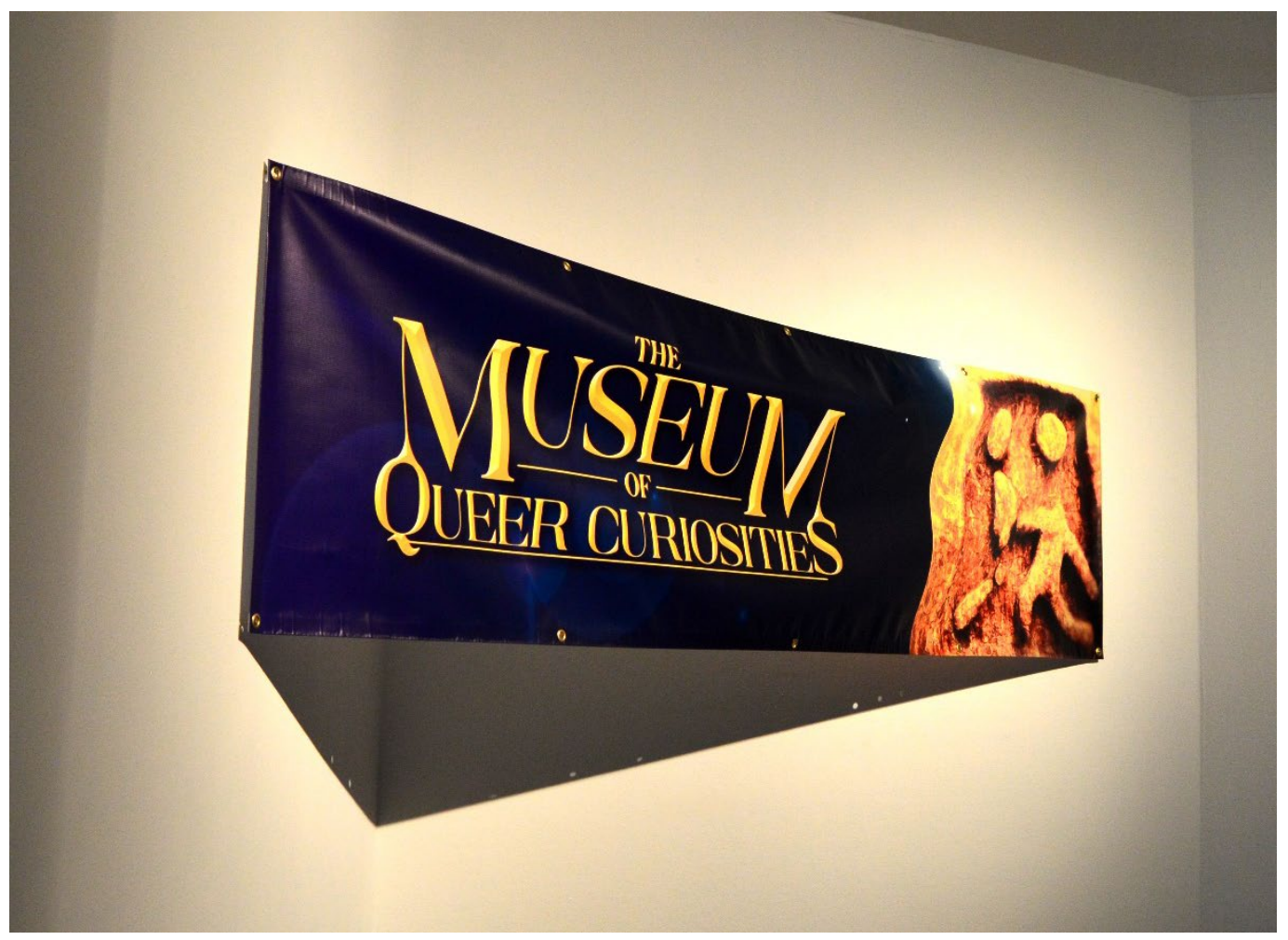

Fig. 3, Title Banner, installation shot. 
Fig. 4, Announcement Card, a showcard told from the voice of the Museum, not the Artist.

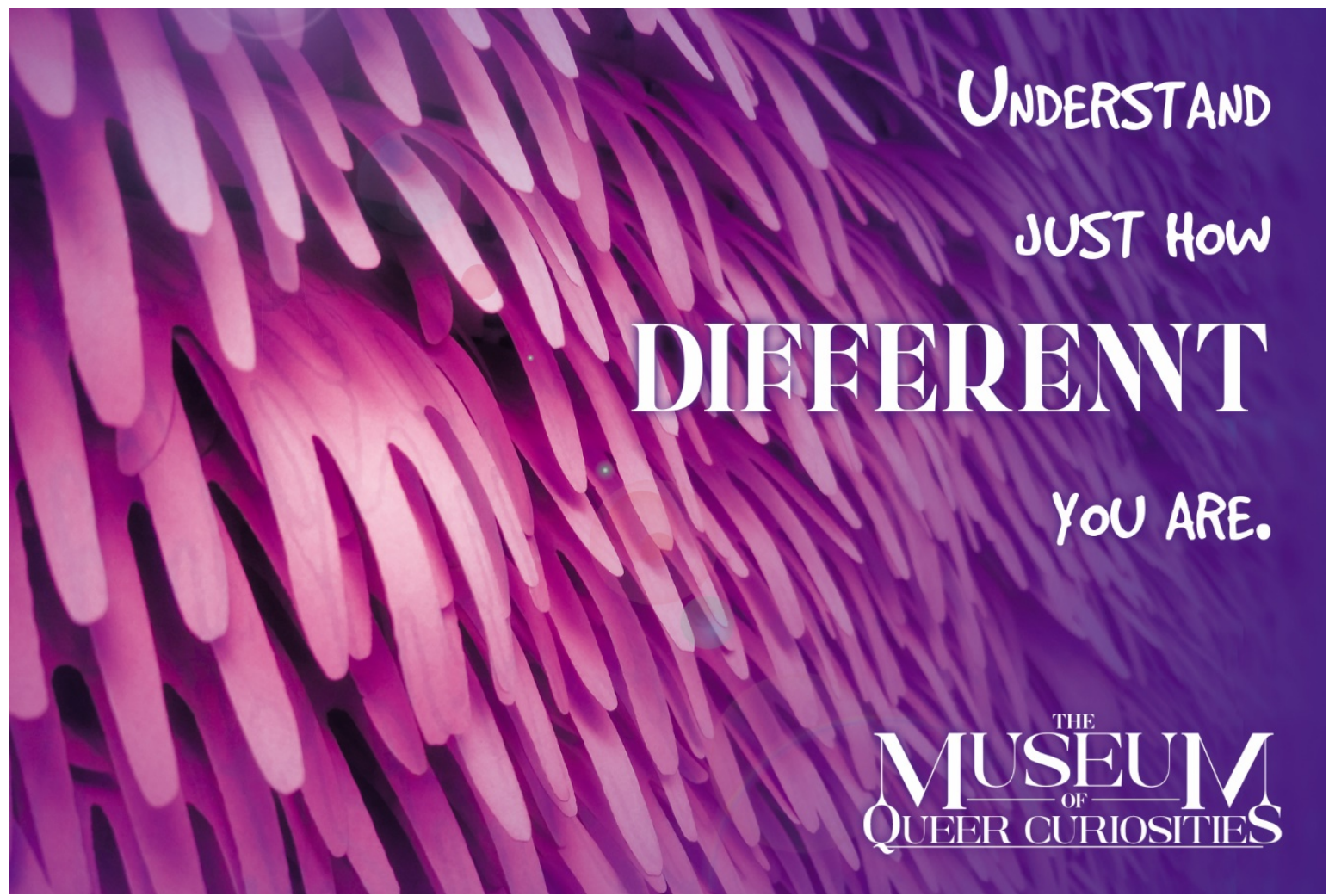

WestVirginiaUniversity.

230023100001

MESAROS GALLERIES

School of Art \& Design

P.O. Box 6111

Morgantown, WV 26506-6111

artanddesign.wvu.edu

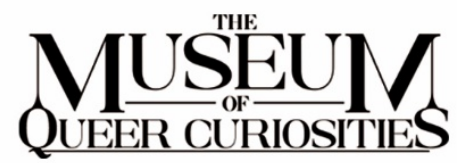

March 23-26, 2020

Reception: Thursday, March 26, 5-6 pm

The Museum of Queer Curiosities is proud to present its first public showing since its founding in 1992. Join us for an in-depth exploration of the Other from All Over,

alive and breathing through the bizarre artifacts curated exclusively for our investigation.

Celebrate the unknown experience for yourself. 


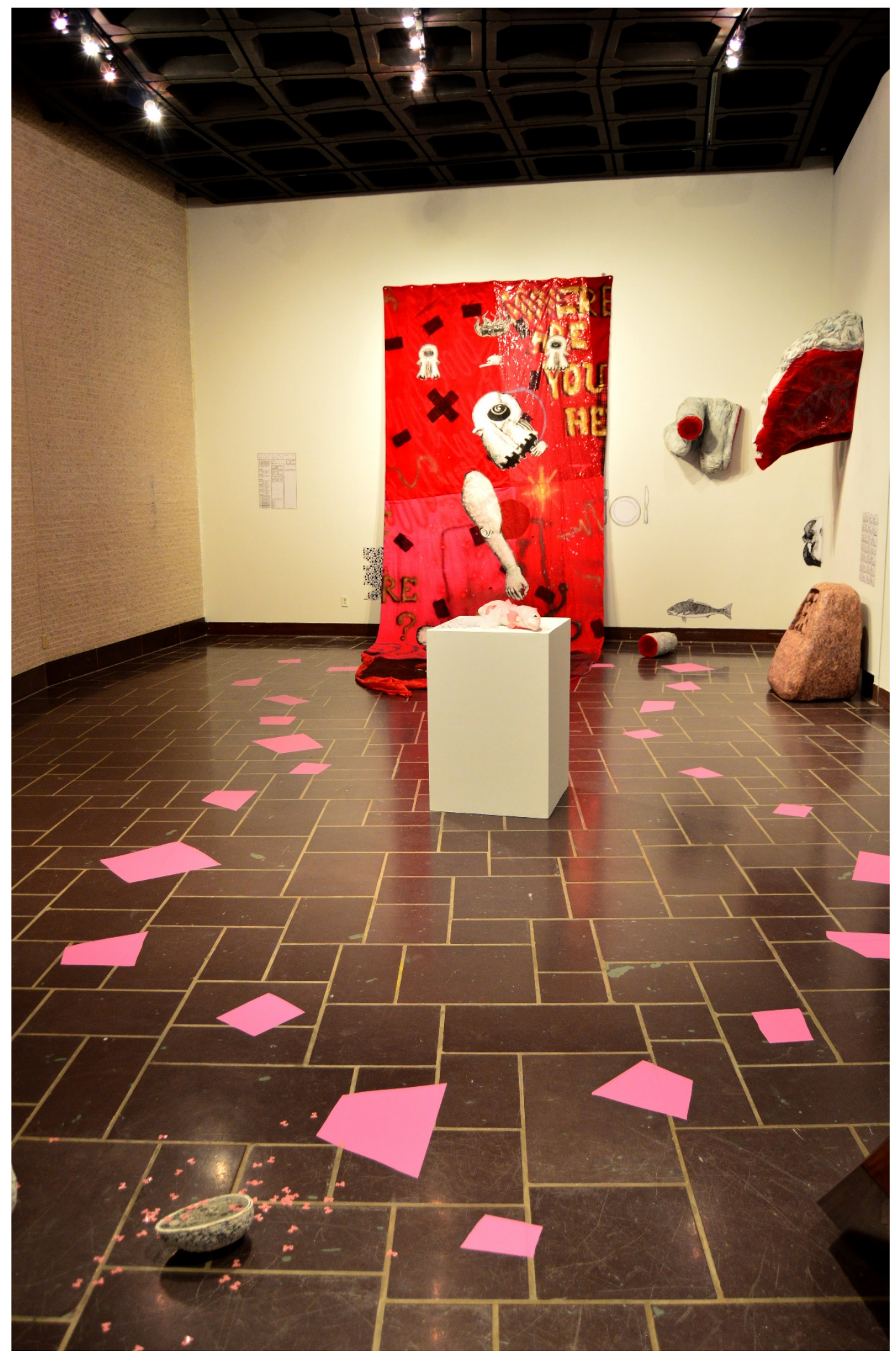

Fig. 5, Guide Path, installation shot. 

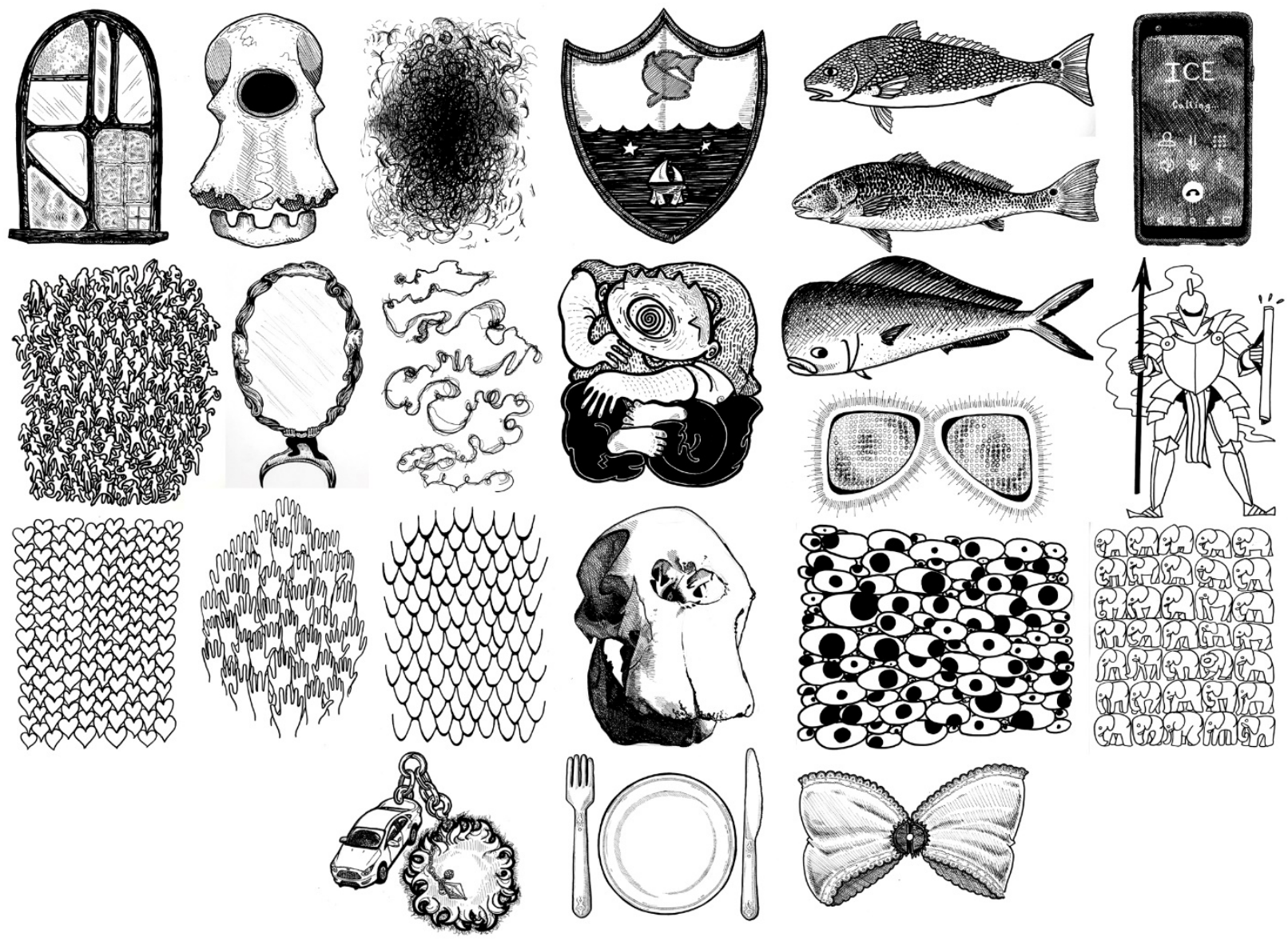

Fig. 6, Additional Information, a series of black and white illustrations used as TMOQC's lexicon, repeated in several iterations throughout the installation, as seen below in

Fig. 7, Additional Information, installation shot.

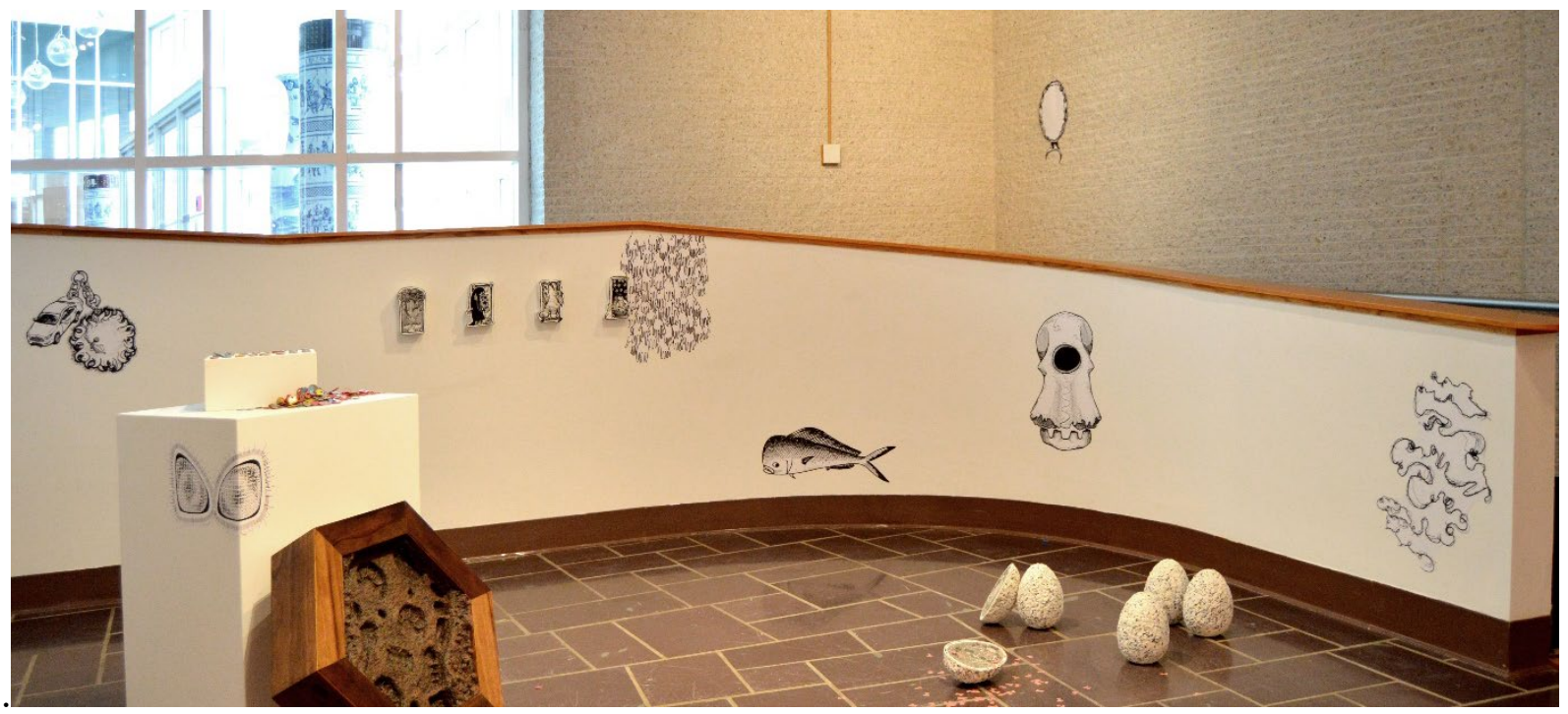




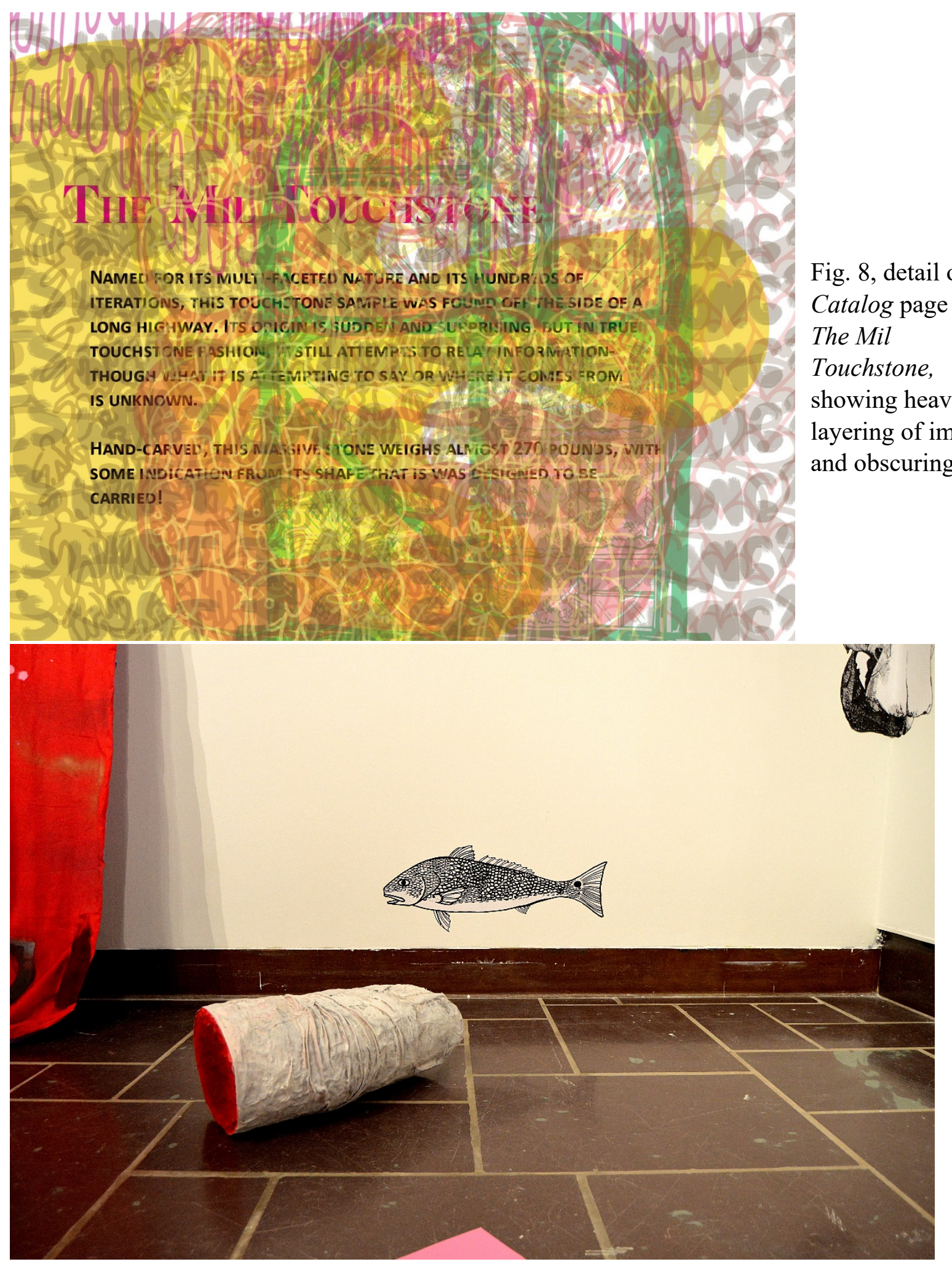

Fig. 9, Formulaic Statue, detail installation shot. The finger of the statue lies askew on the floor. 

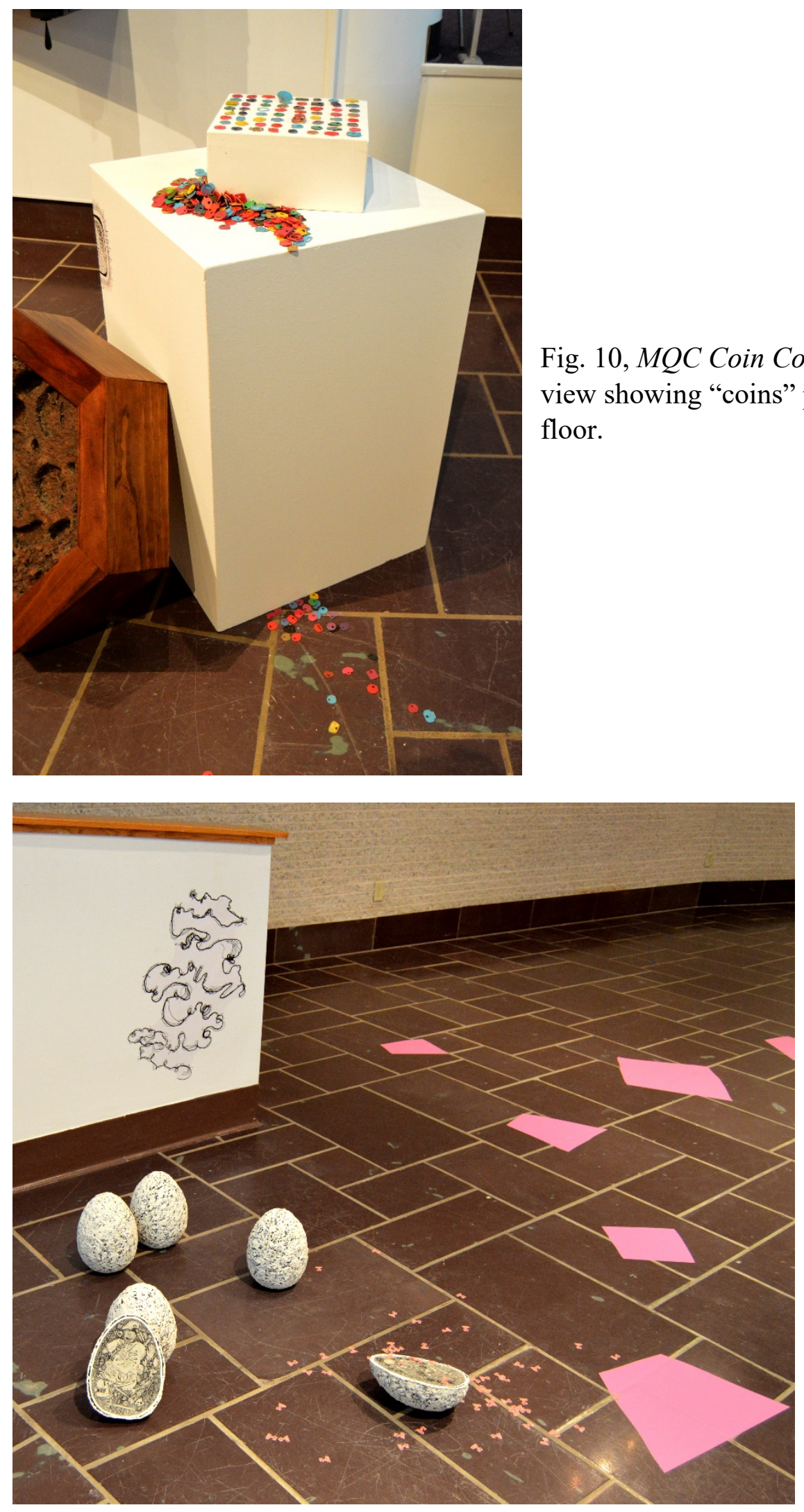

Fig. 11, Successful Reveal, installation shot. 

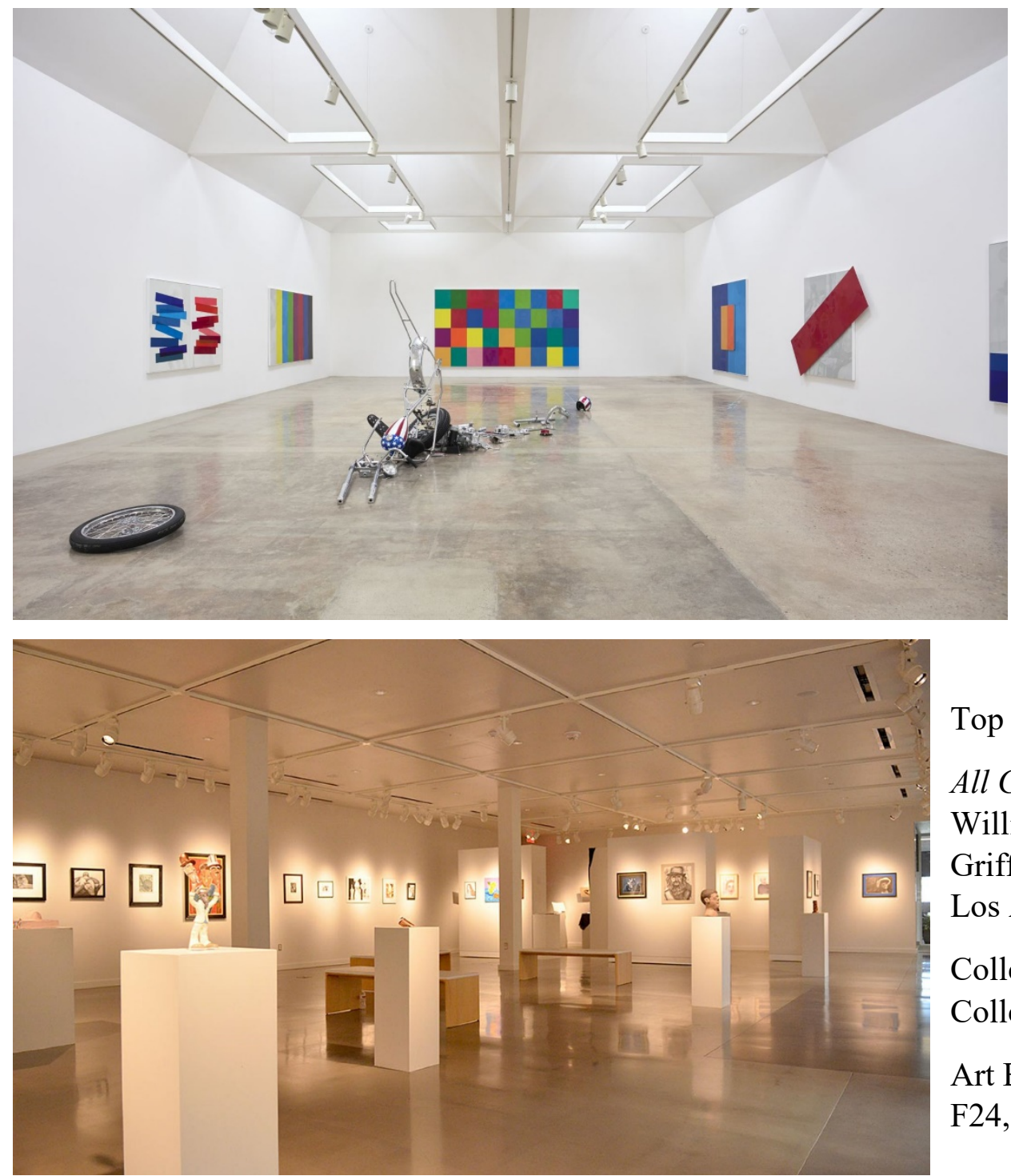

Fig. 12, Examples of common installation styles of an "art gallery", showing minimum labelling with maximum space at eye-level or with plenty of surrounding space in the round.

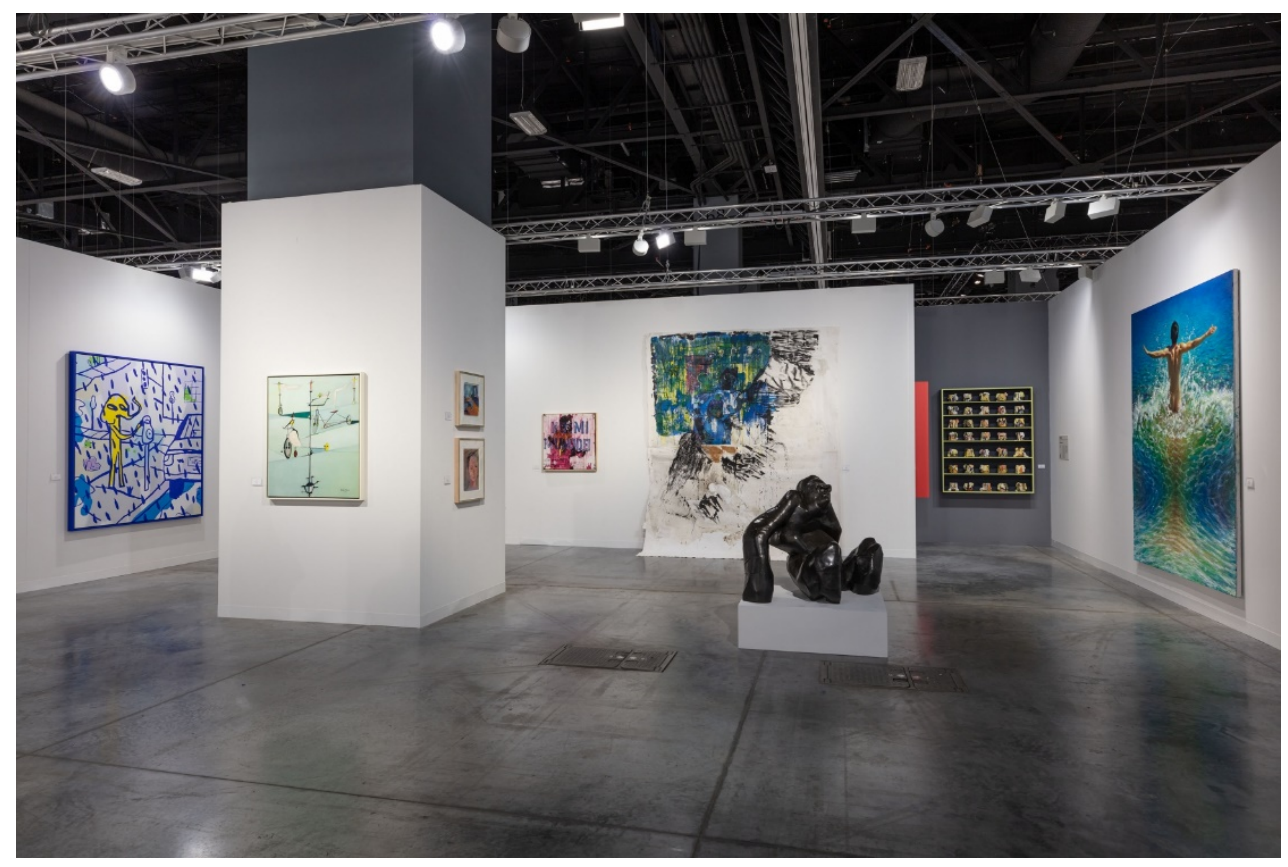



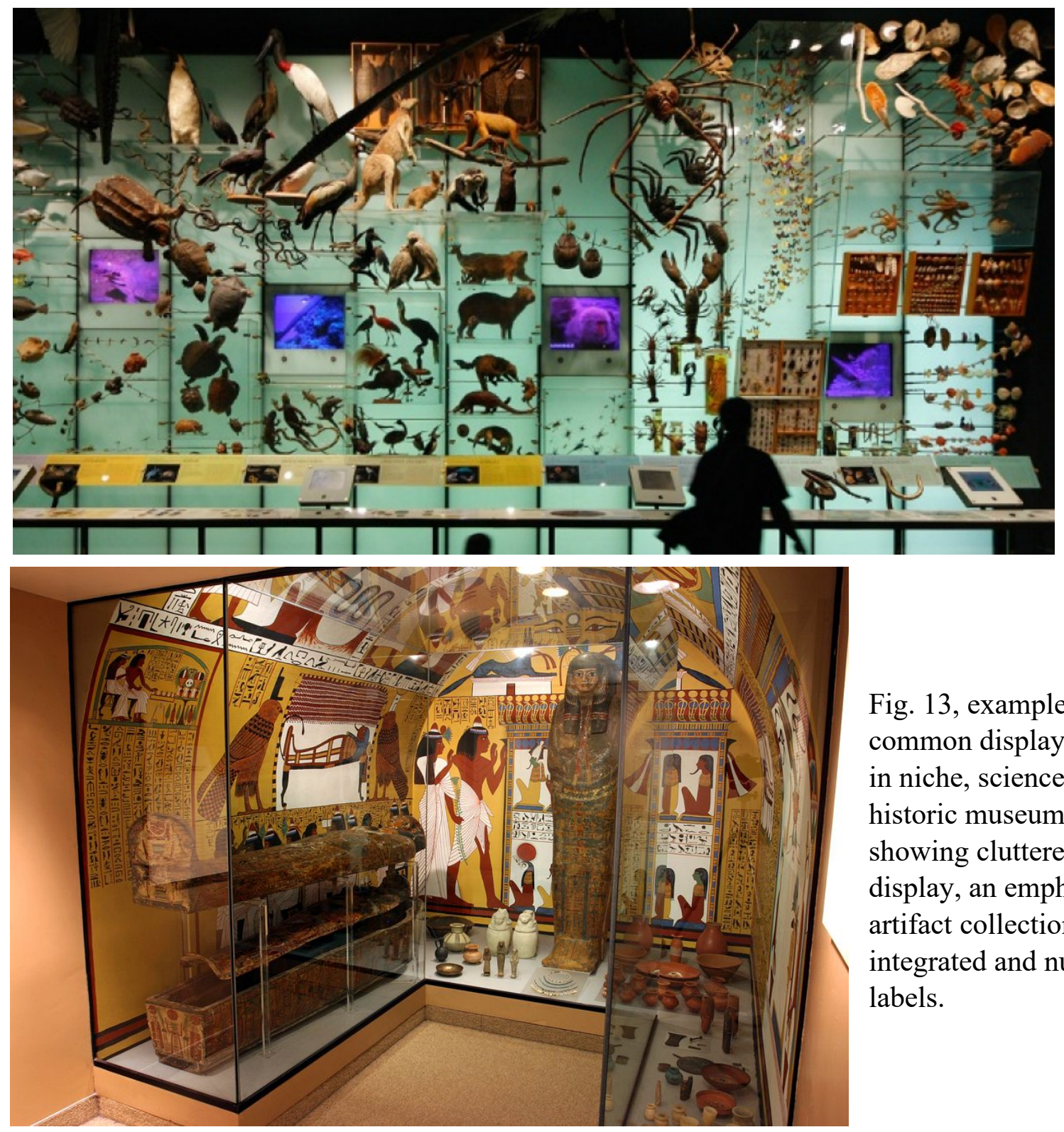

Fig. 13, examples of common display tactics in niche, science, and historic museums, showing cluttered display, an emphasis on artifact collection, and integrated and numerous labels.

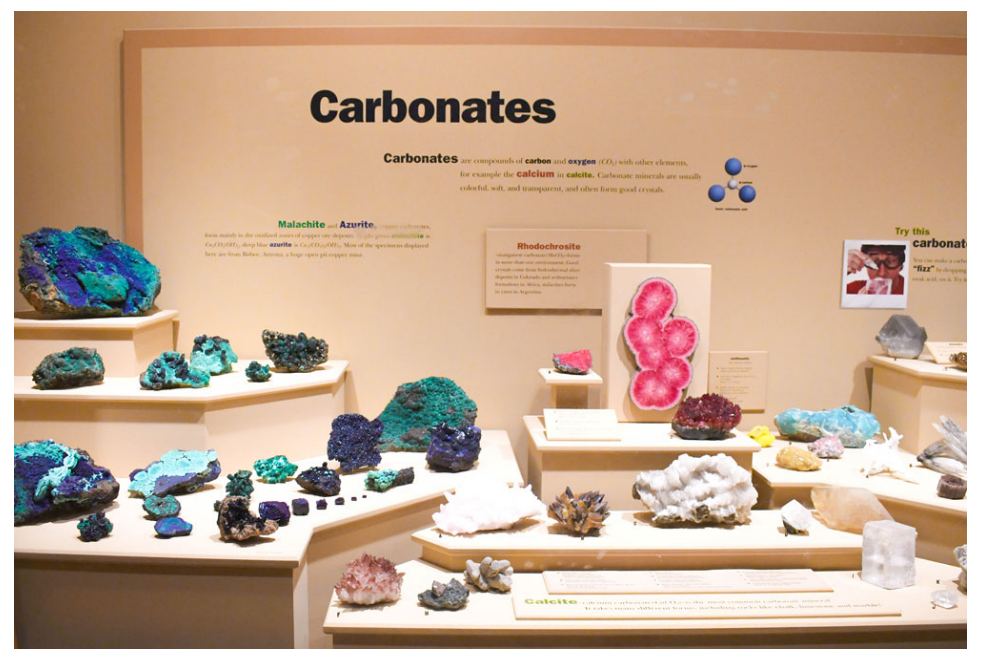

Top to Bottom:

The Hall of Biodiversity, American Museum of Natural History, New York, NY.

Walton Hall of Ancient Egypt, Carnegie Museum of Natural History, Pittsburgh, PA.

Gems and Minerals, Denver Museum of Nature and Science, Denver, CO. 


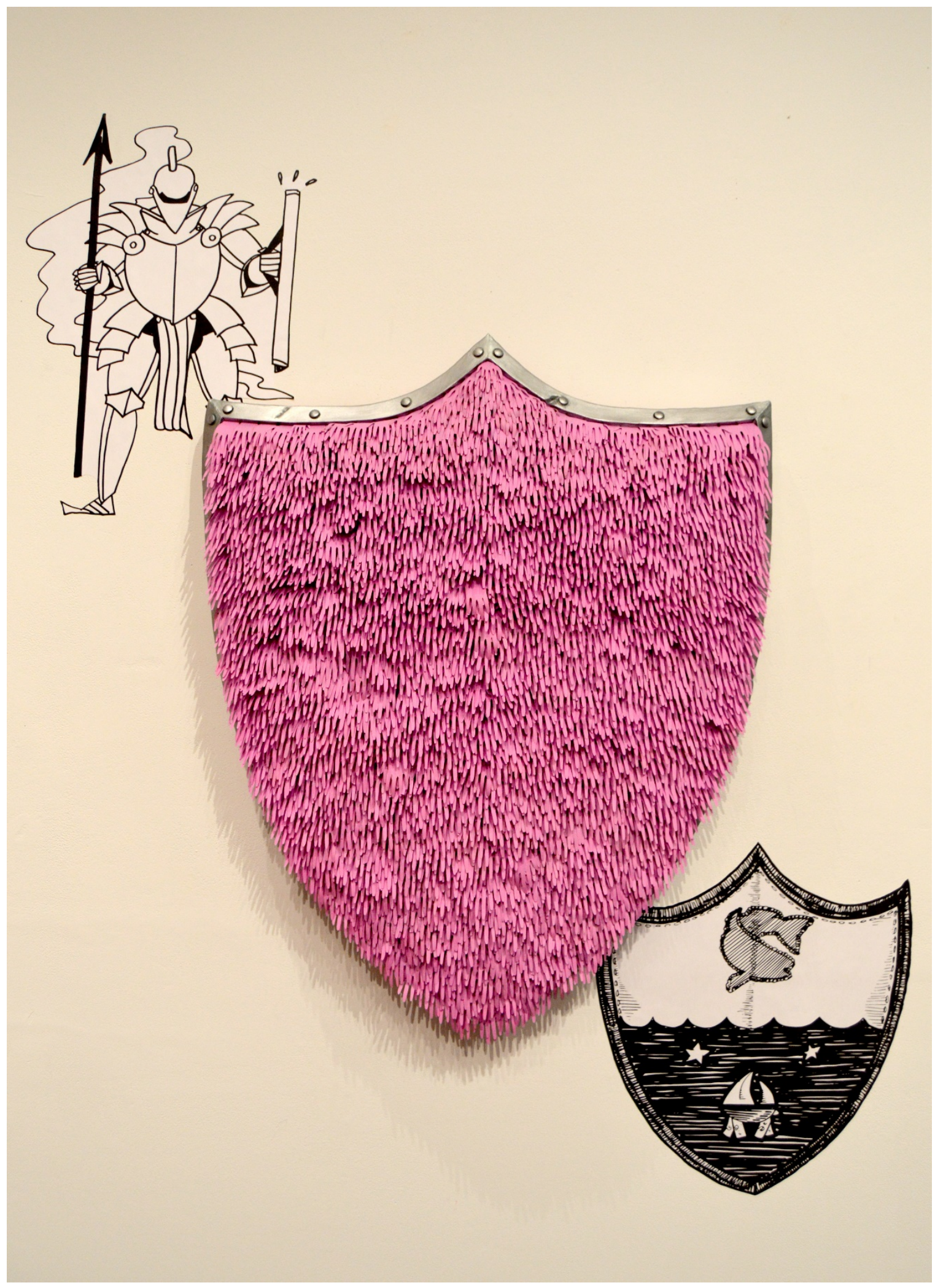

Fig. 14, Strange Shield, installation shot. 


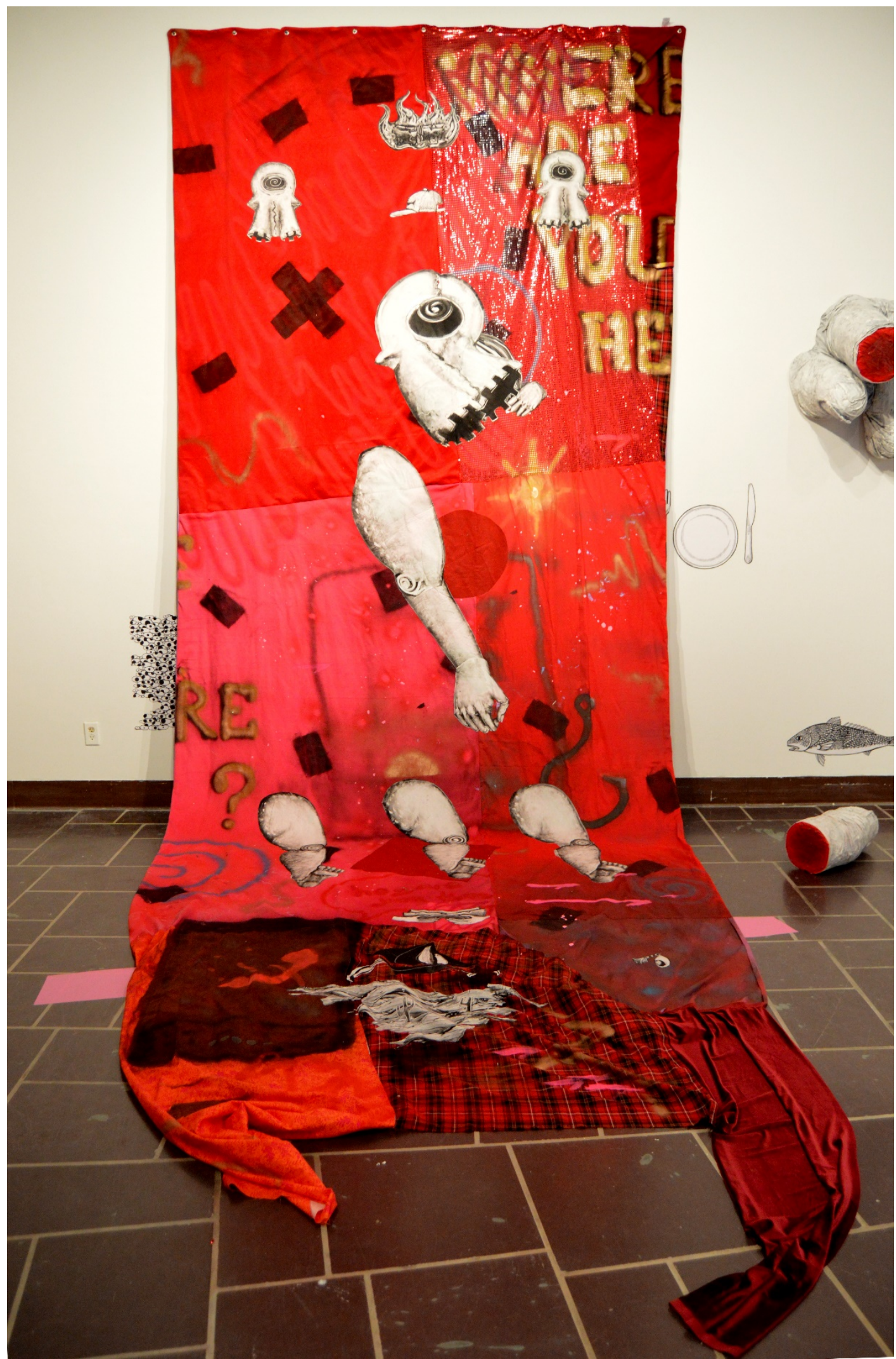

Fig. 15, Historic Shroud, installation shot. 


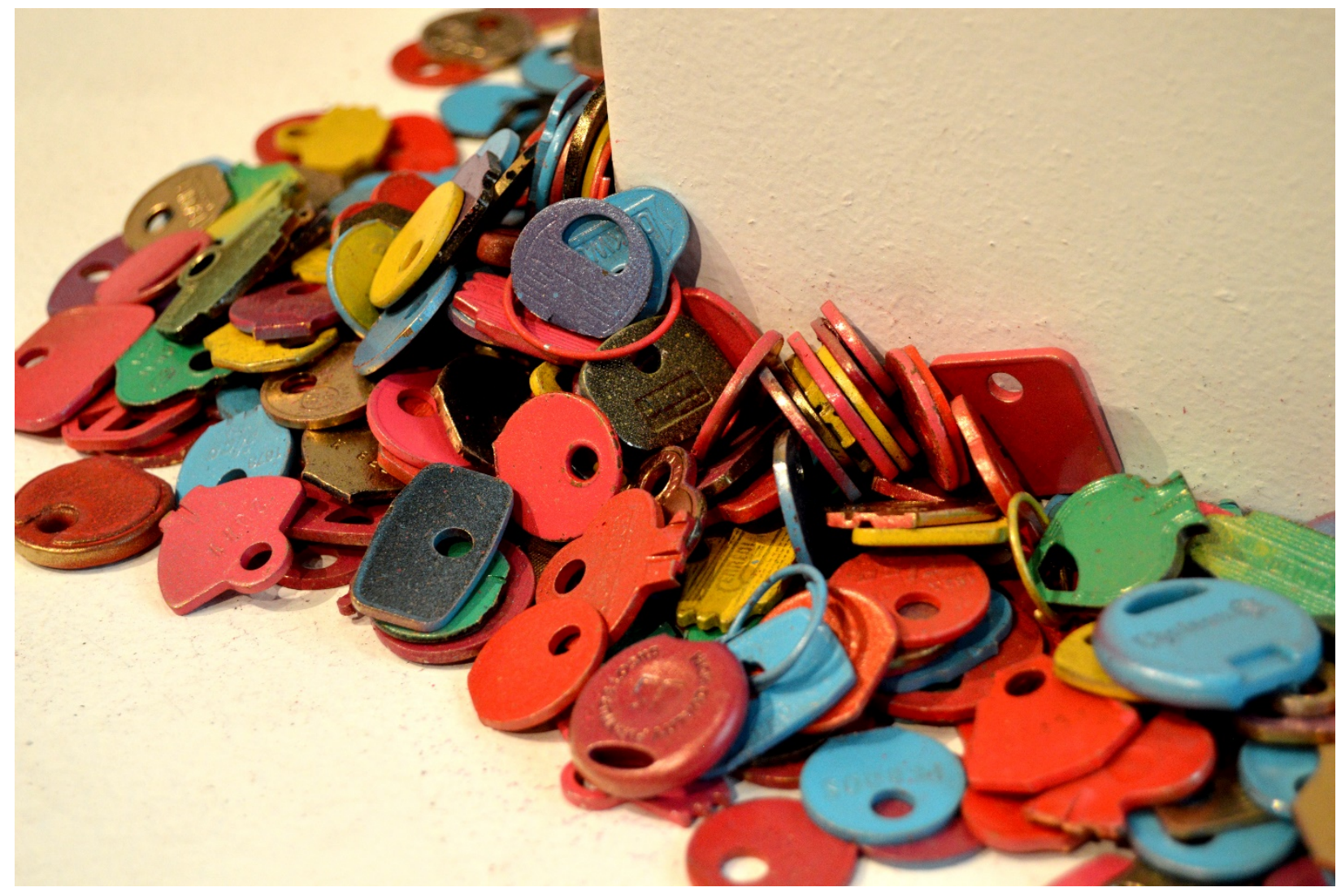

Fig. 16, detail of MQC Coin Collection. Some of the keys are magenta.

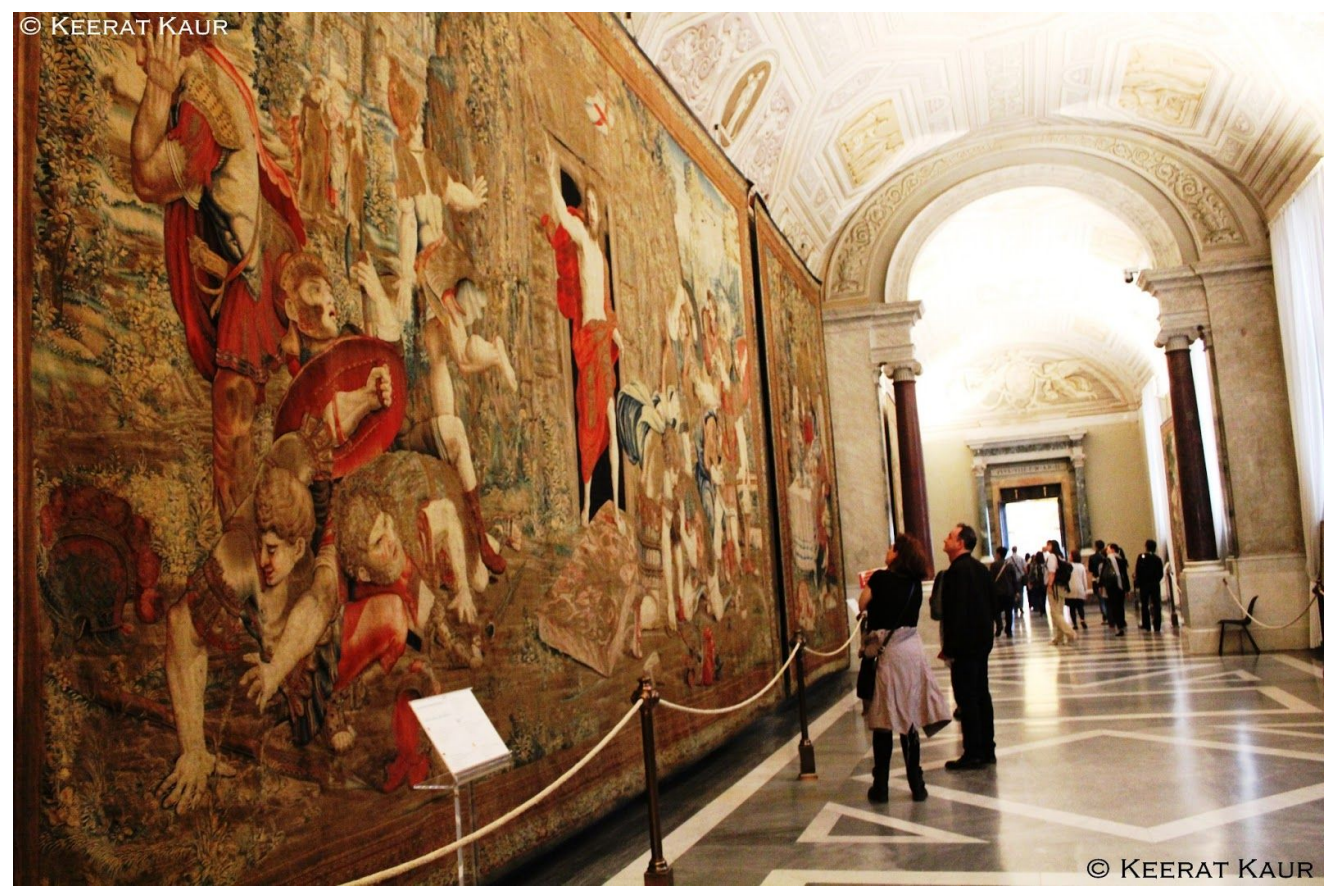

Fig. 17, Tapestry collection at the Vatican Museum, Vatican, Italy. 


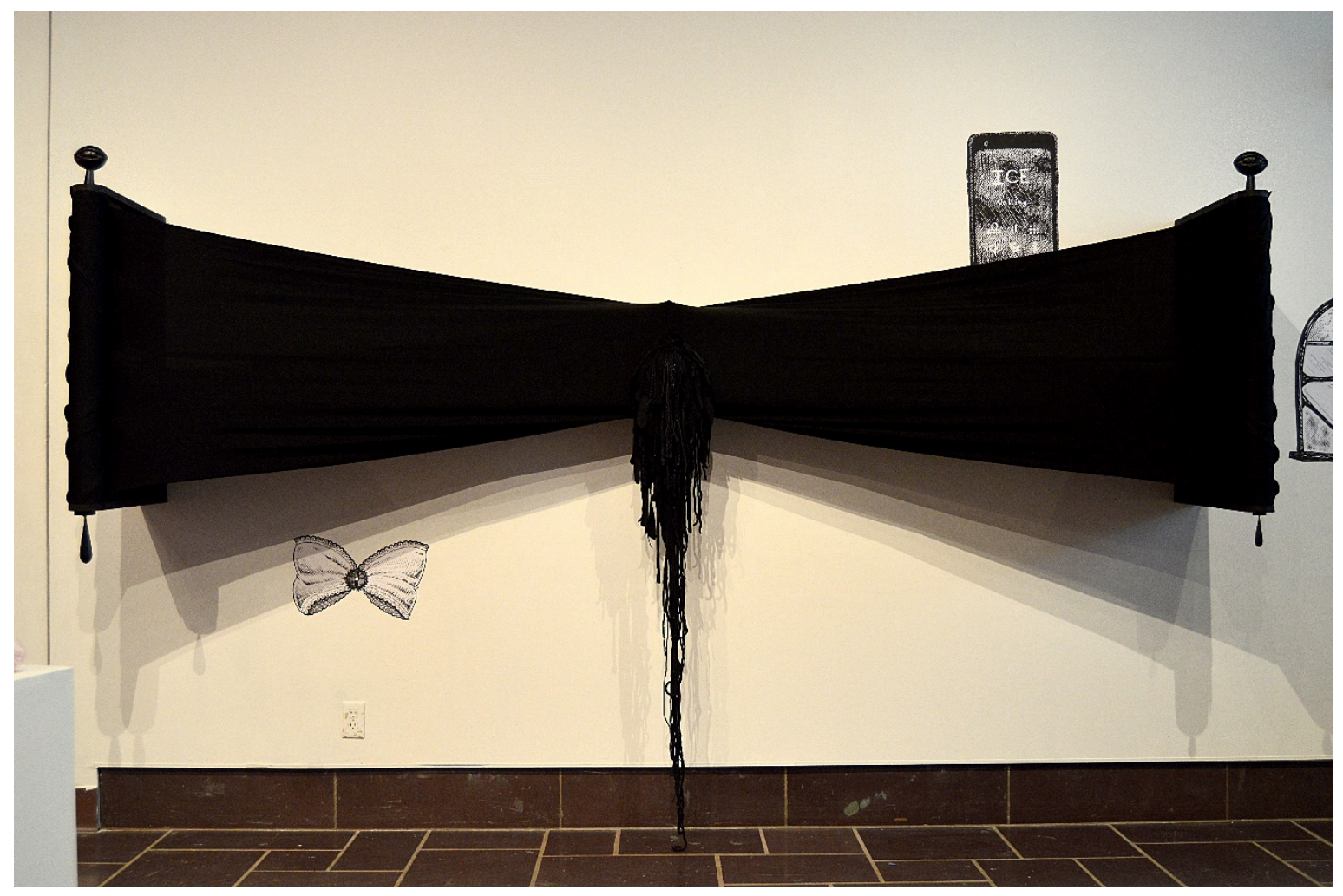

Fig. 18, Instructional Book of Progress, installation shot.

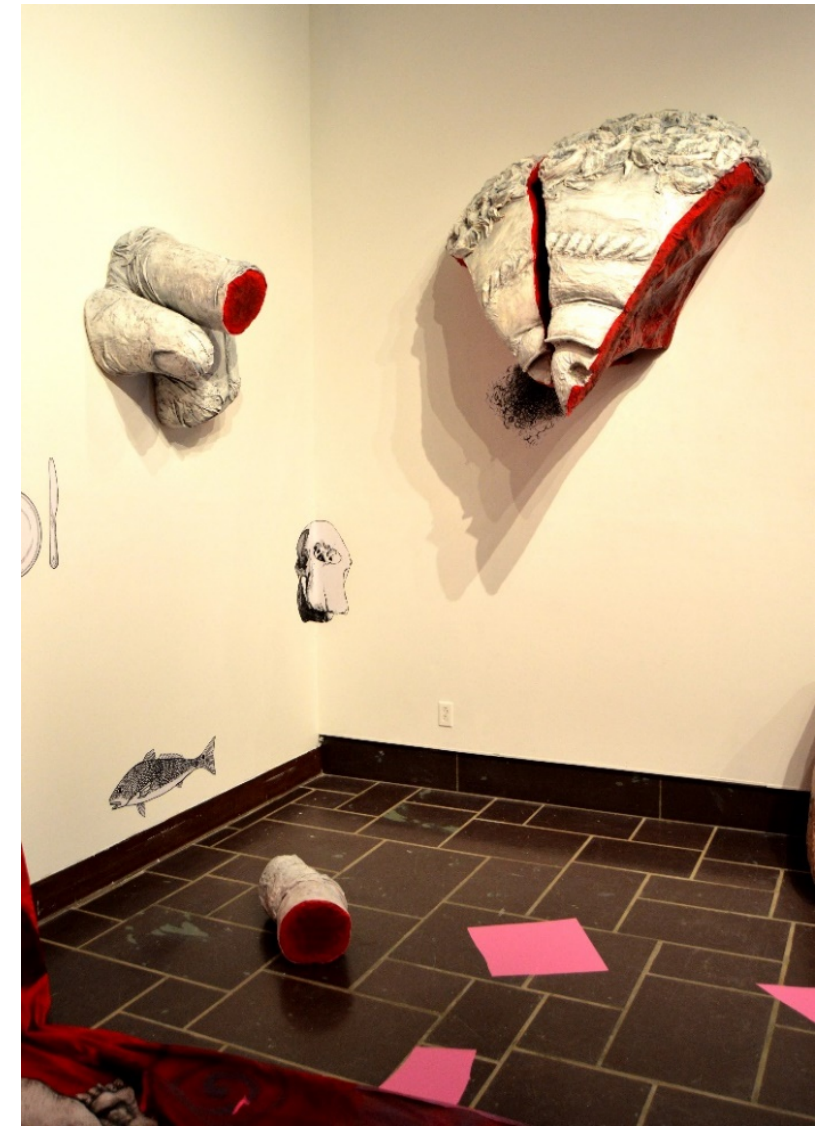

Fig. 19, Formulaic Statue, installation shot. 


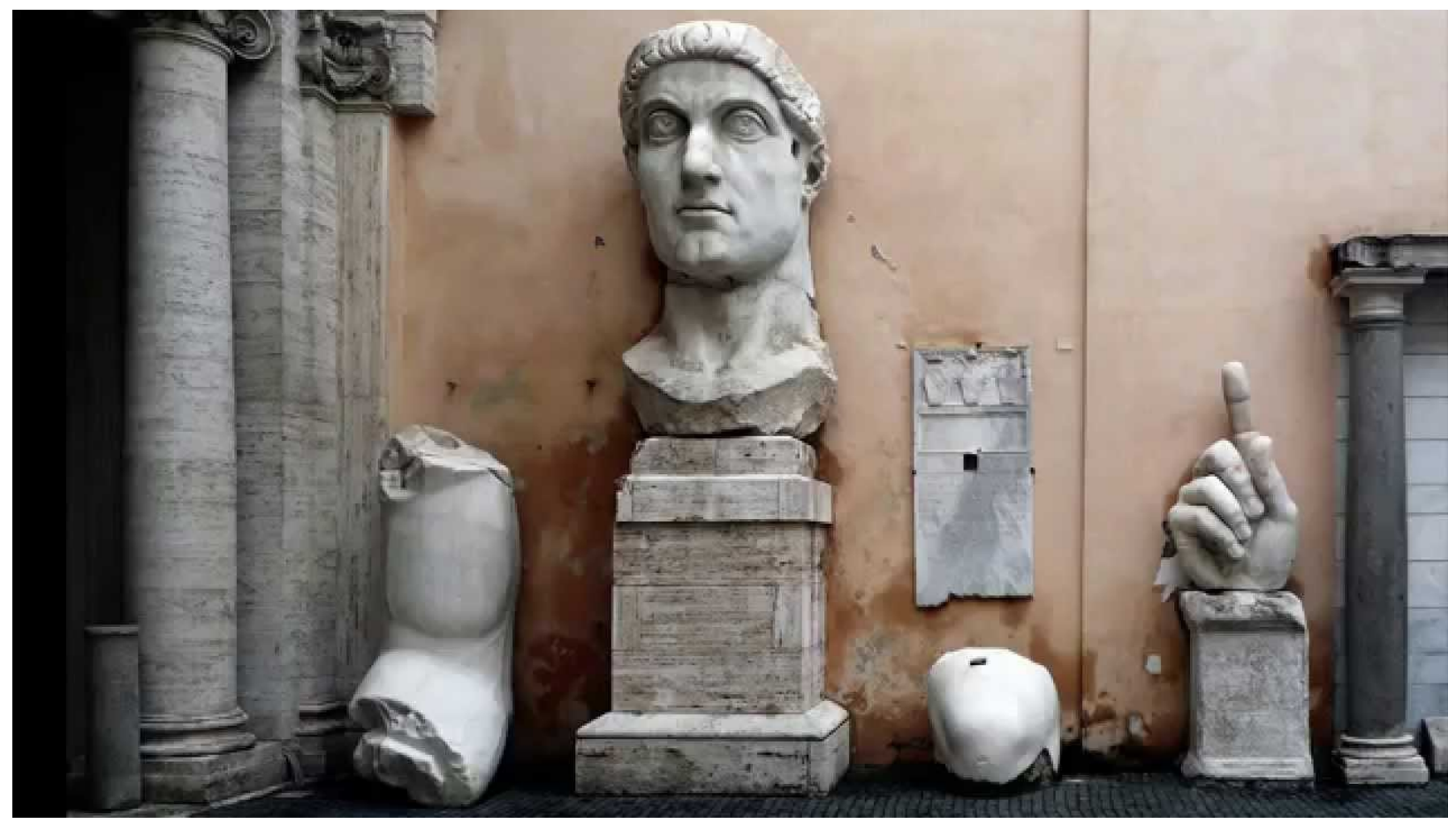

Fig. 20, The Colossus of Constantine, 312-315 C.E., The Capitoline Museums, Rome, Italy.
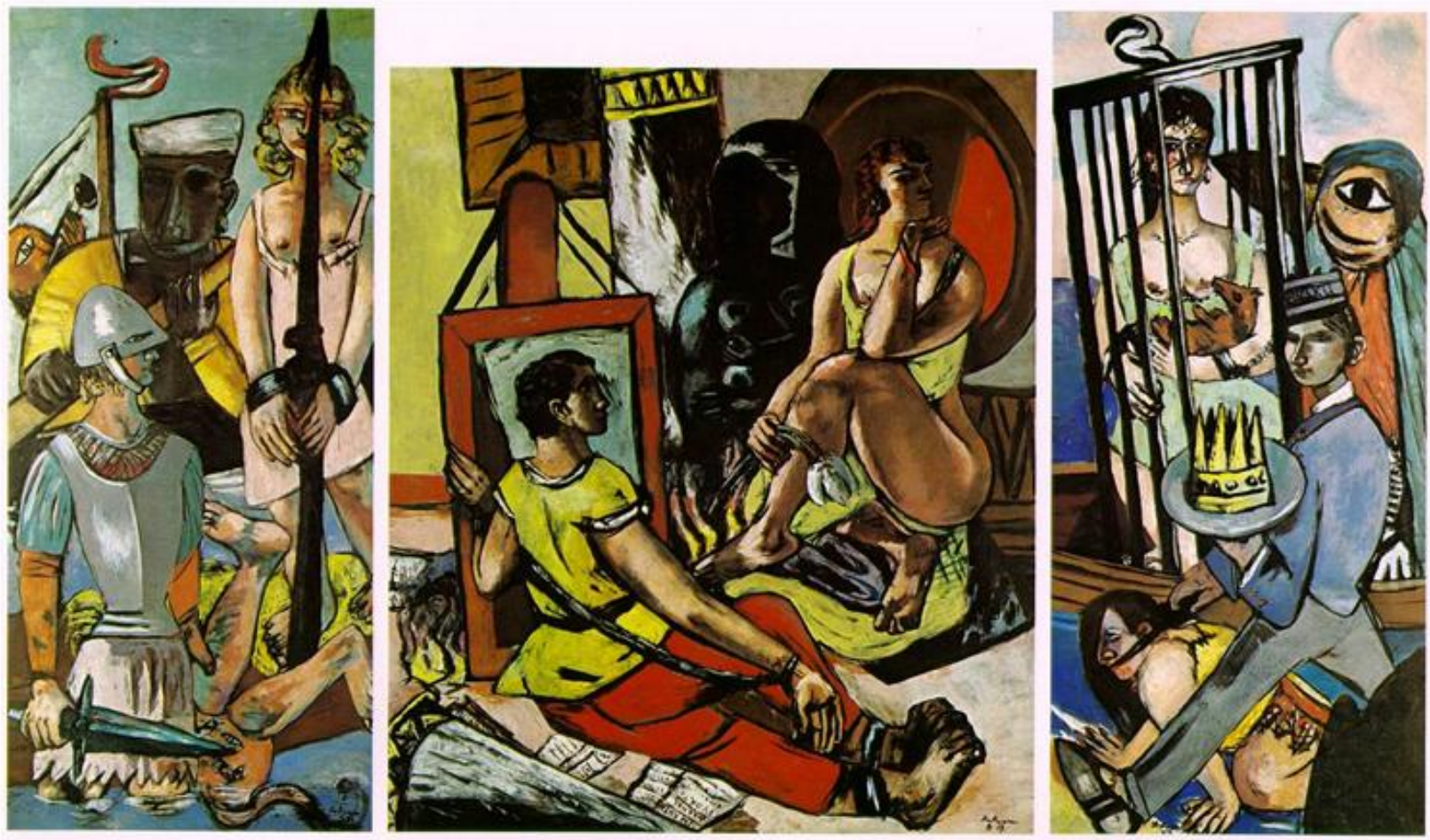

Fig. 21, The Temptation of St. Anthony, Max Beckmann, oil on canvas, 1936-37. 


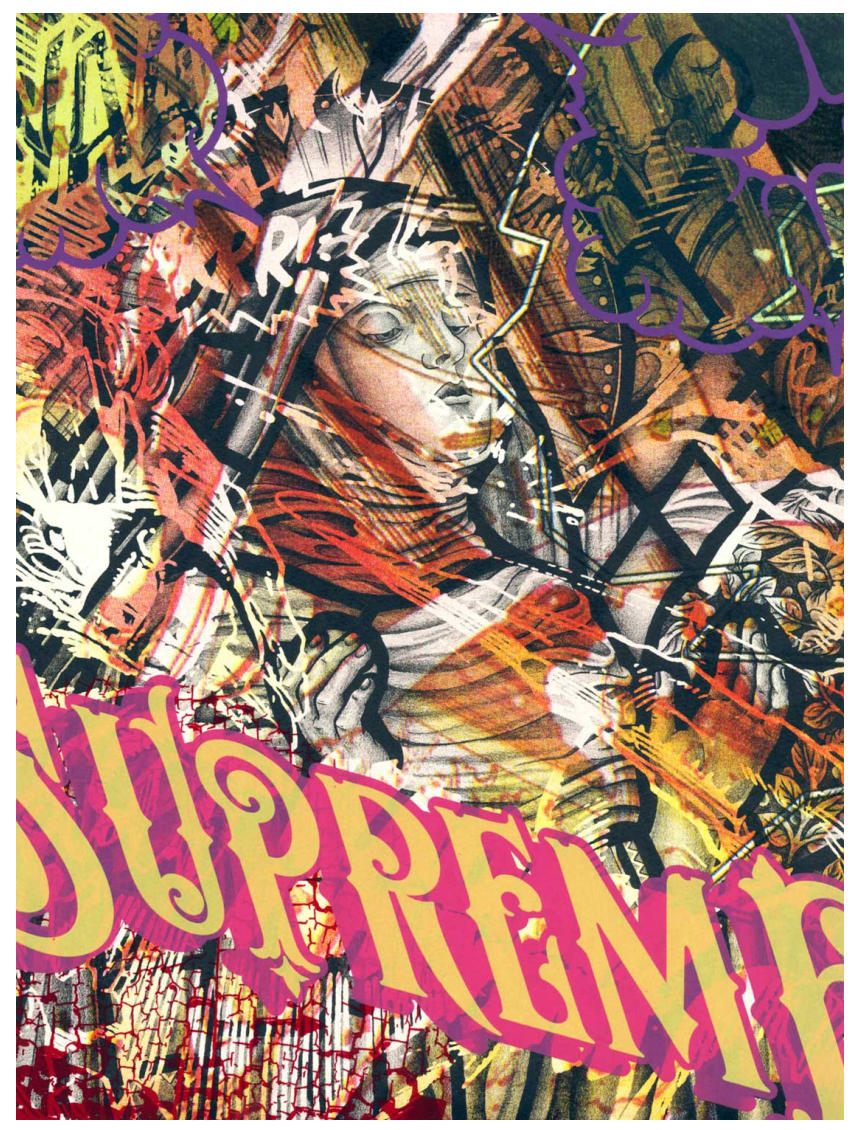

Fig. 22, The Wretched Sound of Mysticism Dying, Aaron Coleman. Lithography and screenprint on paper. 12" x 16". 2015.

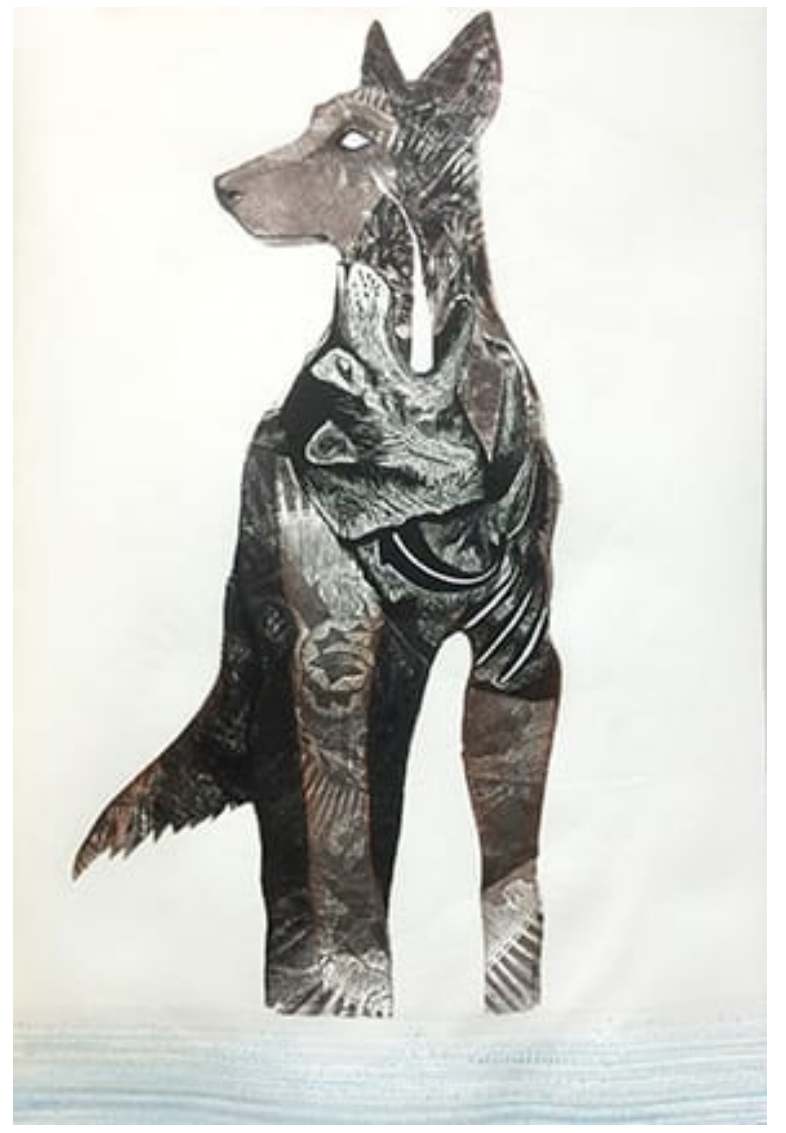

Fig. 23, What Comes in the Stillness, Johanna Mueller. Multi-plate relief engraving. 22" x 14". 2016. 


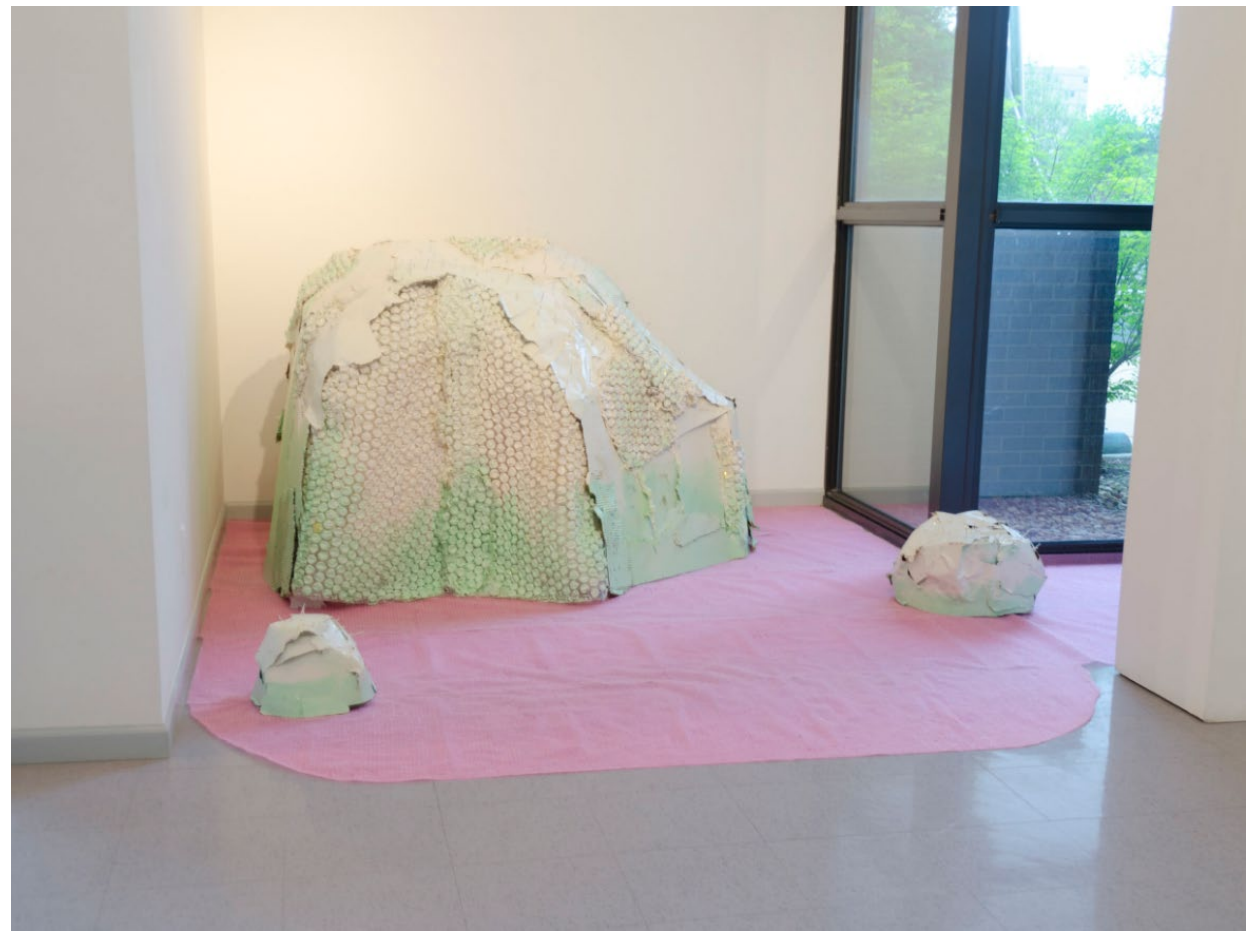

Fig. 24, It's Safe in Here, Alexander Martin. Mixed media. 2017.

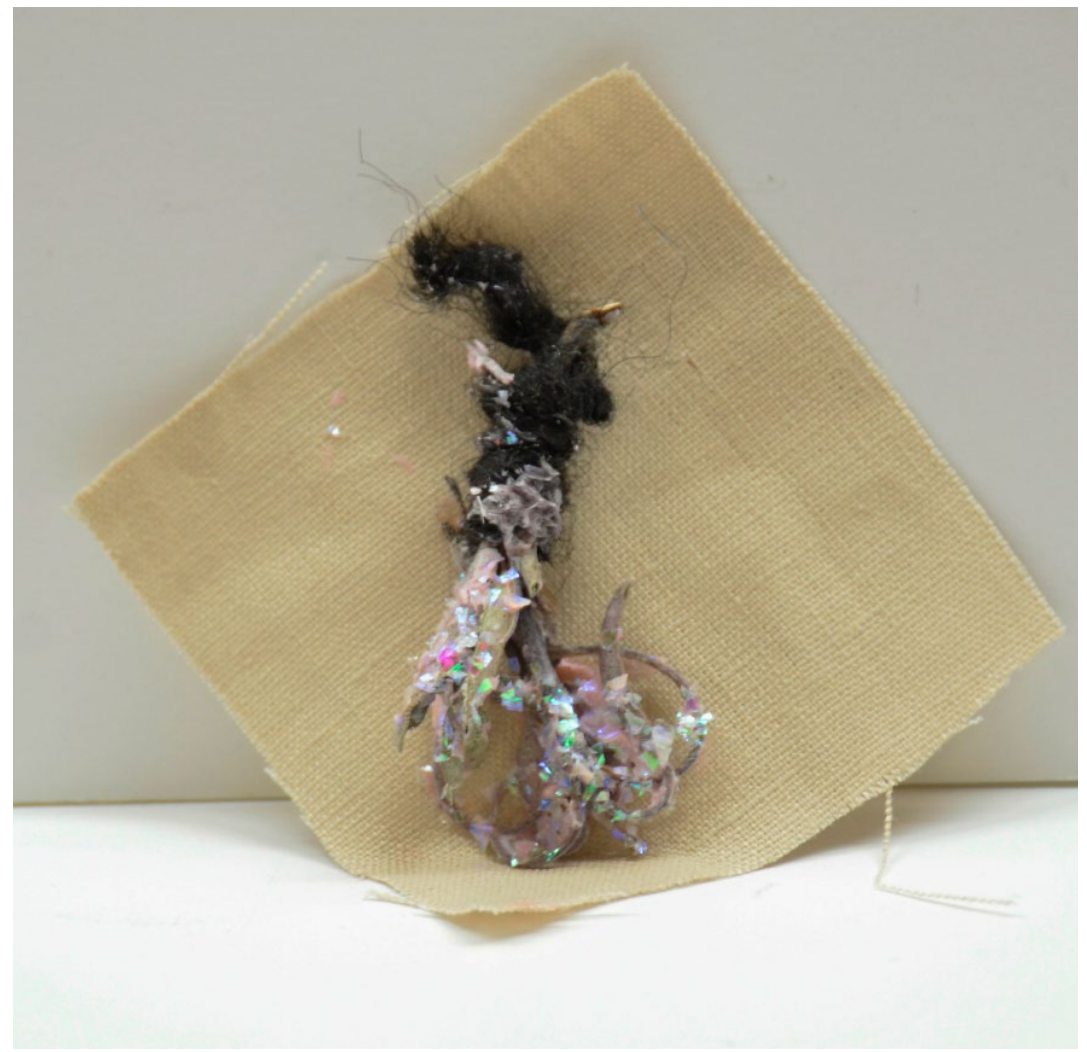

Fig. 25, Object from the Queercraft series, Alexander Martin. Mixed media. 

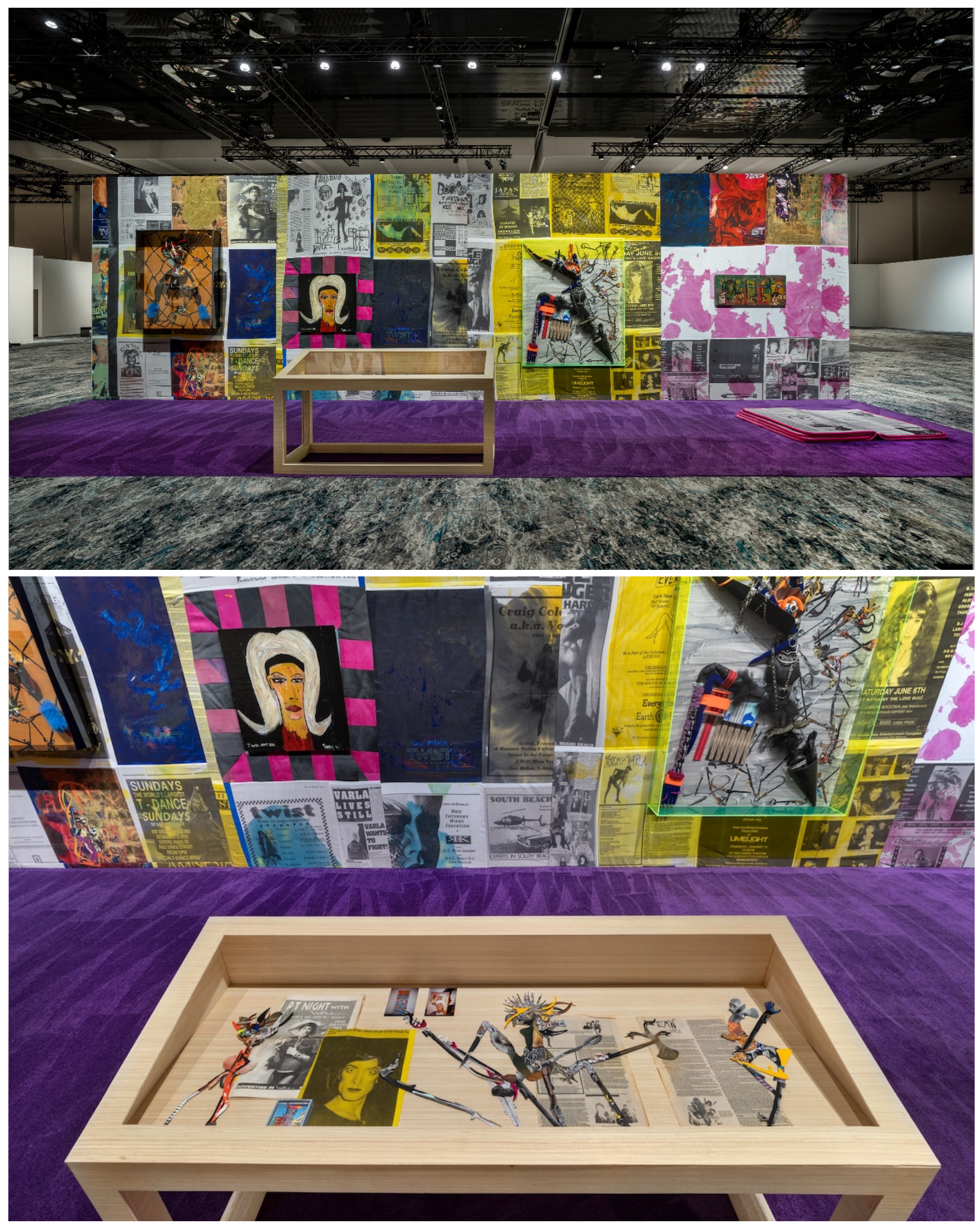

Fig. 26, Varla TV, Pepe Mar. Installation and detail shot at Art Basel Miami 2019 -Meridians. Mixed media. 2018-2019. 


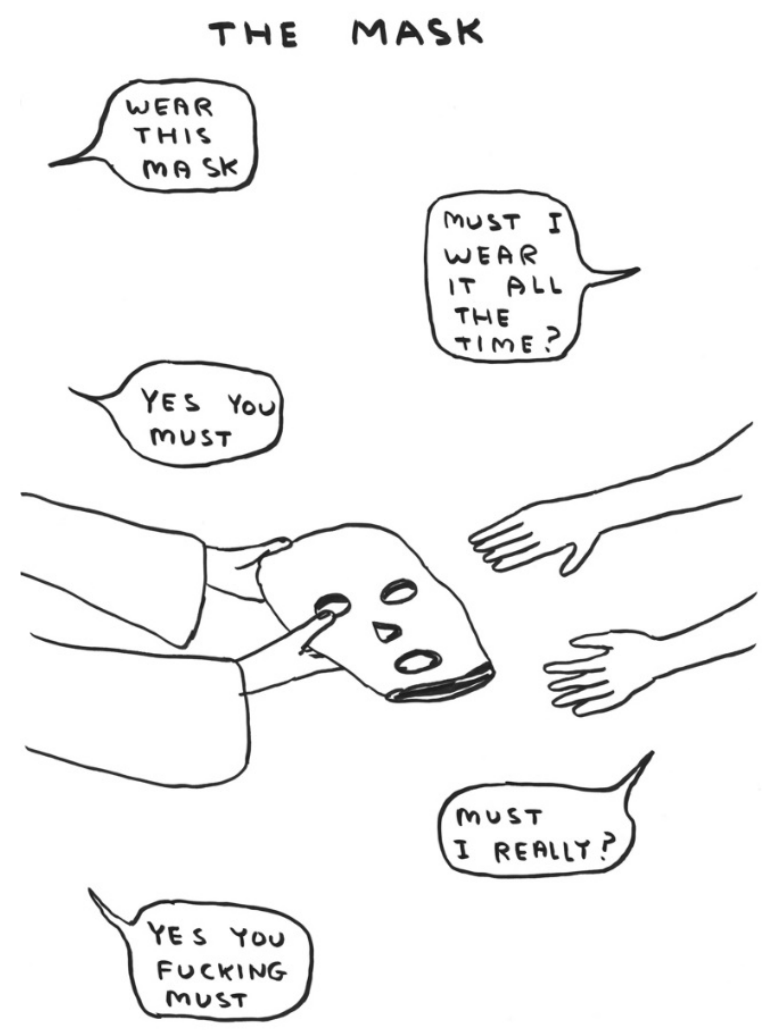

Fig. 27, Untitled (The Mask), and Untitled, (The Common Man), respectively. David Shrigley. Ink drawings. 2019.

\section{WISH TO HAVE THE SAME EXPERIENCES AS THE COMMON MAN}

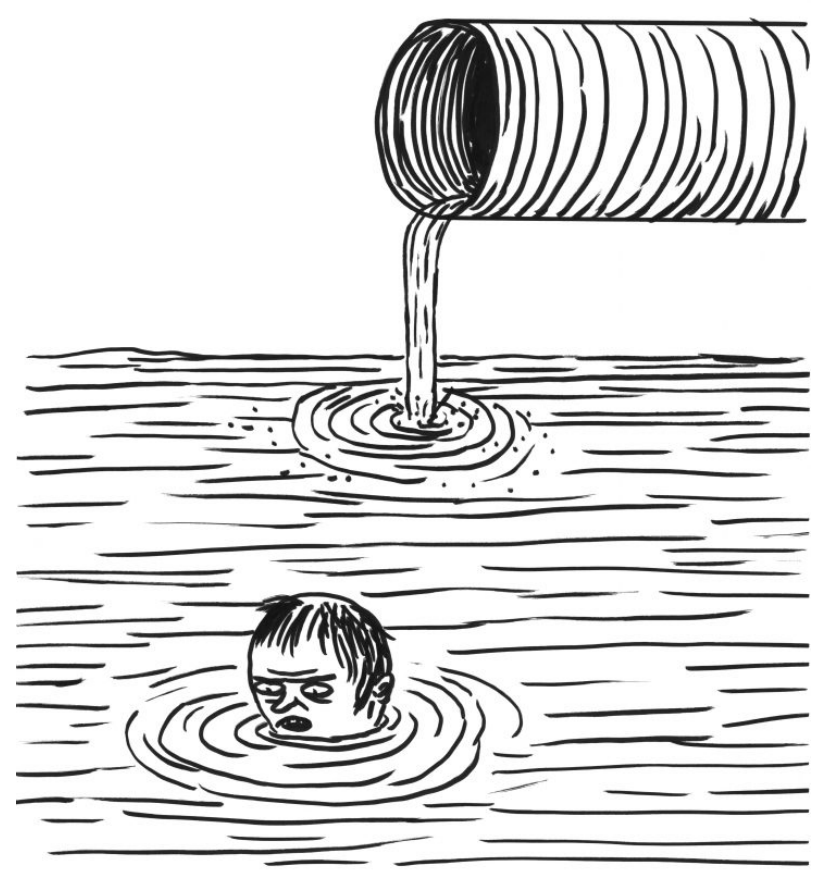




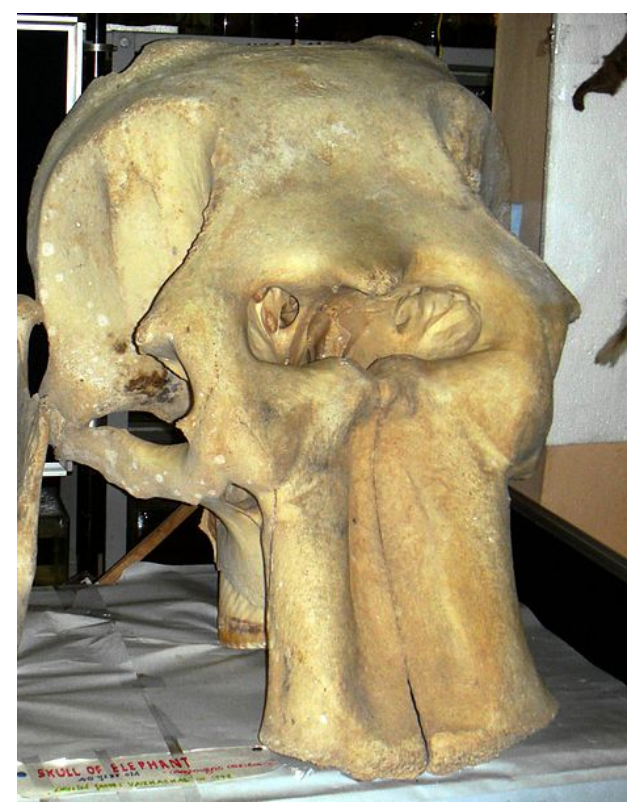

Fig. 28, the top part of an elephant skull without tusks. Note the large cavity that was the naval cavity- the sockets for the eyes are almost indistinguishable if you do not know where to look.

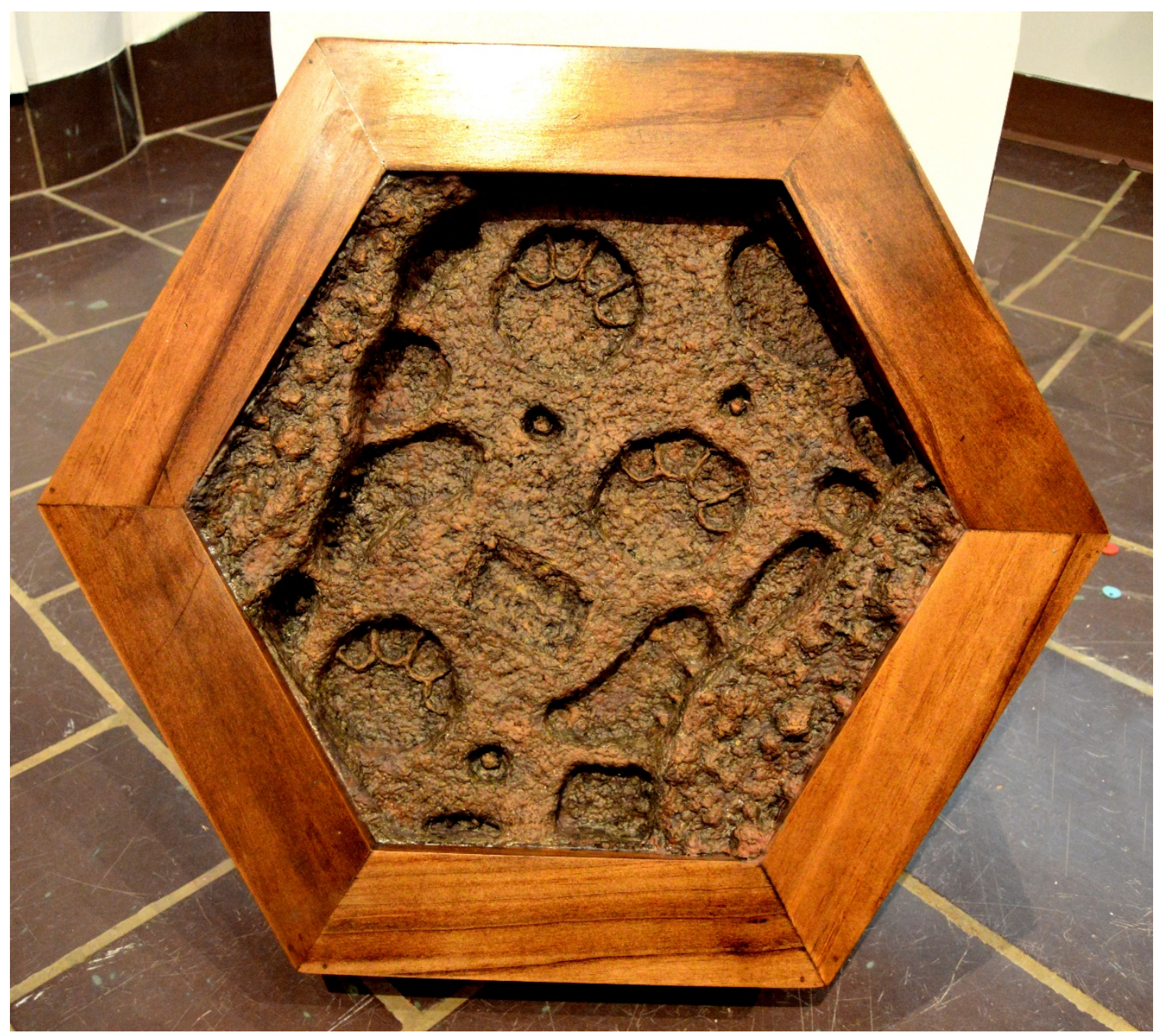

Fig. 29, Casting. Installation shot. 


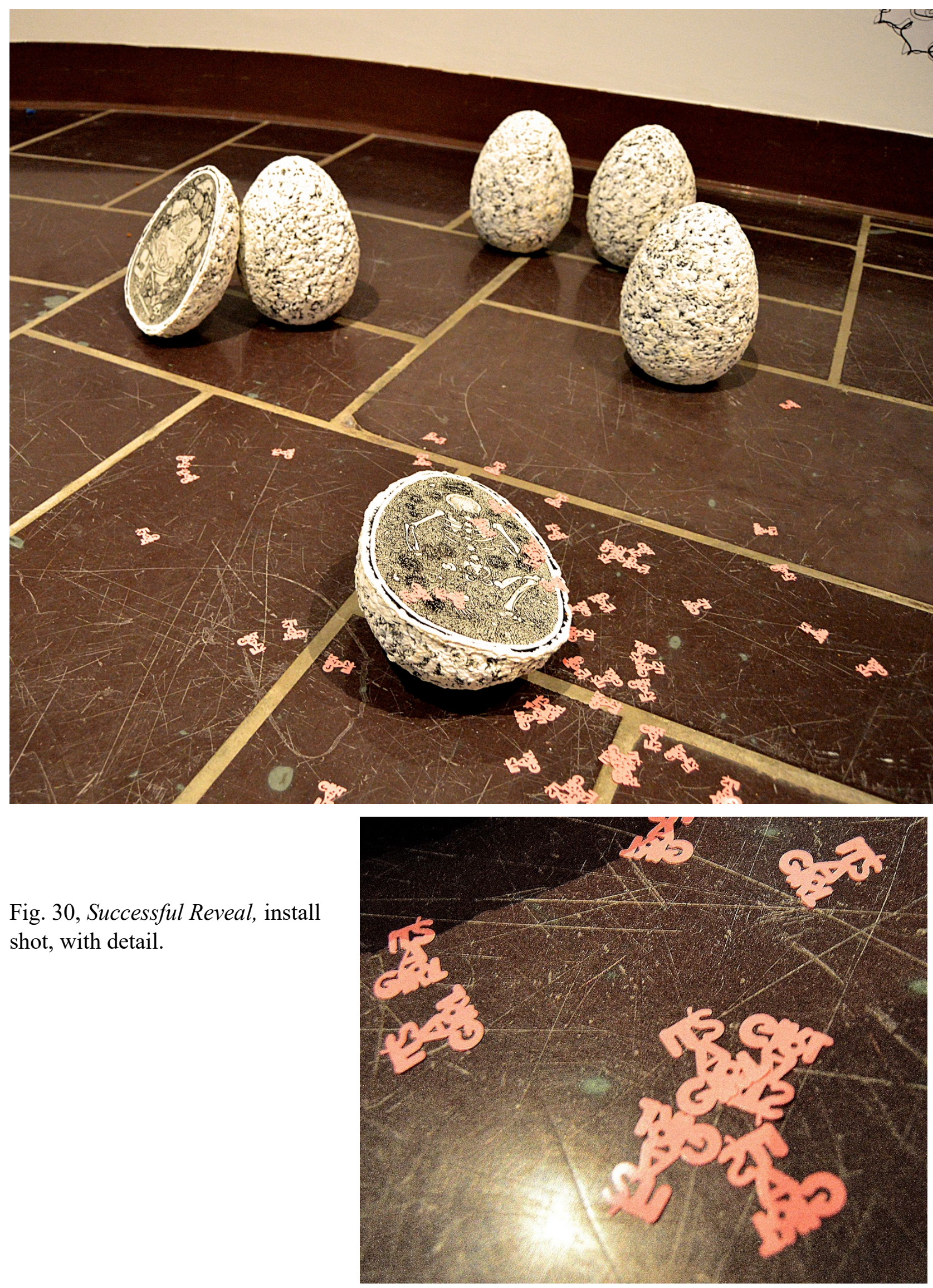




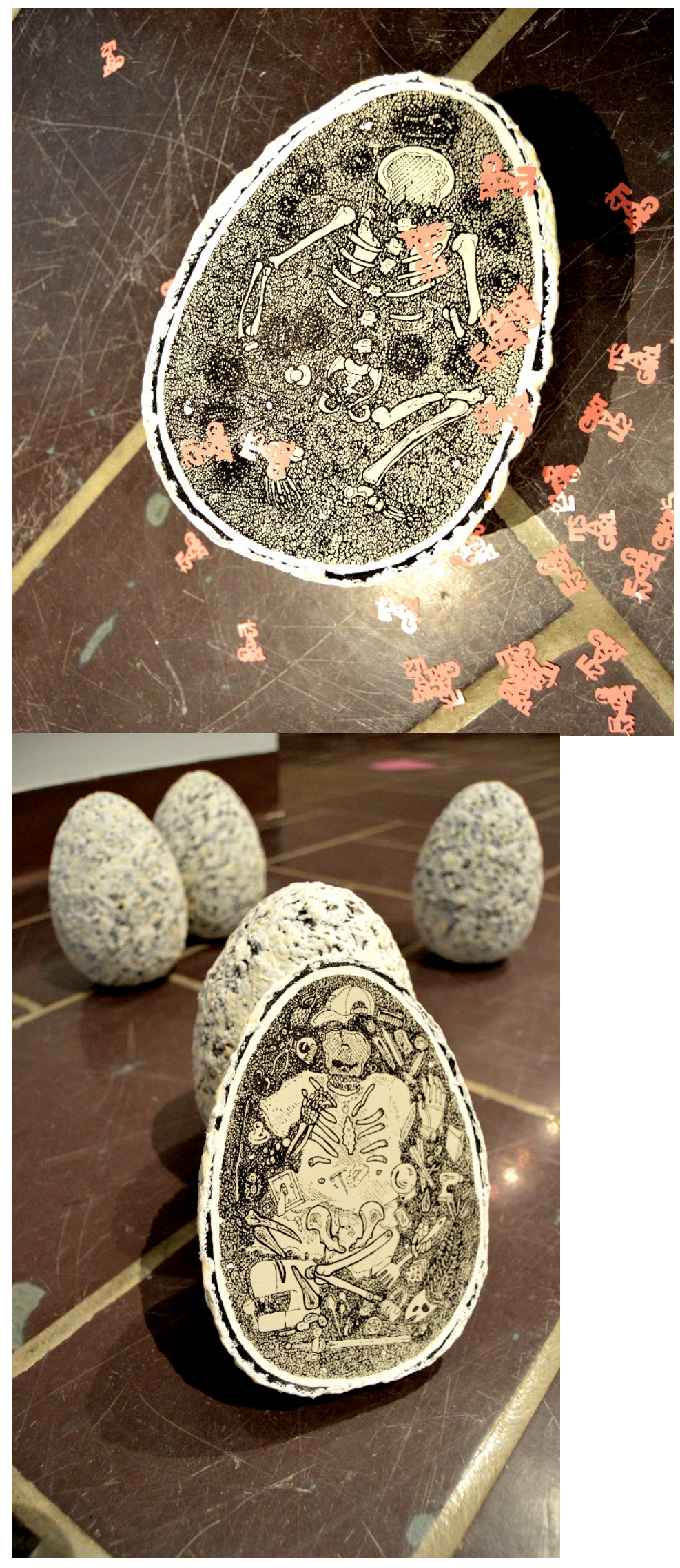

Fig. 30, detail, contd. 


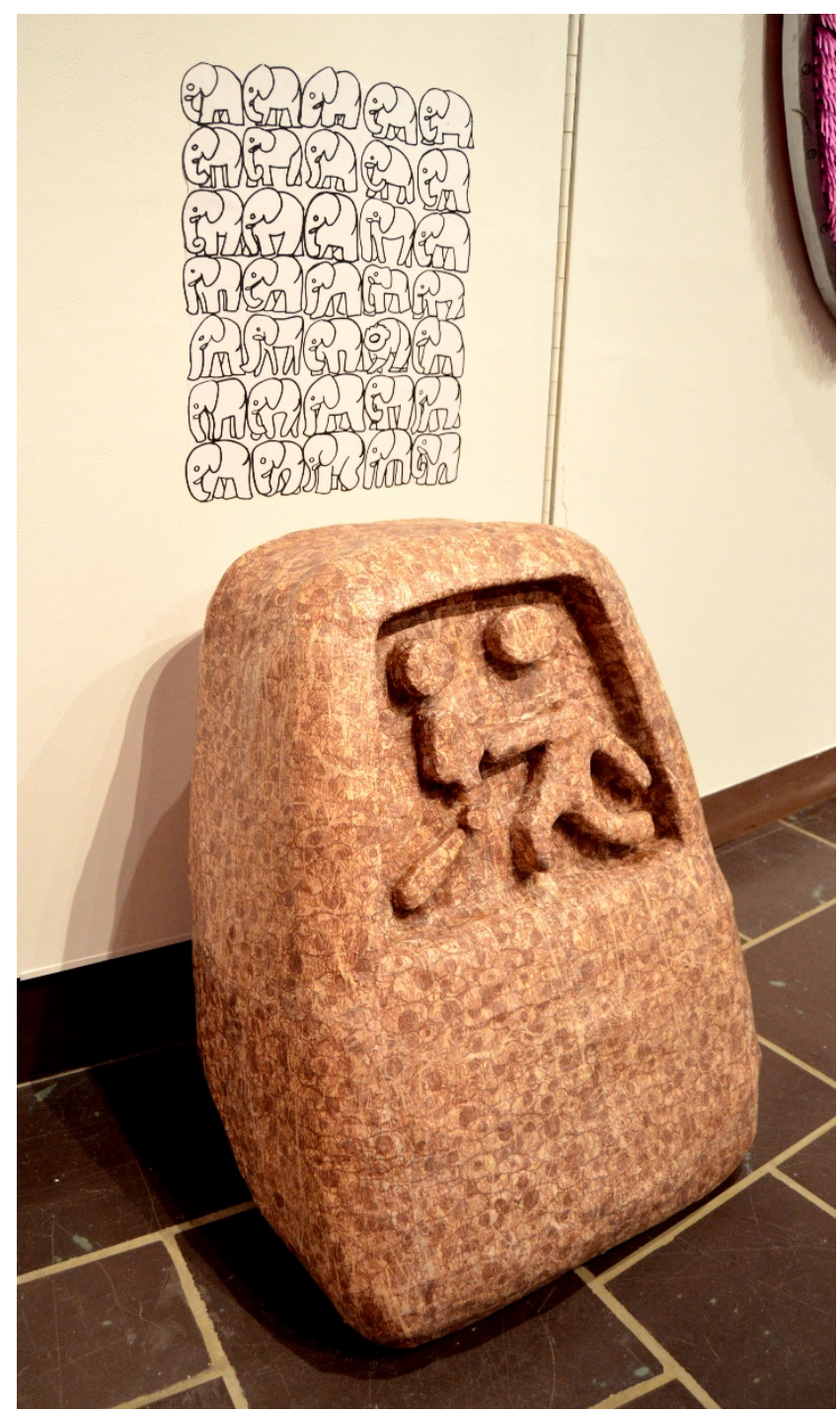

Fig. 31, The Mil Touchstone, installation shot with detail.

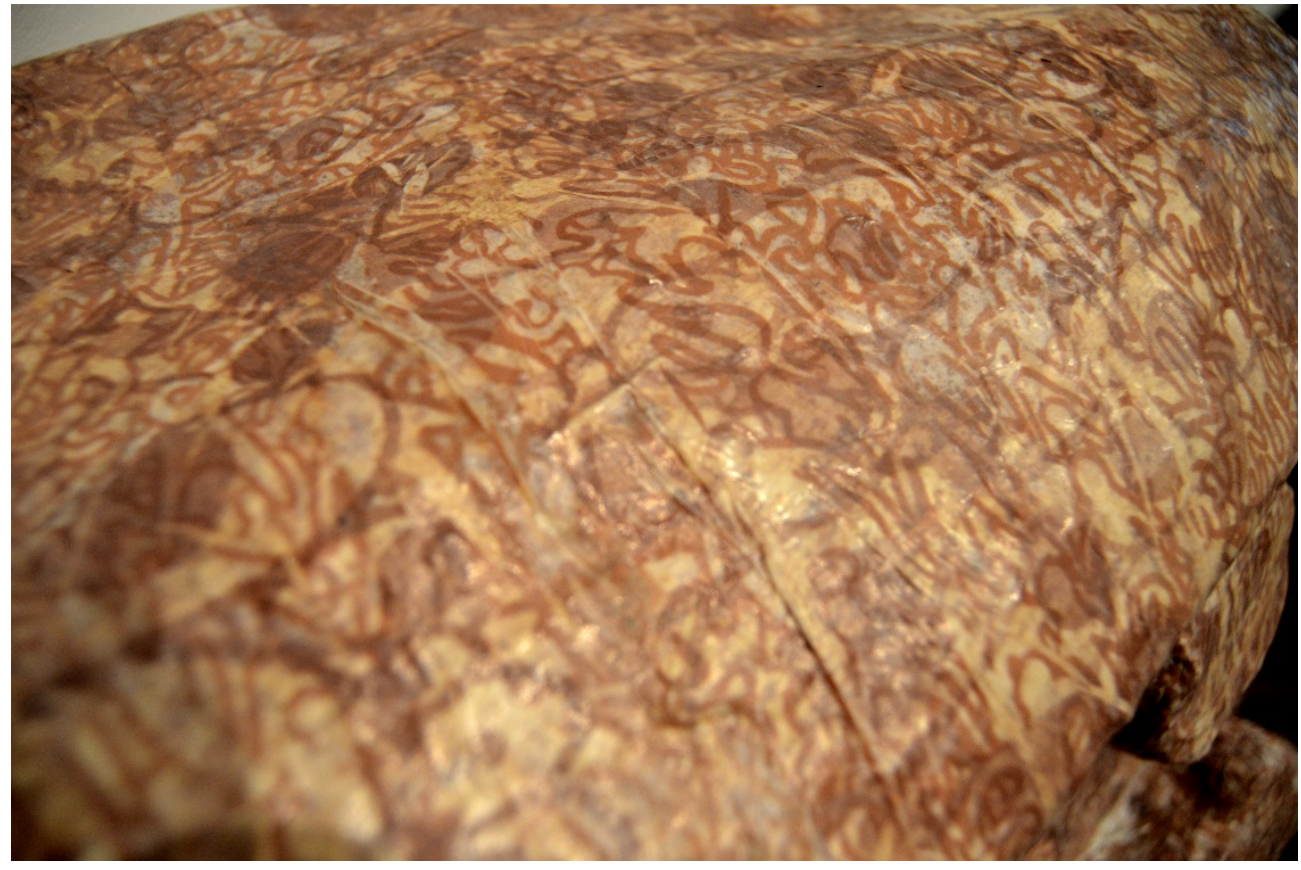



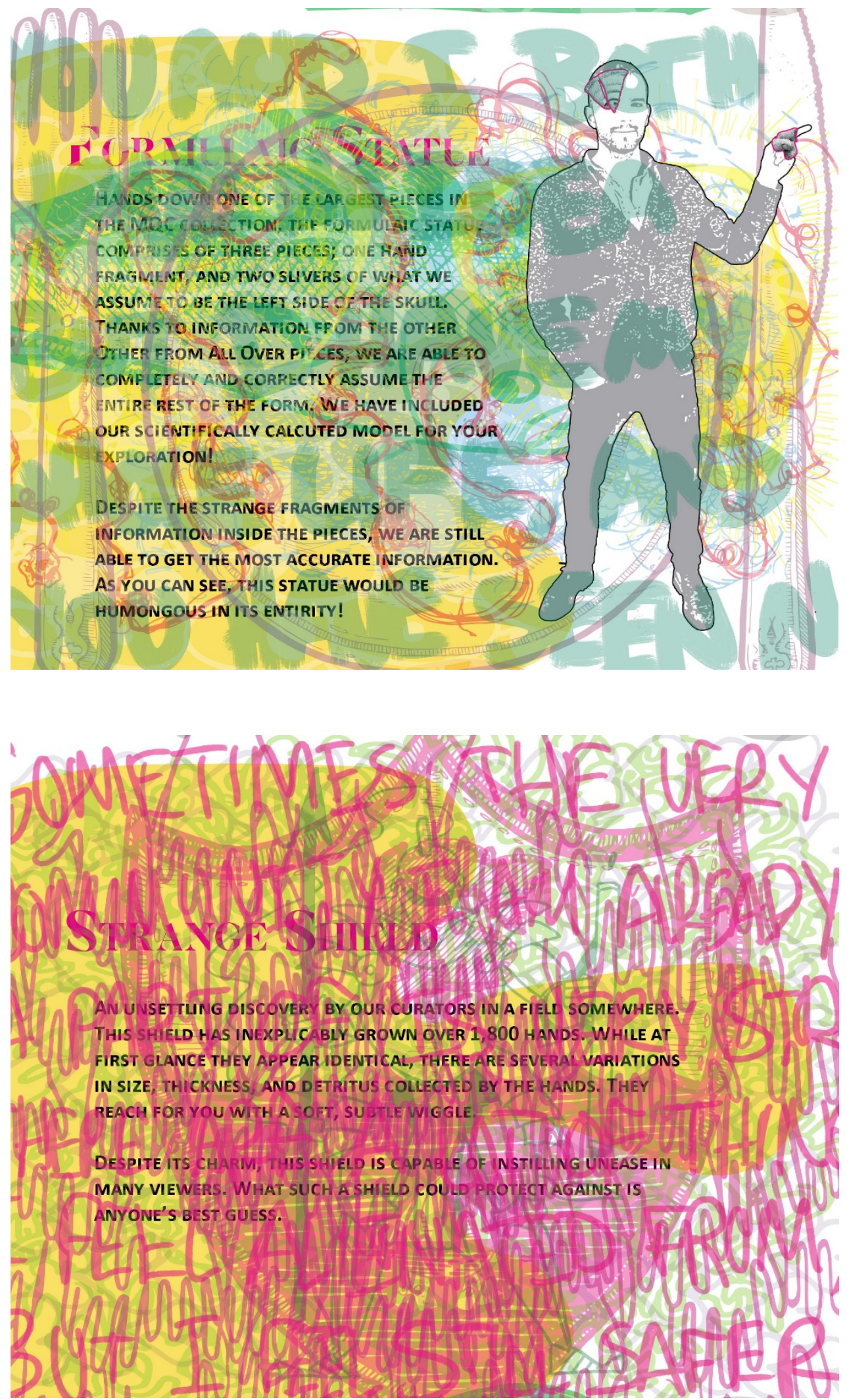

Fig. 32, Catalog label for the Formulaic Statue.
Fig. 33, Catalog

label for the Strange Shield 


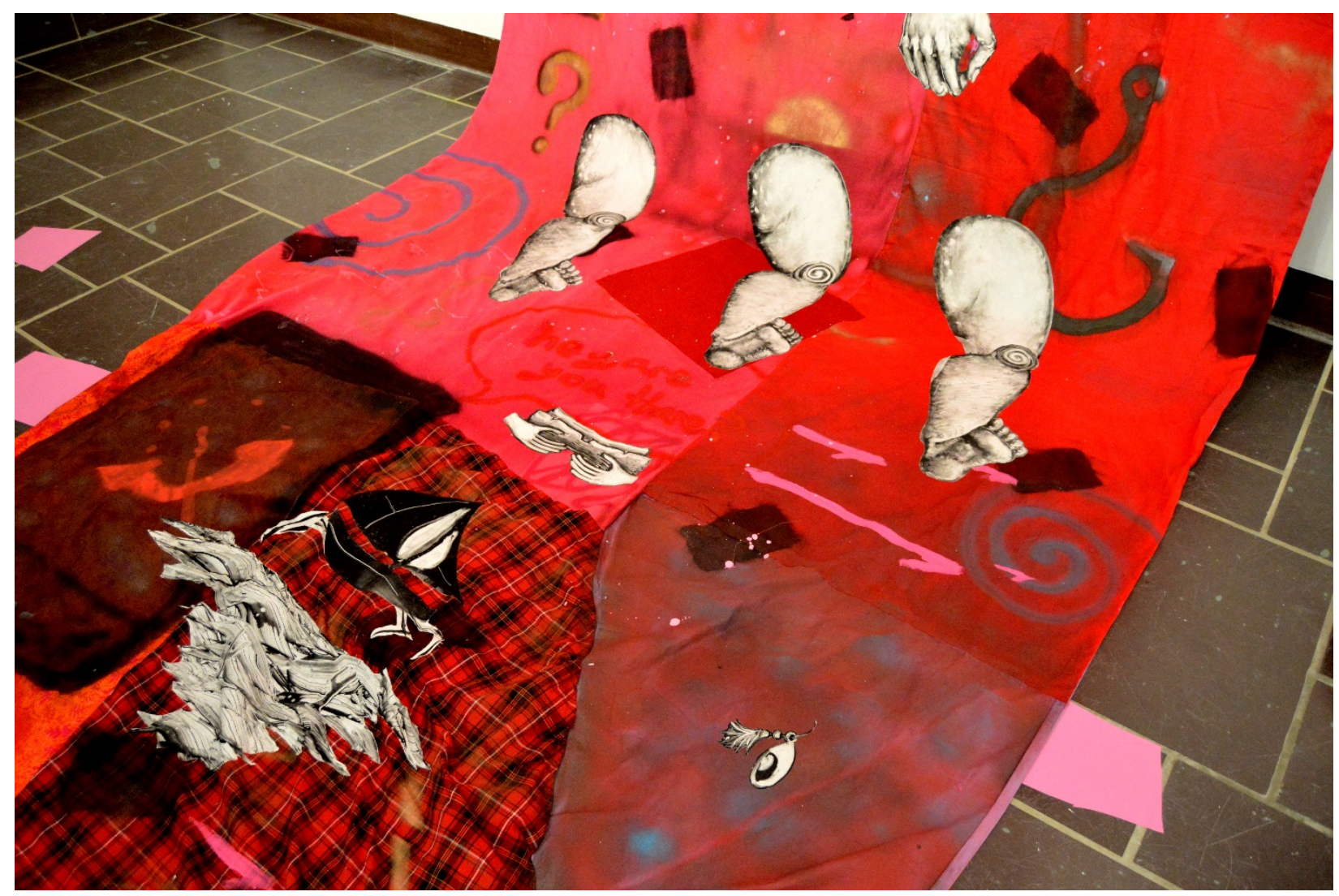

Fig. 34, Historic Shroud, detail.
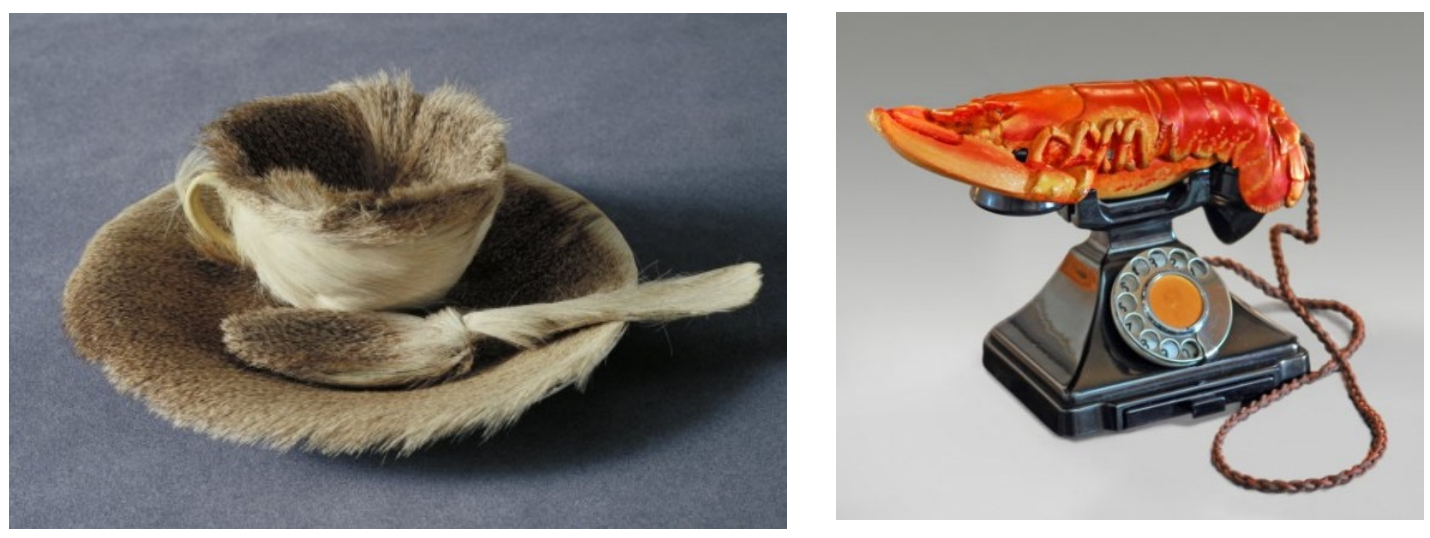

Clockwise:

Fig. 35, Untitled (Fur Teacup), Meret Oppenheim, fur on teacup set, 1936.

Fig 36, Lobster Telephone, Salvador Dali. Mixed media, 1981.

Fig. 37, Object of Destruction, Man Ray. Metronome with photograph.

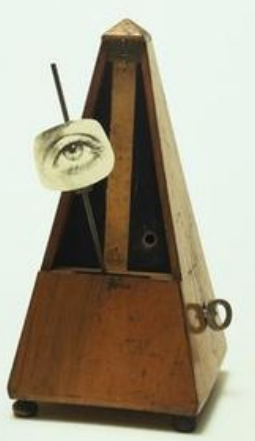




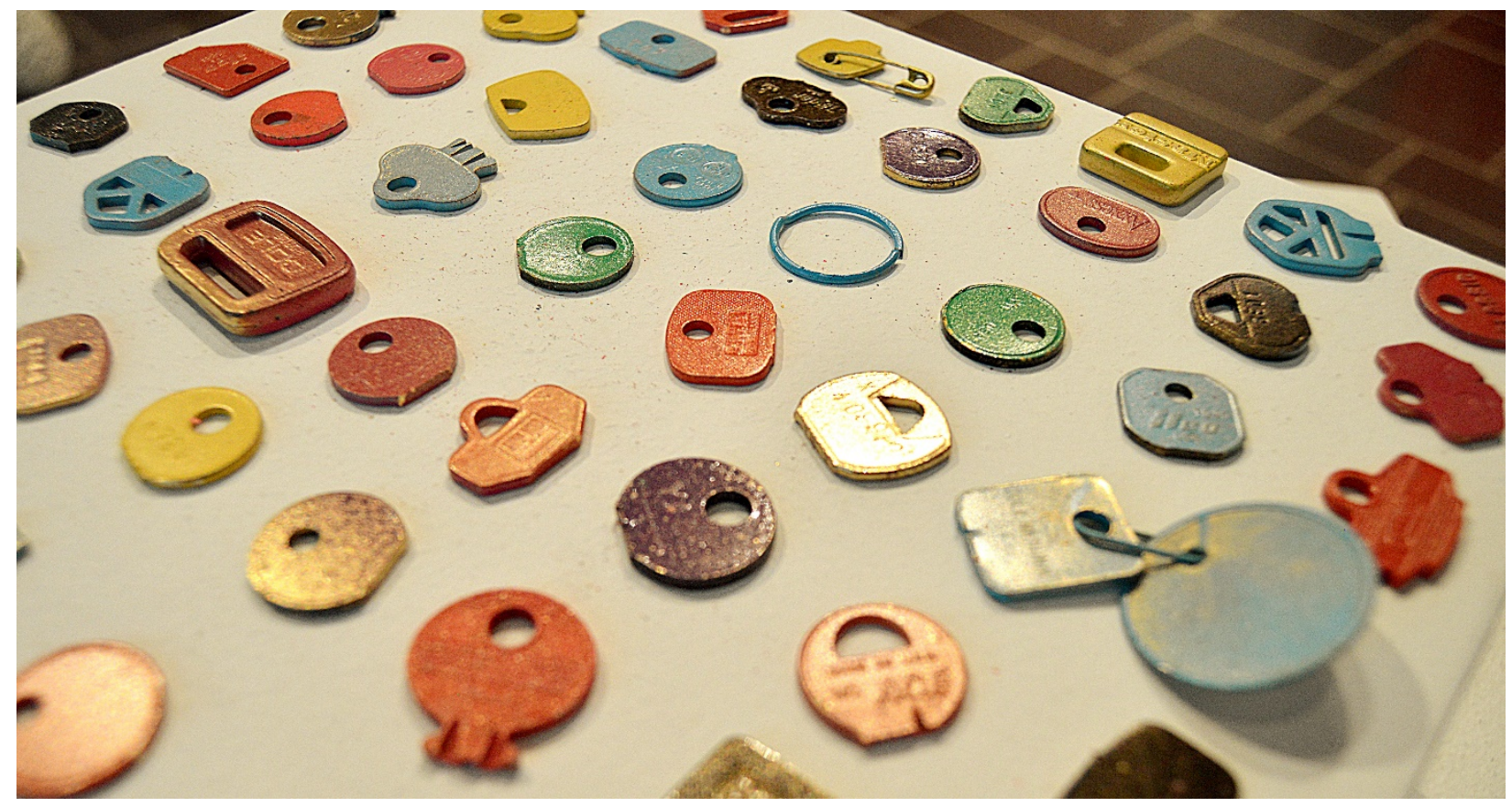

Fig. 38, MQC Coin Collection, detail shot.

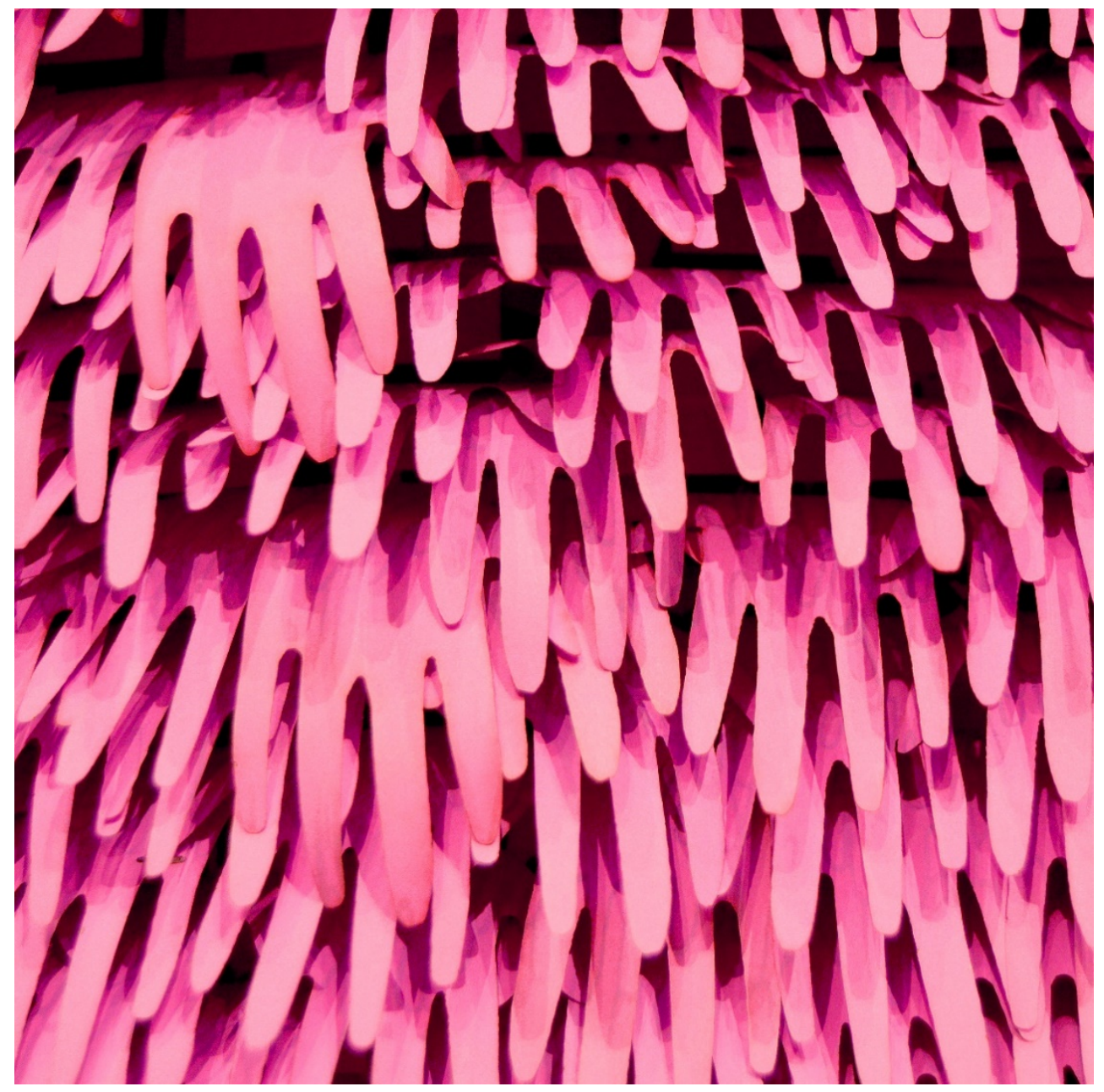

Fig. 39, Strange

Shield, detail shot. 


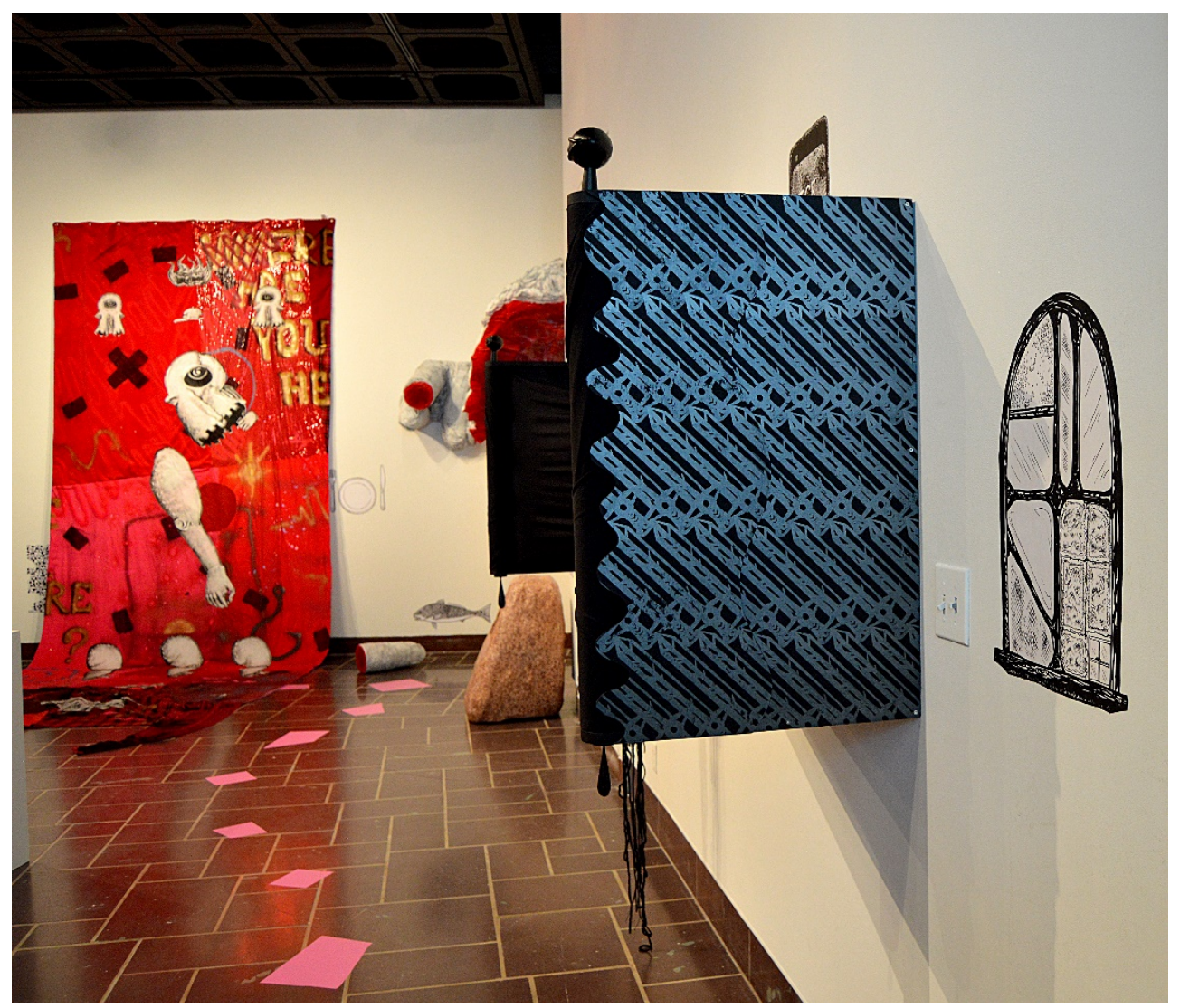

Fig 40,

Instructional Book of Progress, detail and install shot highlighting the swords that appear more strongly in bright light.

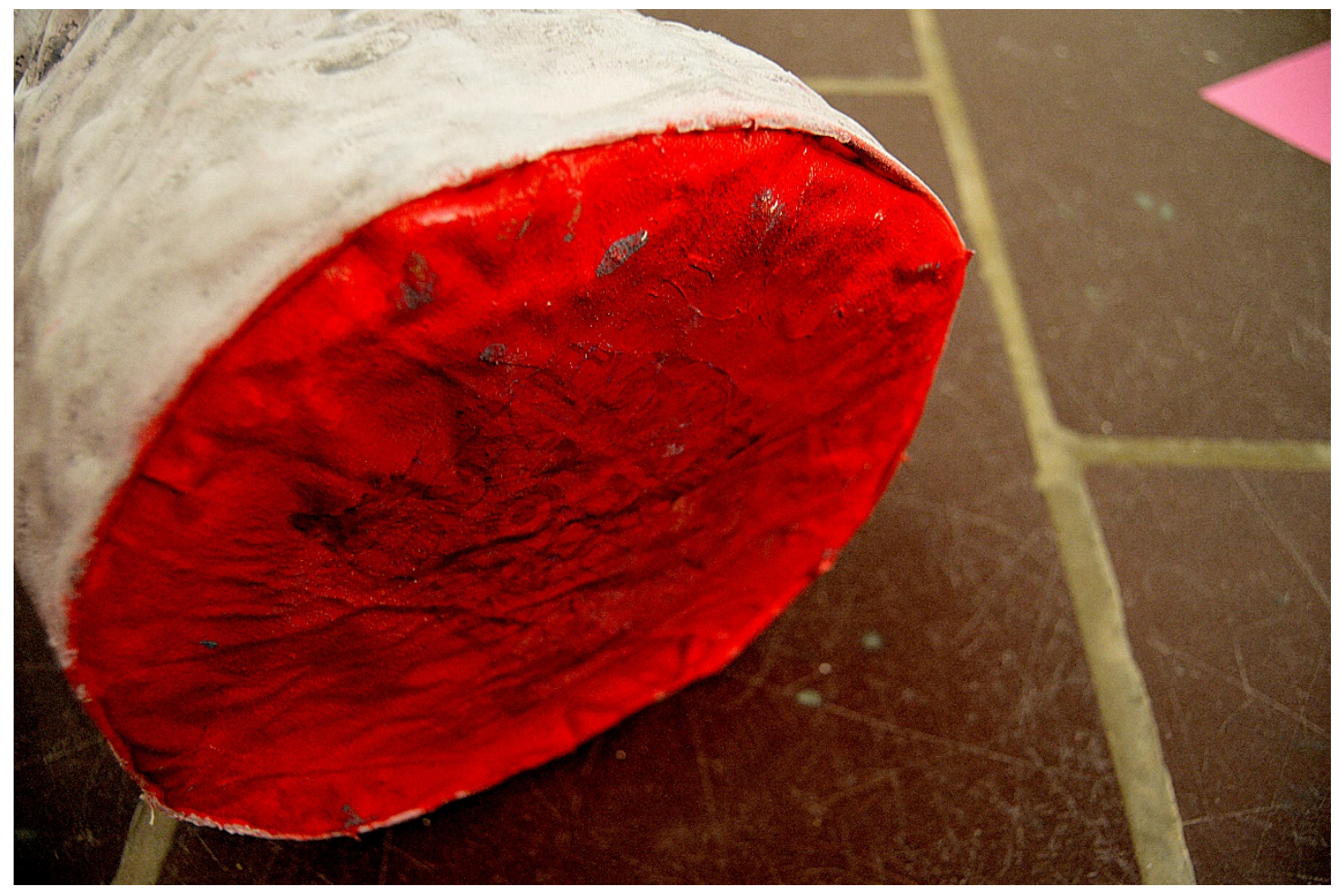

Fig. 41, Formulaic Statue, detail, showing the symbols and words on the interior of the red surface. 


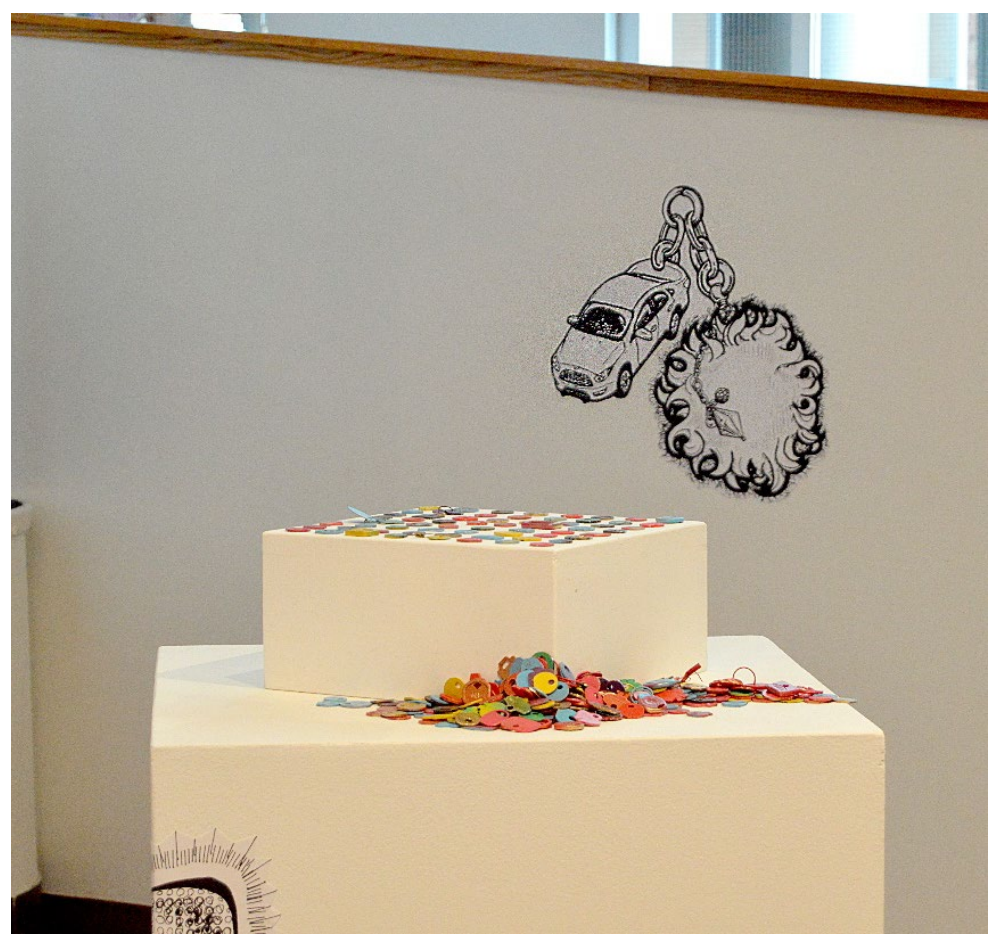

Fig. 42, Additional Information (Car Fob), installation shot.

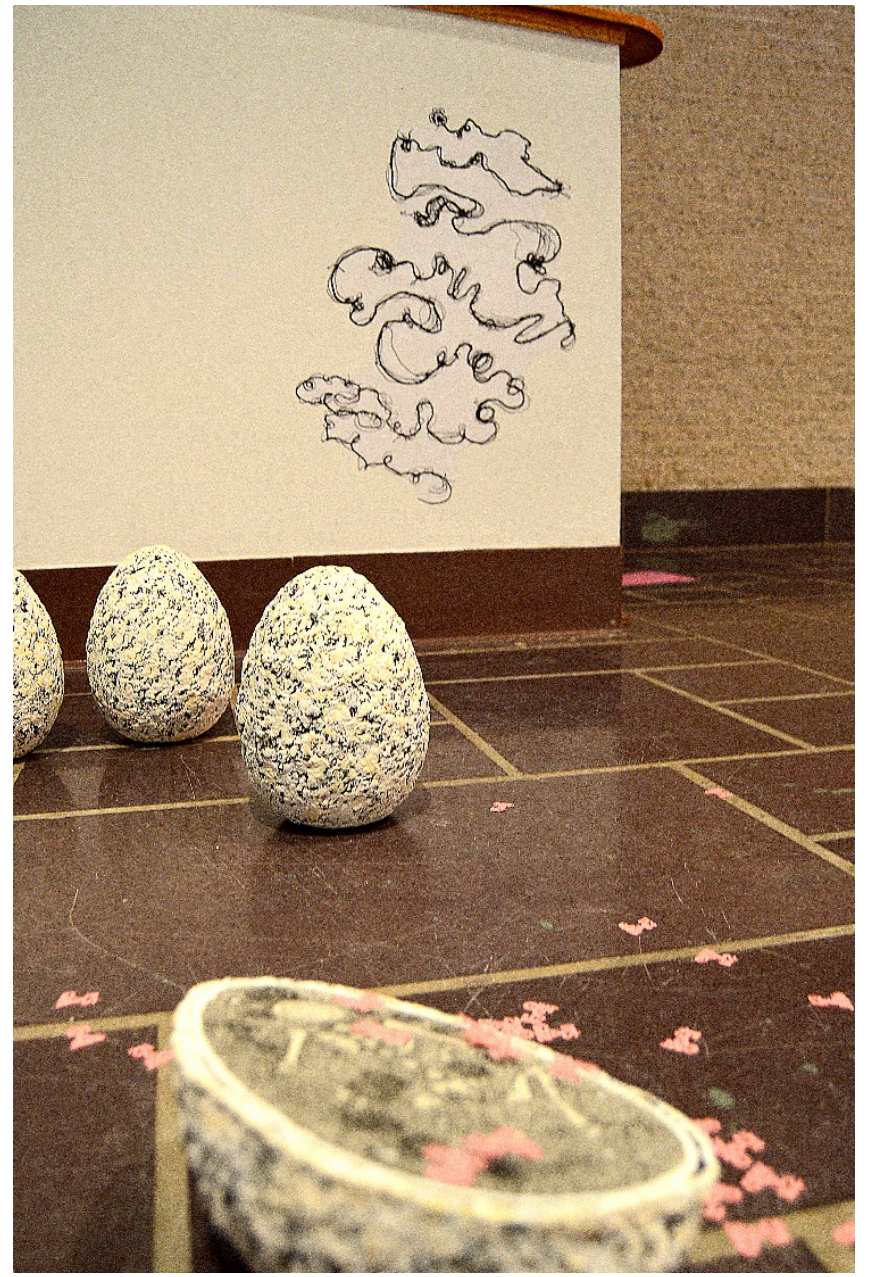

Fig. 43, Additional Information (Long Hair), installation shot. 


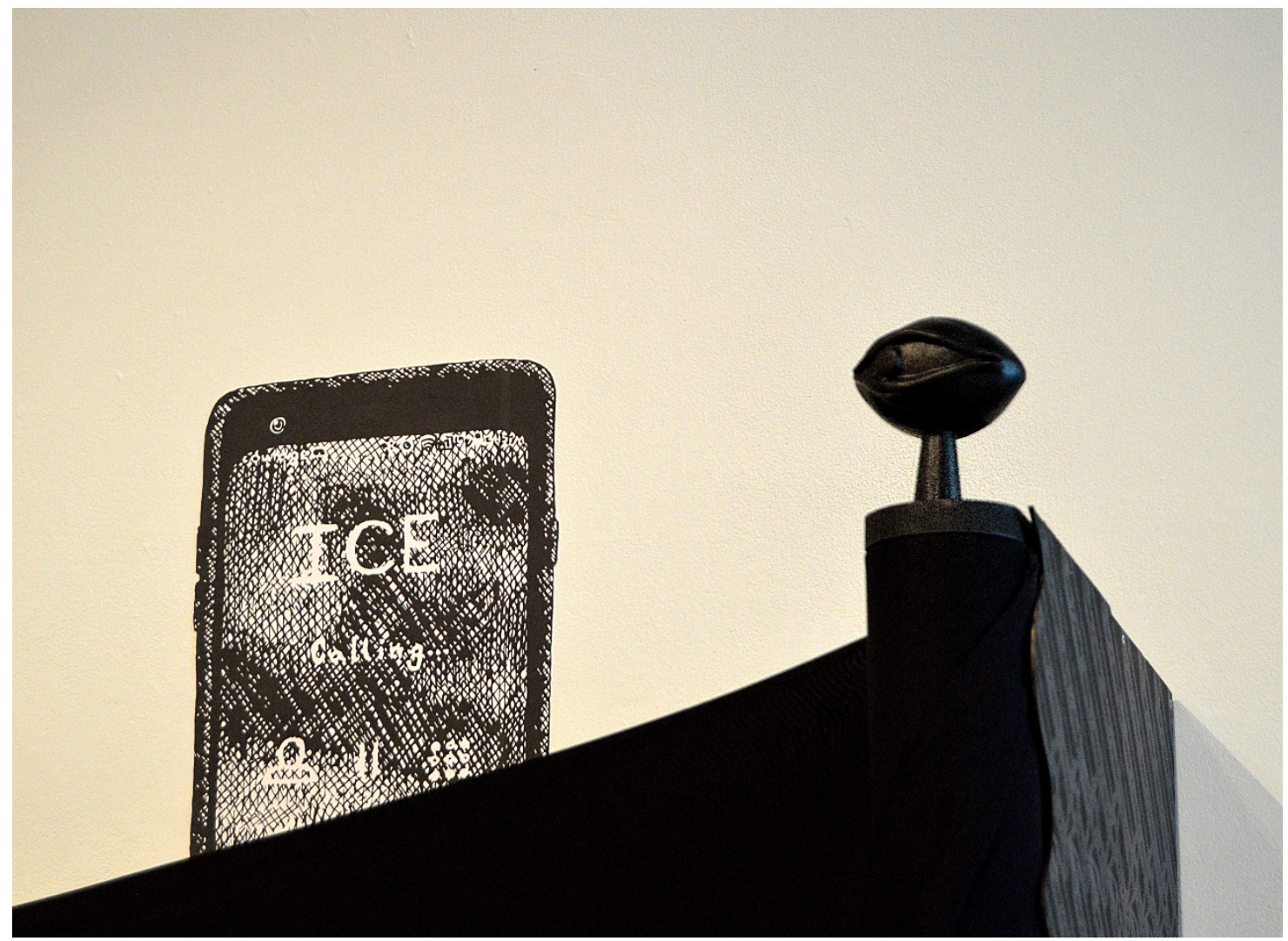

Fig. 44, Additional Information (Emergency Contact), installation view.

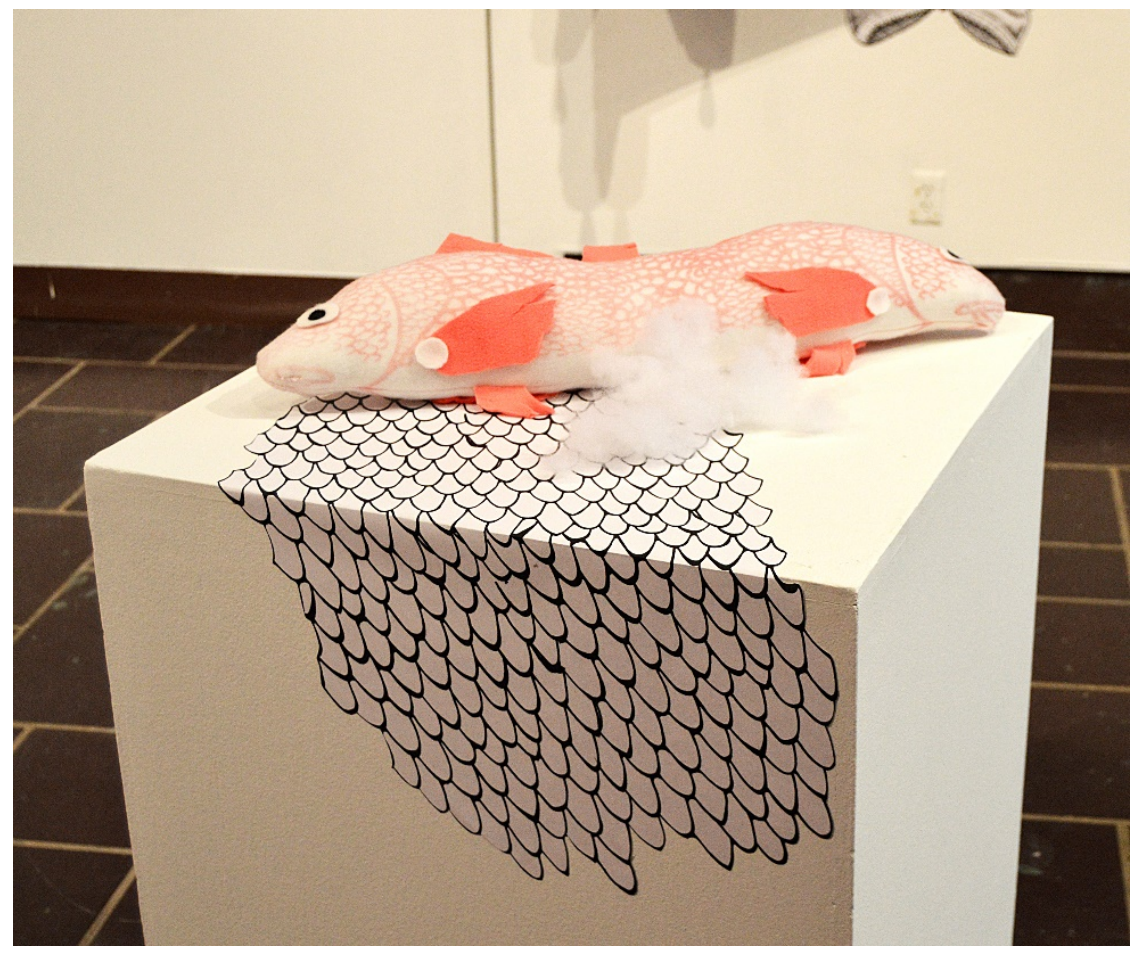

Fig. 45, Unconditional Fish, installation. 


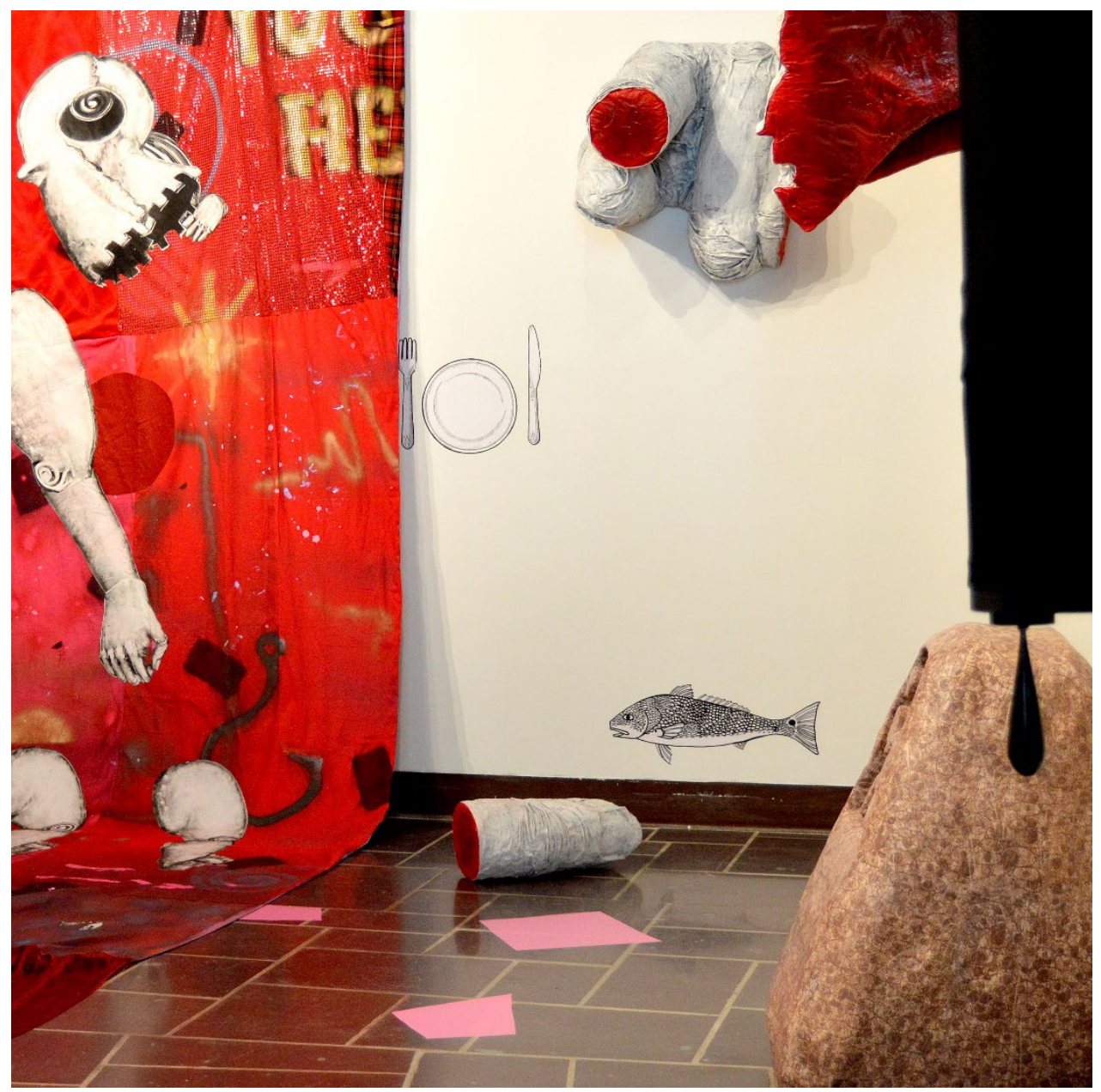

Fig. 46, Additional Information (Redfish), installation shot.

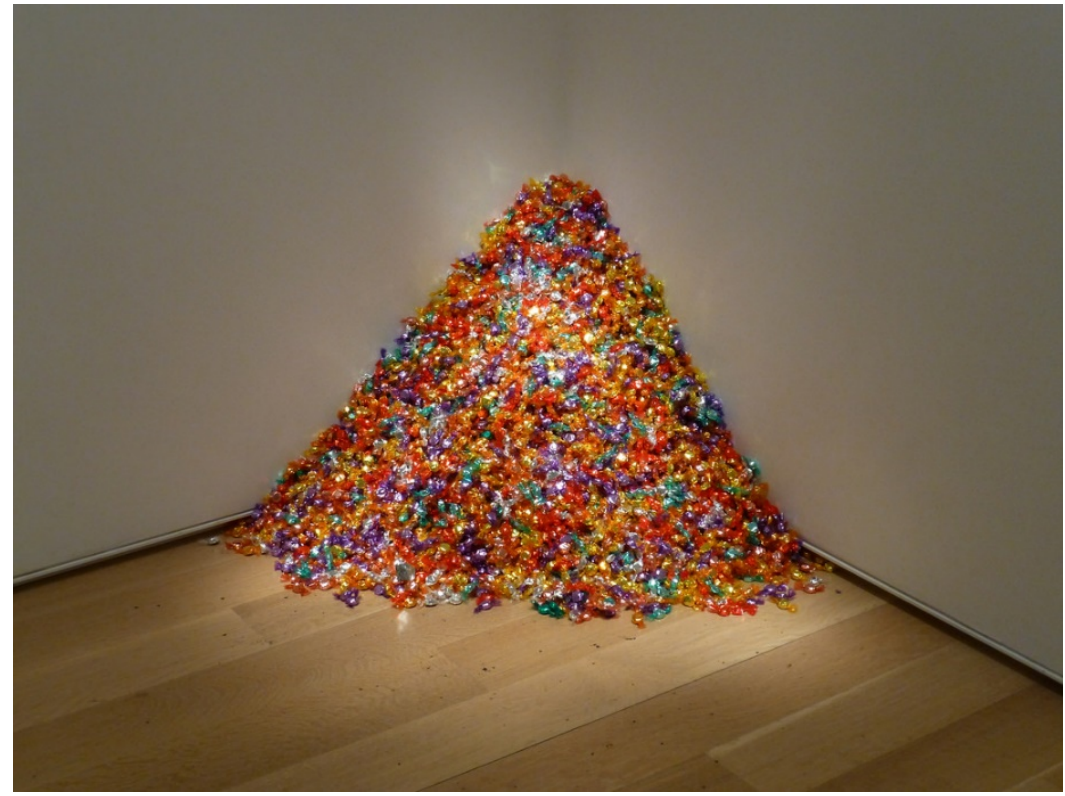

Fig. 47, Candy Pile, Felix Gonzales-Torres. Individually wrapped candies in cellophane. Approx. 175 lbs. 1991. 

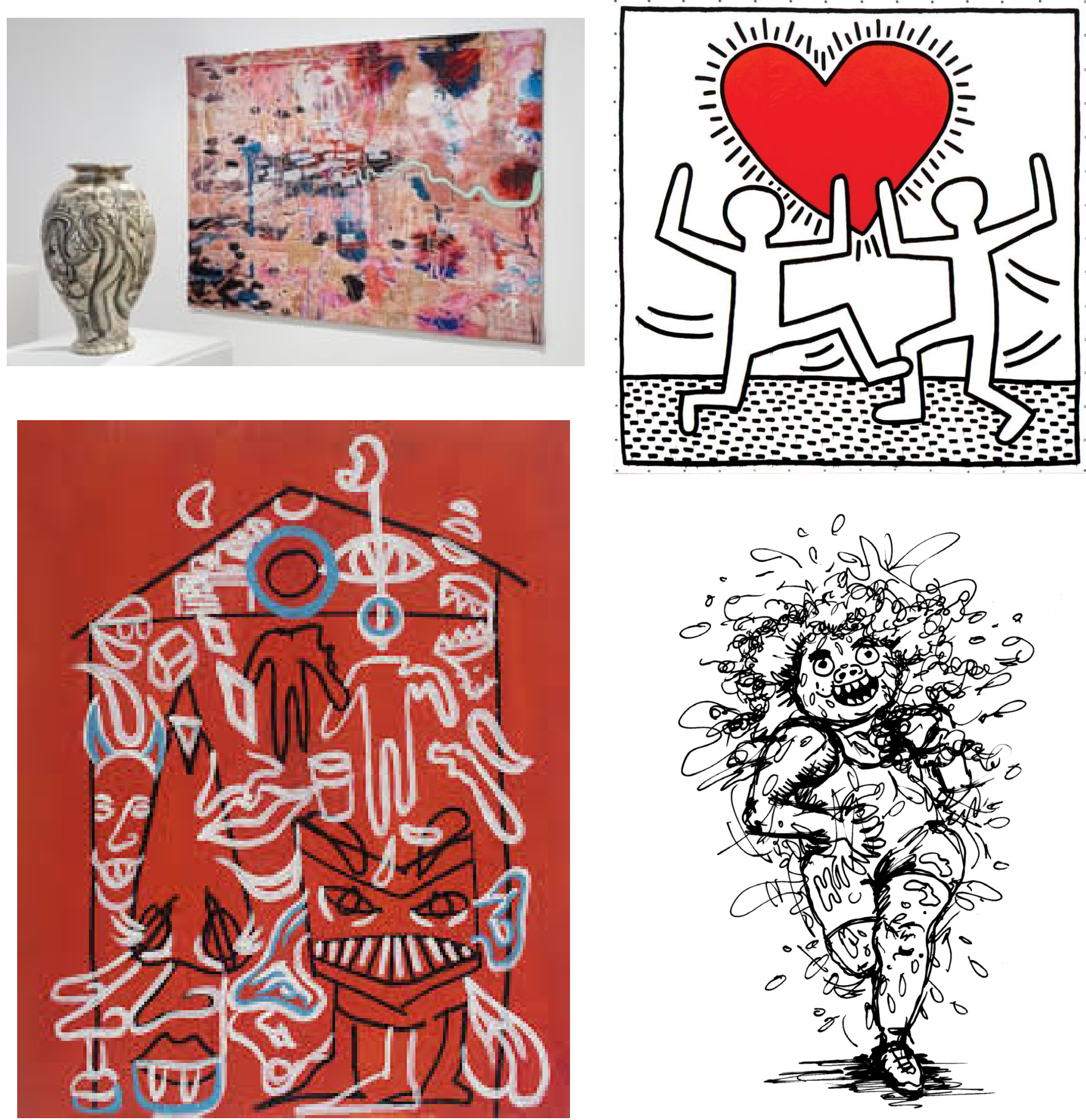

Left to Right:

Fig. 48, Excerpt from Super Rich Interior Decoration, Grayson Perry, 2019.

Fig. 49, Untitled, 1982, Keith Haring. Acrylic on vinyl tarpaulin. 180 x 180 in. 1982.

Fig. 50, House of Fears, Marco DaSilva, painting.

Fig. 51, Untitled, animation still, Barbara Lane Tharas. 2015. 

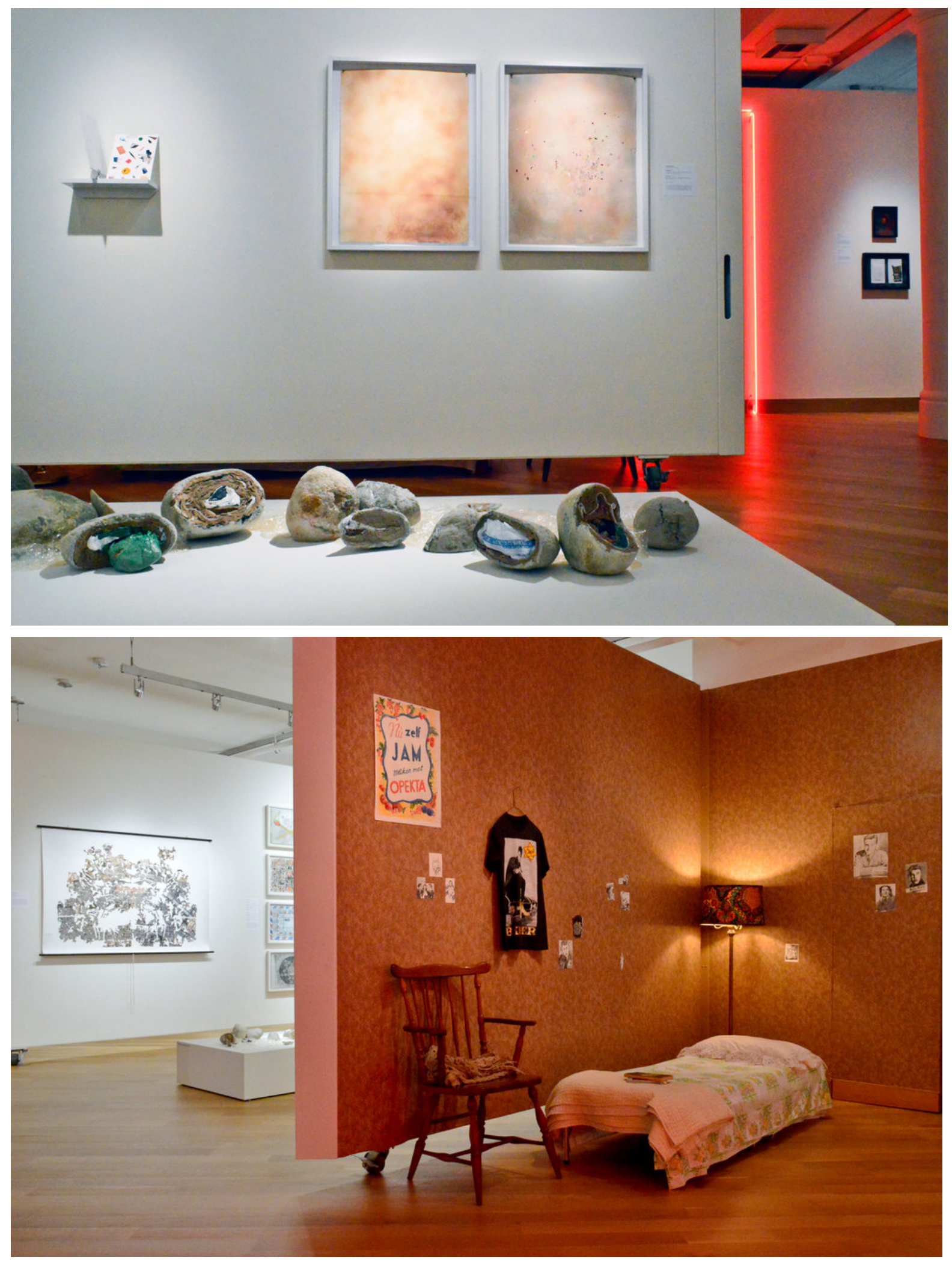

Fig. 52, FOUND: Queer Archaeology, Queer Abstraction, installation shots. Leslie-Lohman Museum of Gay and Lesbian Art. 2017. 


\section{BIBLIOGRAPHY}

American Heritage ${ }^{\circledR}$ Dictionary of the English Language, Fifth Edition. S.v. "individuation."

Retrieved April 292020 from https://www.thefreedictionary.com/individuation

“Another Way Millennials Are Ruining Their Parents' Retirement.” Money. Ad Practitioners,

LLC., February 11, 2017. https://money.com/millennials-ruining-parents-retirement/.

Barker, Meg-John, and Jules Scheele. Queer: a Graphic History. London: Icon Books, 2016.

Barr, Alfred H. Fantastic Art, Dada and Surrealism. 3rd ed. New York: Arno Press, 1936.

Bem, Sandra Lipsitz. "Dismantling Gender Polarization and Compulsory Heterosexuality:

Should We Turn the Volume down or Up?" The Journal of Sex Research 32, no. 4

(1995): 329-34. www.jstor.org/stable/3813357

Bergner, Daniel. "The Struggles of Resisting the Gender Binary." The New York Times

Magazine. The New York Times Co., June 4, 2019.

https://www.nytimes.com/2019/06/04/magazine/gender-nonbinary.html.

Bishop, Claire. Installation Art: a Critical History. New York: Routledge, 2005.

Butler, Judith. "Performative Acts and Gender Constitution: An Essay in Phenomenology and Feminist Theory." Theatre Journal 40, no. 4 (1988). https://doi.org/10.2307/3207893.

“Catharsis - Criticism.” In Catharsis - Criticism. Encyclopedia Britannica, Inc., September 26, 2018. https://www.britannica.com/art/catharsis-criticism.

Clark, Arthur. "Empathy and Sympathy: Therapeutic Distinctions in Counseling." Journal of Mental Health Counseling 32, no. 2 (2010): 95-101. https://doi.org/10.17744/mehc.32.2.228n116thw397504.

Crane, Diana. Fashion and Its Social Agendas Class, Gender and Identity in Clothing. Chicago, IL: University of Chicago Press, 2000. 
Elliot, Christine and William Reynolds, “Making It Millennial,” Deloitte Insights. Deloitte. April 2, 2014. https://www2.deloitte.com/us/en/insights/industry/public-sector/makingit-millennial.html

Freeland, Cynthia A. Art Theory: A Very Short Introduction. Oxford: Oxford University Press. 2003.

Goffman, Erving. "Gender Display." Studies in the Anthropology of Visual Communications 3, no. 2 (1976): 69-77. https://repository.upenn.edu/svc/vol3/iss2/3.

Grant, Jaime M., Lisa A. Mottet, Justin Tanis, Jack Harrison, Jody L. Herman, and Mara Keisling. Injustice at Every Turn: A Report of the National Transgender Discrimination Survey. Washington: National Center for Transgender Equality and National Gay and Lesbian Task Force, 2011.

Greshko, Michael. "Famous Viking Warrior Was a Woman, DNA Reveals.” National Geographic Magazine. National Geographic Society, September 12, 2017. https://www.nationalgeographic.com/news/2017/09/viking-warrior-womanarchaeology-spd/\#close.

Hale, C. Jacob. "Consuming the Living, Dis(Re)Membering the Dead in the Butch/Ftm Borderlands." GLQ: A Journal of Lesbian and Gay Studies 4, no. 2 (1998): 311-48. https://doi.org/10.1215/10642684-4-2-311.

Hein, George E. “The Role of Museums In Society: Education And Social Action.” Curator: The Museum Journal 48, no. 4 (2005): 357-63. https://doi.org/10.1111/j.21516952.2005.tb00180.x. 
Hingston, Sandy. "How Millennials Are Ruining the Workforce - and Everything Else," Philadelphia Magazine. Philadelphia Magazine. January 9, 2016. https://www.phillymag.com/news/2016/01/08/boomers-millennials-workforce.

Johnson, Joy L., and Robin Repta. "Sex and Gender: Beyond the Binaries.” Designing and Conducting Gender, Sex, \& Health Research, 2012, 17-38. https://doi.org/10.4135/9781452230610.n2.

Jolly, Eshin, Diana Tamir, Bethany Burum, and Jason Mitchell. "Wanting without Enjoying: The Social Value of Sharing Experiences.” PLoS One, April 18, 2019. https://doi.org/10.1371/journal.pone.0215318.

Kaplan, Jonas T., Sarah I. Gimbel, and Sam Harris. "Neural Correlates of Maintaining One’s Political Beliefs in the Face of Counterevidence." Scientific Reports 6, no. 1 (2016). https://doi.org/10.1038/srep39589.

Lombardi, Emilia. "Varieties of Transgender/Transsexual Lives and Their Relationship with Transphobia." Journal of Homosexuality 56, no. 8 (2009): 977-92. https://doi.org/10.1080/00918360903275393.

Macleod, Suzanne, Laura Hourston Hanks, Jonathan Hale, and Rachel Morris. Museum Making: Narratives, Architectures, Exhibitions. Abingdon: Routledge, 2012. https://ebookcentral.proquest.com/lib/wvu/reader.action?docID=956902\&ppg=27\#.

Mahnke, Aaron.”Hard Rain.” LORE. Podcast audio. http://www.radiolab.org/story/91518-goaton-a-cow/. 28:35-30:40.

Mayor, Adrienne. The First Fossil Hunters: Paleontology in Greek and Roman Times. Princeton, NJ: Princeton Univ. Press, 2001. www.jstor.org/stable/j.ctt7s6mm.9. 
Mclemore, Kevin A. "Experiences with Misgendering: Identity Misclassification of Transgender Spectrum Individuals.” Self and Identity 14, no. 1 (2014): 51-74. https://doi.org/10.1080/15298868.2014.950691.

Merriam-Webster.com Dictionary, s.v. “compassion,” accessed April 18, 2020, https://www.merriam-webster.com/dictionary/compassion.

Merriam-Webster.com Dictionary, s.v. "sympathy," accessed April 19, 2020, https://www.merriam-webster.com/dictionary/sympathy.

Merriam-Webster.com Dictionary, s.v. “queer,” n.d. https://www.merriamwebster.com/dictionary/queer.

Nadal, Kevin L., Chassitty Whitman, Linsey Davis, Tanya Erazo, and Kristin Davidoff. "Microaggressions Toward Lesbian, Gay, Bisexual, Transgender, Queer, and Genderqueer People: A Review of the Literature." The Journal of Sex Research 53, no. 4-5 (2016): 488-508. https://doi.org/10.1080/00224499.2016.1142495.

Palmer, Parker J. "The Heart of a Teacher Identity and Integrity in Teaching.” Change: The Magazine of Higher Learning 29, no. 6 (1997): 14-21. https://doi.org/10.1080/00091389709602343.

Peterdi, Gabor F. "History of Printmaking." In Encyclopedia Britannica. Encyclopedia Britannica, Inc., January 21, 2019. https://www.britannica.com/art/printmaking/History-of-printmaking. Quaintance, Morgan. "Human Zoos: From Colonial Practice to Participatory Art.” Contemporary \&. Institut für Auslandsbeziehungen, April 19, 2014. https://www.contemporaryand.com/magazines/from-colonial-practice-to-participatory$\underline{\operatorname{art} / .}$ 
Roets, Arne, and Alain Van Hiel. "Allport's Prejudiced Personality Today.” Current Directions in Psychological Science 20, no. 6 (2011): 349-54. https://doi.org/10.1177/0963721411424894.

Schnitzler, Lena, Sian Smith, Heather Shepherd, Joanne Shaw, Skya Dong, Delesha Carpenter, Frances Nguyen, and Haryana Dhillon. "Communication during Radiation Therapy Education Sessions: The Role of Medical Jargon and Emotional Support in Clarifying Patient Confusion." Patient Education and Counseling 100, no. 1 (January 2017): 11220. https://doi.org/10.1016/j.pec.2016.08.006.

Sexual Violence \& Transgender/Non-Binary Communities, National Sexual Violence Resource Center, https://www.nsvrc.org/sites/default/files/publications/201902/Transgender_infographic_508_0.pdf, 2019.

Sidanius, Jim, Stacey Sinclair, and Felicia Pratto. "Social Dominance Orientation, Gender, and Increasing Educational Exposure1." Journal of Applied Social Psychology 36, no. 7 (2006): 1640-53. https://doi.org/10.1111/j.0021-9029.2006.00074.x.

Sinclair, Lisa, Beverley Fehr, Wan Wang, and Elise Regehr. "The Relation Between Compassionate Love and Prejudice: The Mediating Role of Inclusion of Out-Group Members in the Self." Social Psychological and Personality Science 7, no. 2 (March 2016): 176-83. doi:10.1177/1948550615609736.

Sklar, Howard. The Art of Sympathy in Fiction: Forms of Ethical and Emotional Persuasion. Amsterdam: John Benjamins Publishing Company, 2013.

"Surrealism." Heilbrunn Timeline of Art History. The Metropolitan Museum of Art, n.d. http://www.metmuseum.org/toah/hd/surr/hd_surr.htm. 
“The Clouds of MOGAI Heaven.” tumblr. Accessed April 2, 2020. http://uncommongenders.tumblr.com/.

The Great Soviet Encyclopedia, 3rd Edition. S.v. "Stylization." Retrieved April 1, 2020 from https://encyclopedia2.thefreedictionary.com/Stylization.

The Royal Institute, "Color Mixing: The Mystery of Magenta," Youtube video, 5:13, February 13, 2013. https://www.youtube.com/watch?v=iPPYGJjKVco.

Warner, Michael. Fear of a Queer Planet: Queer Politics and Social Theory. Minneapolis, MN: Univ. of Minnesota Press, 1995. 